\title{
Advanced Materials for RSOFC Dual Operation with Low Degradation
}

Eric Tang, Tony Wood, Sofiane Benhaddad, Casey Brown, Hongpeng He, Jeff Nelson, Oliver Grande, Ben Nuttall, Mark Richards, Randy Petri (Primary Contact)

Versa Power Systems

Phone: (303) 226-0762

E-mail: randy.petri@versa-power.com

DOE Technology Development Manager: Kathi Epping

Phone: (202) 586-7425

E-mail: kathi.epping@ee.doe.gov

DOE Project Officer: David Peterson

Phone: (303) 275-4956

E-mail:david.peterson@go.doe.gov

Contract Number: DE-EE0000464

Project Start Date: September 1, 2009

Project End Date: August 31, 2012

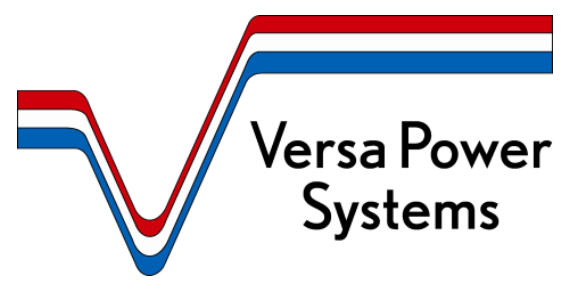




\section{DISCLAIMER}

This report was prepared as an account of work sponsored by an agency of the United States Government. Neither the United States Government nor any agency thereof, nor any of their employees, makes any warranty, expressed or implied, or assumes any legal liability or responsibility for the accuracy, completeness, or usefulness of any information, apparatus, product, or process disclosed, or represents that its use would not infringe privately owned rights. Reference herein to any specific commercial product, process, or service by trade name, trademark, manufacturer, or otherwise, does not necessarily constitute or imply its endorsement, recommendation, or favoring by the United States Government or any agency thereof. The views and opinions of authors expressed herein do not necessarily state or reflect those of the United States Government or any agency thereof. 


\section{Table of Contents}

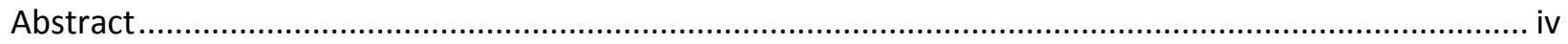

List of Abbreviations ......................................................................................................

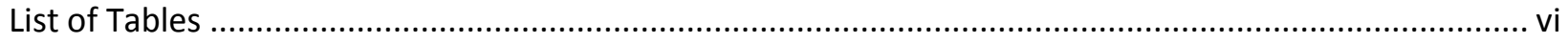

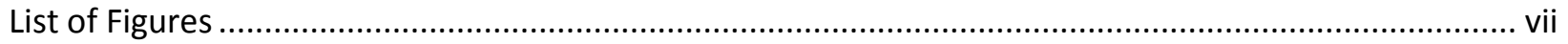

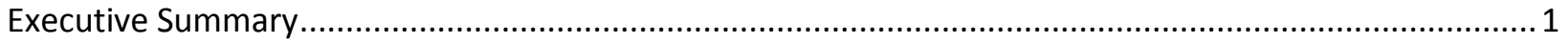

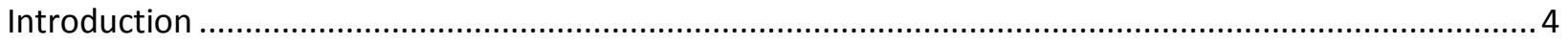

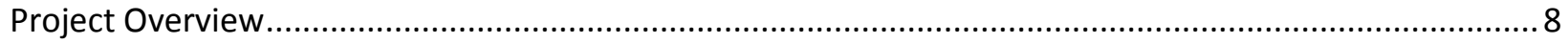

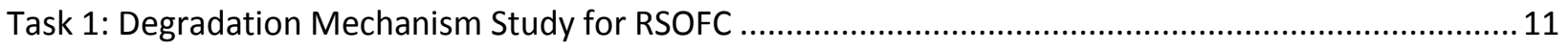

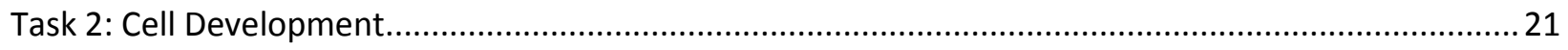

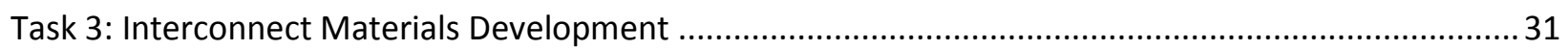

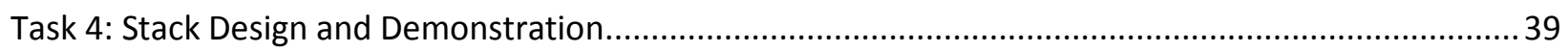

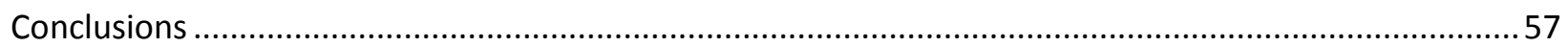

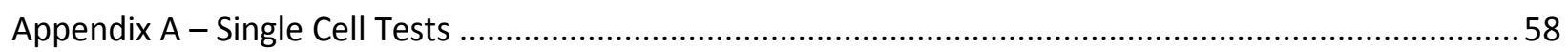

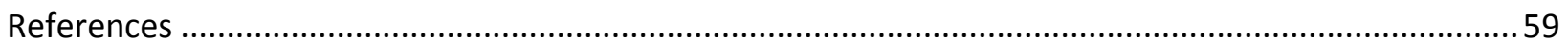




\begin{abstract}
Reversible solid oxide fuel cells (RSOFCs) are energy conversion devices. They are capable of operating in both power generation mode (SOFC) and electrolysis modes (SOEC). RSOFC can integrate renewable production of electricity and hydrogen when power generation and steam electrolysis are coupled in a system, which can turn intermittent solar and wind energy into "firm power." In this DOE EERE project, VPS continuously advanced RSOFC cell stack technology in the areas of endurance and performance.
\end{abstract}

Over 20 types of RSOFC cells were developed in the project. Many of those exceeded performance (area specific resistance less than $300 \mathrm{~m} \Omega-\mathrm{cm}^{2}$ ) and endurance (degradation rate less than $4 \%$ per 1000 hours) targets in both fuel cell and electrolysis modes at $750^{\circ} \mathrm{C}$. One of those cells, RSOFC-7, further demonstrated the following:

- Steady-state electrolysis with a degradation rate of $1.5 \%$ per 1000 hours

- Ultra high current electrolysis over $3 \mathrm{~A} / \mathrm{cm}^{2}$ at $75 \%$ water electrolysis efficiency voltage of $1.67 \mathrm{~V}$

- Daily SOFC/SOEC cyclic test of over 600 days with a degradation rate of $1.5 \%$ per 1000 hours

- Over 6000 SOFC/SOEC cycles in an accelerated 20-minute cycling with degradation less than 3\% per 1000 cycles

In RSOFC stack development, a number of kW-class RSOFC stacks were developed and demonstrated the following:

- Steady-state electrolysis operation of over 5000 hours

- Daily SOFC/SOEC cyclic test of 100 cycles

- Scale up capability of using large area cells with $550 \mathrm{~cm}^{2}$ active area showing the potential for large-scale RSOFC stack development in the future

Although this project is an open-ended development project, this effort, leveraging Versa Power Systems' years of development experience, has the potential to bring renewable energy RSOFC storage systems significantly closer to commercial viability through improvements in RSOFC durability, performance, and cost. When unitized and deployed in renewable solar and wind installations, an RSOFC system can enable higher availability for intermittent renewable resources, thereby improving the commercial viability of these types of energy resources. 


\section{List of Abbreviations}

ASR: Area Specific Resistance

BOP: Balance of Plant

CTE: Coefficient of Thermal Expansion

DOE: Department of Energy

EERE: Energy Efficiency and Renewable Energy

EDX: Energy-Dispersive X-ray Spectroscopy

EIS: Electrochemical Impedance Spectroscope

OCV: Open Circuit Voltage

RSOFC: Reversible Solid Oxide Fuel Cell

SECA: Solid-State Energy Conversion Alliance

SEM: Scanning Electron Microscope

SLPM: Standard Liter Per Minute

SOEC: Solid Oxide Electrolysis Cell

SOFC: Solid Oxide Fuel Cell

TEM: Transmission Electron Microscope

TSC: Tape Casting-Screen Printing-Cosintering

VPS: Versa Power Systems

XRD: X-Ray Diffraction

YSZ: Yttria-Stabilized Zirconia 


\section{List of Tables}

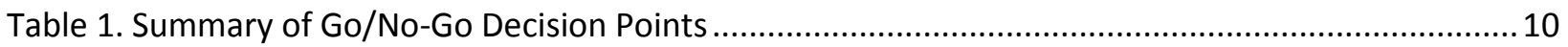

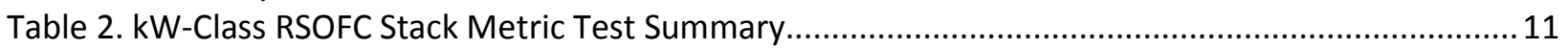

Table 3. Summary of Cell Degradation Rates under Fixed SOEC Operation........................................... 18

Table 4. Summary of Cell Performances under SOFC and SOEC Operation ...........................................25

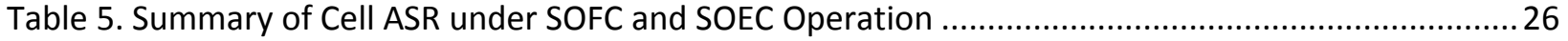

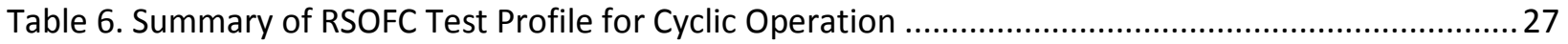

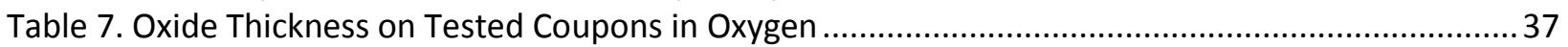




\section{List of Figures}

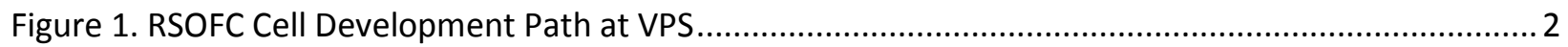

Figure 2. Schematic of the Reversible Solid Oxide Fuel Cell's (RSOFC) Two Modes.................................... 4

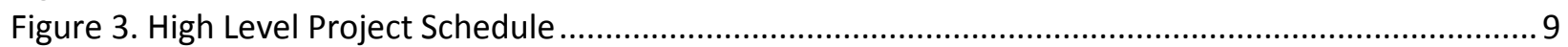

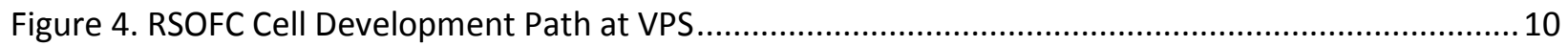

Figure 5. Comparison of Steady-State Electrolysis Tests GLOB 101670, GLOB 101695, and GLOB 101706

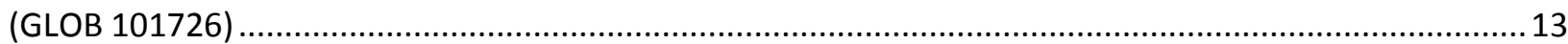

Figure 6. SOFC and SOEC Power Curves at 50\% Humidity for GLOB 101695 at Test Start......................14

Figure 7. SOFC and SOEC Power Curves at 50\% Humidity for GLOB 101695 at Test End ......................... 14

Figure 8. Fuel Cell Anode Side after Test ....................................................................................... 15

Figure 9. Cross-Section SEM Image of Interconnect Oxidation at Fuel Electrode after 8465 Hours SOEC

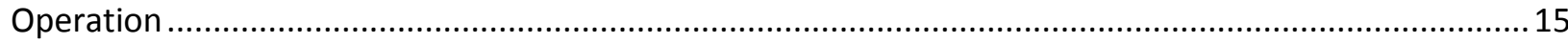

Figure 10. Cross-Section SEM Image of Interconnect Oxidation at Air Electrode after 8400 Hours SOEC

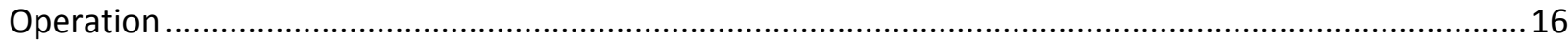

Figure 11. Cell Voltage over Time under Electrolysis Hold Conditions for GLOB 101695 and Retest GLOB

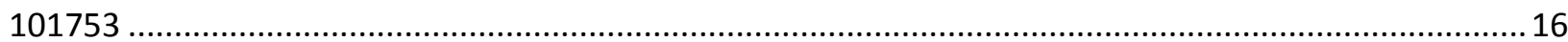

Figure 12. TEM Image of an RSOFC Cell Showing All Interfaces Intact with no Interface Contamination

(Anode and Cathode of Fuel Cell Mode) ....................................................................................... 17

Figure 13. Cell Voltage over Time under Electrolysis Hold Conditions for GLOB 101758 (MAC-RSOFC-5

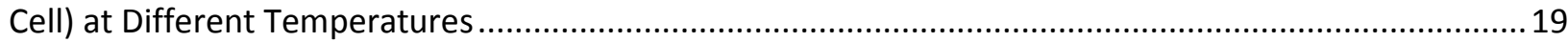

Figure 14. Cell Voltage over Time under Electrolysis Hold Conditions for GLOB 101760 (MAC-RSOFC-5

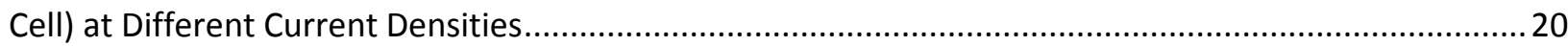

Figure 15. Cell Voltage over Time under Electrolysis Hold Conditions for GLOB 101773 (MAC-RSOFC-5

Cell) at Different Steam Utilizations............................................................................................... 20

Figure 16. Summary of Cell Performance and Endurance Improvement in Electrolysis Mode ................22

Figure 17. Performance of RSOFC-7 Cells in Both Fuel Cell Mode and Electrolysis Mode ........................23

Figure 18. Single-Cell Steady-State Electrolysis Test of an RSOFC-7 Cell for the Go/No-Go Decision........ 23

Figure 19. Single Cell Test of RSOFC-7 Cell Performance at Ultra-High Electrolysis Current Density.........24

Figure 20. Fuel Cell and Electrolysis Cyclic Testing of an RSOFC-7 Cell...................................................28

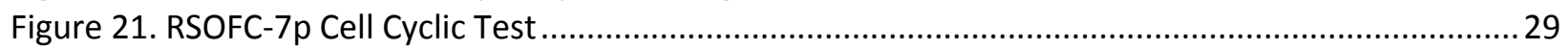

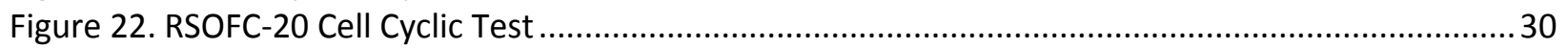

Figure 23. Accelerated RSOFC Cyclic Test at Three Temperatures: $750^{\circ} \mathrm{C}, 700^{\circ} \mathrm{C}$, and $800^{\circ} \mathrm{C} \ldots \ldots \ldots \ldots \ldots . \ldots . \ldots . . . .30$

Figure 24. Accelerated RSOFC Cyclic Test with 20 Minute Cycles ............................................................ 31

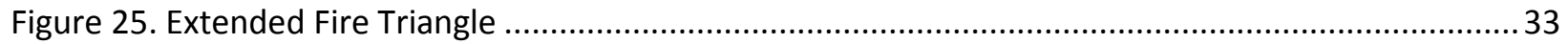

Figure 26. Weight Gain Results of 434LN2, Sanergy, Haynes 230, and Cobalt Coated Sanergy at $800^{\circ} \mathrm{C}$ in

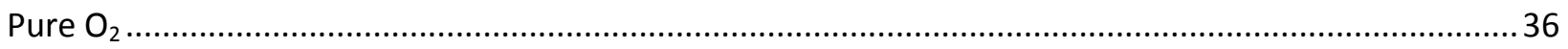

Figure 27. Surface Oxide on Haynes 230 and Sanergy Coated after the Pure Oxygen Test...................... 37

Figure 28. Surface Oxide on Haynes 230 and Sanergy Coated Stainless after the Pure Oxygen Test........ 38

Figure 29. Steady-State Electrolysis Test (5800 Hours) of a 6-Cell Stack with Selected Interconnects...... 38

Figure 30. SEM Image of Anode Interconnect Cross Sections at (a) Steam Inlet Edge and (b) Center ...... 39

Figure 31. Temperature Distribution across Cells under Electrolysis Conditions (Modeled) .................... 42

Figure 32. Stack Current Density Profile (Modeled) ............................................................................... 42

Figure 33. CFD Modeling of a 28-Cell RSOFC Stack in Electrolysis Mode at $3.3 \mathrm{~A} / \mathrm{cm}^{2}$ (Inlet Steam

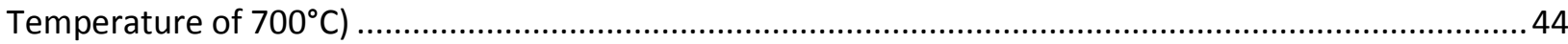

Figure 34. Long-Term Individual Cell Voltage Trends of a 28-Cell kW-Class Stack (GT056019-0150) Tested

in Steady-State Electrolysis Operation........................................................................................... 45 
Figure 35. GT056019-0150 kW-Class Stack ASR over Both Constant Current and Constant Voltage (Shaded Blue) Electrolysis Condition

Figure 36. GT055296-0100 Fuel Cell and Electrolysis Cycles ..........................................................47

Figure 37. Fully Integrated Electrochemical Modeling of a kW-Class Stack Operating at SOFC and SOEC Conditions 48

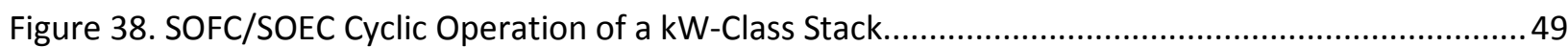

Figure 39. Original (top) and Revised (bottom) Fuel Electrode Contact................................................. 49

Figure 40. kW-Class Stack Built and Tested for Cyclic SOFC/SOEC Operations .......................................50

Figure 41. Cyclic Performance of a kW-Class Stack over 100 SOFC/SOEC Cycles .....................................5 51

Figure 42. Individual Cell Degradation from SOFC/SOEC Cyclic Operation ............................................. 51

Figure 43. Stack Testing of 20-Cell kW-Class RSOFC Stack at Steady-State SOEC Conditions ...................52

Figure 44. Stack Conditioning and Initial Characterization in Fuel Cell Mode ............................................53

Figure 45. Measured Thermal Profile of the kW-Class RSOFC Stack with 6 Scale-Up Cells of $550 \mathrm{~cm}^{2}$

Active Area at Both SOFC and SOEC Operating Modes ......................................................................5

Figure 46. Project Metric Test of a kW-Class RSOFC Stack with $550 \mathrm{~cm}^{2}$ Cells: Average Cell Voltages...... 55

Figure 47. Project Metric Test of a kW-Class RSOFC Stack with $550 \mathrm{~cm}^{2}$ Cells: Individual Cell Voltages ... 56

Figure 48. Schematic of Single-Cell Test Assembly ............................................................................. 58 


\section{Executive Summary}

Reversible solid oxide fuel cells (RSOFCs) are energy conversion devices. They are capable of operating in both power generation mode (SOFC) and electrolysis modes (SOEC). RSOFC can integrate renewable production of electricity and hydrogen when power generation and steam electrolysis are coupled in a system, which can turn intermittent solar and wind energy into "firm power." In order to address the technical and cost barriers, EERE funded a number of research projects over the past ten years.

Although significant progress was made in those projects, further development is required, especially in the areas of RSOFC performance and endurance. In this project, Versa Power Systems (VPS) is addressing the following technical barriers from the Fuel Cell section of the Hydrogen, Fuel Cells and Infrastructure Technologies Program Multi-Year Research, Development and Demonstration Plan:
A. Durability
B. Cost
C. Performance

The project objectives are to meet the following performance and endurance targets in a kW-class RSOFC stack demonstration:

- $\quad$ RSOFC dual mode operation of 1500 hours with more than ten SOFC/SOEC transitions

- Operating current density of more than $300 \mathrm{~mA} / \mathrm{cm}^{2}$ in both SOFC and SOEC modes

- Overall decay rate of less than $4 \%$ per 1000 hours of operation

Meeting those performance and endurance technical targets will be the key RSOFC cell stack technology development step towards meeting DOE's Technical Targets for Distributed Water Electrolysis Hydrogen Production by an RSOFC system.

In order to advance RSOFC cell stack technology in the areas of endurance and performance, VPS identified four task areas in an effort to improve the performance and endurance of RSOFC systems: degradation mechanism study, cell material development, interconnect material development, and stack design and demonstration. A stage-gate project management process was employed with a quantitative go/no-go decision point. The scope of the work was carried out by:

- Building on VPS's strong SOFC cell and stack baseline and leveraging cell and stack advancements from the DOE SECA project,

- Carrying out parallel materials development activities and integrating them with cell production technology development, and

- Conducting RSOFC stack and process designs to address durability, performance, and cost in both fuel cell and electrolysis operating modes.

The development path for RSOFC cell technology at VPS can be summarized in Figure 1. More than 20 materials systems have been developed in the project. At the project go/no-go milestone test, one of the best cell materials system-RSOFC-7-demonstrated 223 and $224 \mathrm{~m} \Omega-\mathrm{cm}^{2}$ area specific resistance (ASR) values in electrolysis and fuel cell modes, respectively, at $750^{\circ} \mathrm{C}$ compared with the target of less than $300 \mathrm{~m} \Omega-\mathrm{cm}^{2}$. The same materials system also demonstrated an approximately $1.5 \%$ per 1000 hours degradation rate as compared with the target of $4 \%$ per 1000 hours. To further explore the performance capability in electrolysis mode, a single stack repeat unit using RSOFC-7 was tested at ultra-high electrolysis current. Using the 2017 DOE water electrolysis efficiency target of 75\% to establish the electrolysis operating voltage of $1.67 \mathrm{~V}$, the cell demonstrated excellent performance, exceeding 3 $\mathrm{A} / \mathrm{cm}^{2}$ at $75 \%$ water electrolysis efficiency. This compares favorably to current electrolysis technologies. 
After the initial focus on performance improvement, the emphasis in RSOFC materials system development in the project was placed on endurance for both SOEC steady-state and SOFC/SOEC transient conditions. Twelve materials systems as highlighted in yellow in Figure 1 were developed based on the RSOFC-7 cell. RSOFC cell materials systems have further been validated in fuel cell/electrolysis cyclic operation. A cyclic test profile was designed to simulate an integrated reversible SOFC/solar power system. In an RSOFC cell test of over 14,500 hours (about 600 days), the degradation in fuel cell mode was about $0.6 \%$ per 1000 hours. Operating at twice the current density in SOEC mode, the degradation was slightly more than double at about $1.5 \%$ per 1000 hours. This was similar to the steady-state SOEC degradation rate at the same current density. In both cases, the degradation rate of the RSOFC-7 exceeded the project target of less than $4 \%$ per 1000 hours. To further validate the SOFC/SOEC cyclic capability of the materials systems, a single cell stack repeat unit with one RSOFC-7 cell was tested in an accelerated cycling test to more than 6,000 SOFC/SOEC cycles. Most of transients in this test were conducted in 20 minutes ( 8 minutes in SOFC, 8 minutes in SOEC, and 4 minutes in transient). The cyclic degradation rate is identical to that of daily cycle at $3 \mathrm{mV} / 100$ cycles. This represents daily cycles for more than 15 years and compares favorably to the current battery technologies.

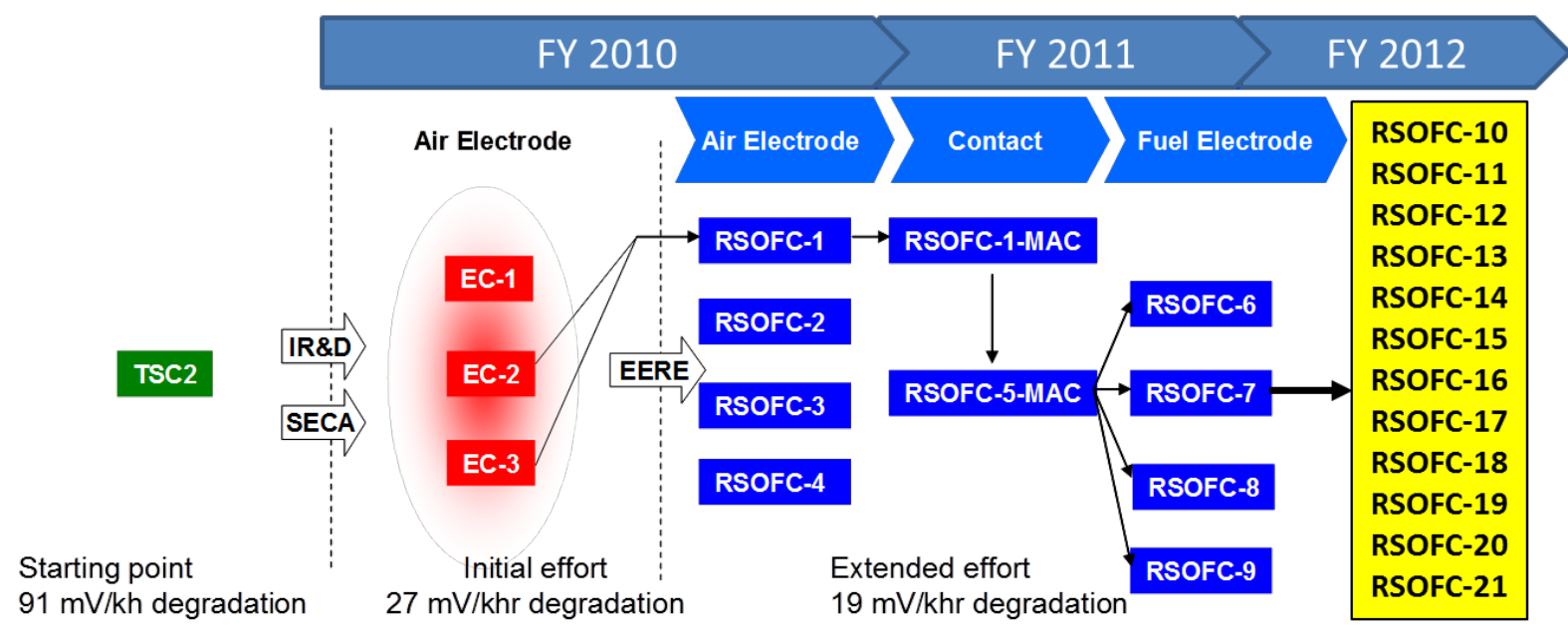

Figure 1. RSOFC Cell Development Path at VPS

In RSOFC stack development, VPS has developed electrochemical modeling code that integrates with Fluent to allow fully coupled electrochemical, thermal, and flow modeling of an operating RSOFC stack. A number of RSOFC stacks were built based on VPS's baseline stack design. One kW-class RSOFC stack demonstrated long-term steady-state electrolysis operation for over 5000 hours with less than $4 \%$ per 1000 hours degradation rate. In parallel, the project team focused on cyclic operation capability and scale up potential of the RSOFC stack. A kW-class stack demonstrated over $100 \mathrm{SOFC/SOEC} \mathrm{cyclic}$ operations. The cyclic degradation in SOFC and SOEC were $13 \mathrm{mV}$ and $64 \mathrm{mV}$ per 100 cycles, respectively. This degradation rate is significantly higher than the degradation rate from the single stack repeat unit test. It was determined that the gap was mainly due to thermal management issues - rather than fundamental material issues-in the RSOFC stack. In addition, one scaled-up kW-class stack with large area 25 by $25 \mathrm{~cm}$ cells ( $550 \mathrm{~cm}^{2}$ active area) was built and tested in both steady-state electrolysis and cyclic SOFC/SOEC modes for over 1500 hours. The results demonstrated the potential for large scale RSOFC stack development in the future. Although this end-of-the-project kW-class stack test met most of the technical metrics in performance and endurance, similar thermal management issues recurred during SOFC/SOEC cyclic operation. Mechanical contact loss in one middle cell caused the stack test to 
fail the project technical metric of $4 \%$ degradation rate per 1000 hours of operation during cyclic operation. Improving thermal management in RSOFC stacks for SOFC/SOEC transient operation will be the main direction for future stack development.

Although this project was an open-ended development project; this effort, leveraging VPS's years of development experience, has the potential to bring renewable energy RSOFC storage systems significantly closer to commercial viability through improvements in RSOFC durability, performance, and cost. When unitized and deployed in renewable solar and wind installations, the VPS RSOFC system can enable higher availability for intermittent renewable resources, thereby improving the commercial viability of these types of energy resources. 


\section{Introduction}

\section{Background}

Solid oxide fuel cells (SOFCs) are energy conversion devices. They are capable of operating in both power generation mode and electrolysis mode as shown schematically in Figure 2. In power generation mode, a SOFC converts chemical energy to electrical energy through electrochemical reaction of fuel and oxidant. In electrolysis mode, a solid oxide electrolyzer cell (SOEC) converts electrical energy to chemical energy through steam electrolysis.

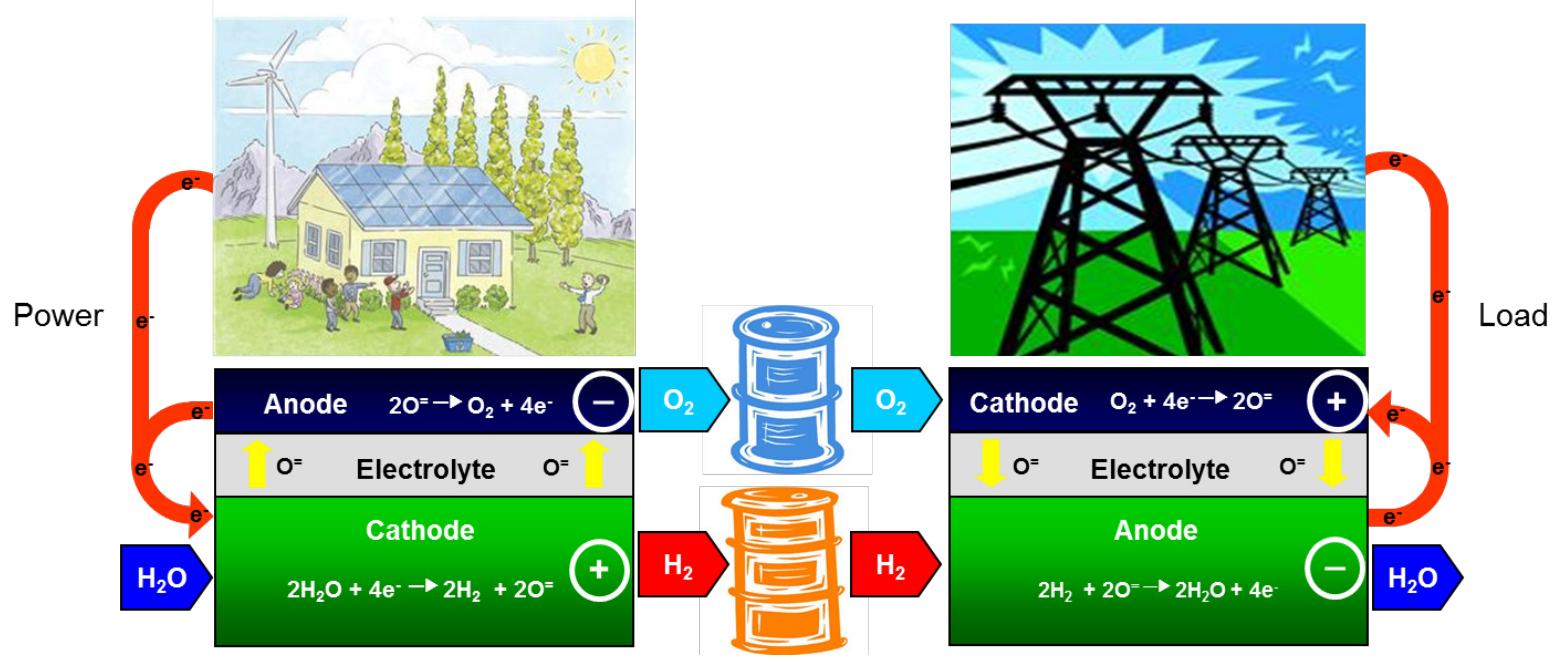

Figure 2. Schematic of the Reversible Solid Oxide Fuel Cell's (RSOFC) Two Modes Left: Electrolysis mode-water input, hydrogen/oxygen output

Right: Power generation mode-hydrogen/air input, power and heat output

Based on this dual mode characteristic, integrated renewable production of electricity and hydrogen becomes possible when power generation and steam electrolysis are coupled in a single, unitized SOFC system. An SOFC designed to operate in both power generation mode and electrolysis mode is called a reversible SOFC (RSOFC).

Solar energy and wind power are the most plentiful and promising renewable resources. Rapid commercialization has occurred in the past ten years. However, solar and wind power are geographically limited and intermittent, so energy conversion and storage is required to mitigate the time-based mismatch between intermittent renewable energy supply and electricity demand. Although batteries are commonly used, their drawbacks of low storage capacity and short life are a significant limitation.

The renewed interest in developing RSOFCs is driven, in part, by the burgeoning renewable wind and solar industry and the need for an energy conversion technology that can serve as the vehicle for changing intermittent solar and wind energy into "firm power."

The RSOFC-enabled renewable power plant would include the following: first, solar or wind energy is harnessed via photovoltaic arrays or wind turbines as the primary power source. This power is used for on-site power loads, although grid support is also possible. Excess electrical energy and water is input to the RSOFC in electrolysis mode, converted to hydrogen, compressed, and stored. When needed-during times of no solar insolation or wind-the stored hydrogen is converted back to electricity and heat via the RSOFC in fuel cell mode. There are also alternative configurations that can result in the production 
of hydrogen for automobiles (fuel cell or hydrogen internal combustion engine vehicles) or other applications.

\section{The RSOFC Technology}

Operating in SOEC mode, the RSOFC uses the same electrochemical principles as other water electrolysis technologies based on PEM and alkaline systems. High temperature steam electrolysis in an RSOFC, however, has the potential for high efficiency and lower costs in that:

- The total energy demand for water splitting is lower in the vapor phase than in the liquid phase and the energy for vaporization can be provided thermally within the RSOFC system rather than electrically

- The electrical energy required for electrolysis decreases with increasing temperature-again using thermal energy from within the RSOFC system, in this case to provide part of the energy for water splitting - thus achieving higher total efficiency

- RSOFCs possess improved thermally-activated reaction kinetics at higher operating temperatures relative to PEM or alkaline technologies, which eliminates the need for noble metal catalysts to obtain high current density

- RSOFCs may also be integrated with plants where high temperature steam is available at low cost such as nuclear, geothermal, and fossil energy plants

Early RSOFC research and development efforts date back to the 1980 s. $^{1}$ The limitations of the SOFC technology of that day resulted in this work being conducted at ultra-high $\left(1000^{\circ} \mathrm{C}\right)$ operating temperatures. Since then, significant progress has been made in advancing the state of the art of SOFC technology, particularly for the VPS-style, planar anode supported cells and stacks.

The U.S. Department of Energy's (DOE) Solid State Energy Conversion Alliance (SECA) program has developed a systematic roadmap to improve the core SOFC cell and stack technology. ${ }^{2}$ VPS has worked with two industrial teams, FuelCell Energy ${ }^{3}$ (FCE) and Cummins Power Generation Inc. ${ }^{4}$ (CPG), in the development of SOFC technology for their stationary and mobile applications, respectively. Under the SECA program, VPS has made significant progress in the area of cost, endurance and efficiency. ${ }^{5}$

In parallel, the DOE initiated an Advanced Electrolysis Technologies to Reduce Cost and Increase Efficiency task within Hydrogen Program. ${ }^{6}$ The four major barriers were identified as follows:

G. Capital Cost: R\&D to develop lower cost materials with improved manufacturing capability to lower capital while improving the efficiency and durability of the system.

$\mathrm{H}$. System Efficiency: development is needed for low-cost cell stack optimization addressing efficiency, compression, and durability.

I. Grid Electricity Emissions (for distributed): Link with renewable power sources, RSOFC has the potential of delivering none-intermittent, low-cost, carbon-free electricity generation.

J. Renewable Electricity Generation Integration (for central): More efficient integration with renewable electricity generation is needed to reduce costs and improve performance. Development of integrated renewable electrolysis systems is needed, including optimization of power conversion and other system components from renewable electricity to provide highefficiency, low-cost integrated renewable hydrogen production.

In order to address the technical and cost barriers, EERE funded a number of research projects over the past ten years, including: 
- Technology Management Inc.: Low cost, high efficiency reversible fuel cell systems

- Ceramatec, Inc: Hybrid, high-temperature electrolysis/fuel cell process using solid oxide fuel cells for co-generation of hydrogen and electricity

- General Electric: High-temperature reversible solid oxide electrolysis materials and system development

- SRI International: Modular system for low-cost generation of hydrogen by high-temperature electrolysis using solid oxide technology with anodic depolarization by carbon monoxide

In those research projects, the feasibility of RSOFC operation was demonstrated through single cell and small stack testing. The economic benefits of RSOFCs were evaluated with various system designs for both distributed and central power systems. For instance, in GE's program, ${ }^{7}$ the technology assessment focused on water electrolysis and steam reforming technologies, including an overview of each technology and a comparative technology analysis of RSOFC versus other electrolysis systems (alkaline and PEM) and steam reforming for hydrogen production. A comparison with alkaline and PEM electrolysis indicated that RSOFCs operating in SOEC mode had the lowest feedstock cost due to the lowest operating voltage. Under the assumptions in this study, the SOEC system resulted in the lowest cost of hydrogen at both distributed and central station sizes. However, those economic analyses were based on the advancement of key technologies yet to be achieved in an RSOFC stack.

Compared to other water electrolysis systems, SOEC electrolysis system development is less mature. The progress in RSOFC in dual mode operation has been limited to lab-scale prototypes to date. However, before RSOFC scale up for system development and demonstration, significant materials development is required to enhance the performance and durability of RSOFC cells and stacks. Previous studies indicated that in order to reduce the capital cost and increase electrical efficiency, thereby reducing the operating cost, the specific hydrogen generation and fuel cell performance need to be improved simultaneously because of the direct correlations between specific hydrogen generation and electrical energy demand.

In particular, an equivalent electrochemical performance, expressed in terms of ASR of less than 300 $\mathrm{m} \Omega-\mathrm{cm}^{2}$, is required to operate RSOFC in both SOFC and SOEC modes. Although significant progress was made in the above mentioned DOE RSOFC-related projects, further progress is required, especially at reducing the operating temperature to less than $800^{\circ} \mathrm{C}$.In addition, the durability of RSOFC operating in $\mathrm{SOEC}$ mode is a key issue. From limited long-term test data (more than 1000 hours), the decay rates from the earlier DOE projects were very high at more than $0.2 \Omega-\mathrm{cm}^{2} / 1000$ hours. An order of magnitude improvement is required to address this technical barrier.

Thus, RSOFC cell and stack durability and performance are key barriers for advancing RSOFC technologies for both distributed and central applications. By conducting an RSOFC cell and stack material development project, VPS reduced the technical gaps significantly in RSOFC performance and durability.

\section{Technology Development at VPS}

VPS has been developing SOFC technology since 1997. From its inception, the research and development program at VPS has focused on low cost, intermediate temperature $\left(700^{\circ} \mathrm{C}\right.$ to $\left.750^{\circ} \mathrm{C}\right)$, planar anode-supported SOFC technology. To ensure the emergence of cost-competitive solutions, the effort emphasized use of conventional materials (such as YSZ and nickel) and early introduction of volume manufacturing processes (such as tape casting, screen printing, and single-pass continuous firing) to deliver a low-cost, mechanically and electrochemically robust cell design. 
Early successes in cell development established a solid foundation for SOFC stack technology development at VPS. The baseline VPS stack is planar, anode supported, with internal manifold metallic bipolar plates in a cross-flow configuration, and sealed with compressible ceramic gaskets. This approach has resulted in cell and stack materials being subjected to a range of validation tests-from one-cell stack repeat units to 28 -cell $\mathrm{kW}$-class stack modules. A randomly selected production cell has demonstrated performance of $1.4 \mathrm{~W} / \mathrm{cm}^{2}$ at $750^{\circ} \mathrm{C}$ and $0.7 \mathrm{~V}$. Steady-state operation for over 26,000 hours and transient testing of 250 deep thermal cycles have been demonstrated. Key engineering solutions have been developed in the areas of thermal management, flow management, internal reforming, thermal expansion following, internal (and external) compression, high temperature current collection, etc.

Recently, VPS has undertaken stack development in the SECA SOFC program. Excellent progress has been made in cell and stack technology advancement. A list of major accomplishments includes:

- Understanding degradation mechanisms and reducing degradation to $0.3 \%$ per 1000 hours for more than 17,000 hours in single cell and $0.5 \%$ per 1000 hours in $\mathrm{kW}$-class stack for more than 20,000 hours

- Enhancing cell performance by greater than $10 \%$, especially at lower operating temperature, through cathode improvements

- Scaling up cell size (from 12.5 by $12.5 \mathrm{~cm}$ to 25.4 by $25.4 \mathrm{~cm}$ ) and establishing a new baseline cell at $550 \mathrm{~cm}^{2}$ active area with VPS's TSC cell manufacturing process

- Scaling up stack size and establishing a new baseline stack of $16 \mathrm{~kW}$ (96 large area cells) as the building block for large power plants

- Incorporating new stack design improvements and component advancements to meet cost targets

- Demonstrating 60-kW SOFC stack modules in systems

In order to understand the feasibility of RSOFC dual mode operation, as well as the technical gaps of existing SOFC technology, an internally-funded research project in RSOFC was undertaken at VPS prior to this project. VPS tested five-cell stack repeat units for durations in excess of 1000 hours for RSOFC operation and several other short-term performance tests. The longest test has run for approximately 3000 hours and another test has completed over 100 simulated full-cycles (fourteen hours in SOEC mode, and eight hours in SOFC mode, and two total hours of transition). Based on the results from those initial explorations, VPS developed a solid technical baseline compared to earlier DOE EERE projects. ${ }^{7}$

Developing high performance at low temperature operation $\left(700\right.$ to $\left.800^{\circ} \mathrm{C}\right)$ is one of the key strategies for improving SOFC stability and reducing cell and stack cost at VPS. A literature survey identified that the lower standard operating temperature of the VPS technology may provide some advantages in SOEC operation in terms of anode stability, specifically the avoidance of nickel coarsening. The VPS cathode and cell have demonstrated some of the best performance and degradation numbers in the literature in SOFC mode. In addition, the results of VPS's internally-funded effort have demonstrated SOEC performance comparable to the best reported in the literature. In the absence of clear disadvantages it therefore seems prudent to focus, in a first instance, on the baseline VPS technology and variants thereof for RSOFC evaluation and development.

In order to address key technical and cost barriers, VPS focused on advancing RSOFC cell stack technology in the areas of durability and performance in this project. This was achieved through RSOFC materials development and reversible stack development with specific technical metrics: 
- RSOFC area specific resistance of less than $300 \mathrm{~m} \Omega-\mathrm{cm}^{2}$ in both SOFC and SOEC operating modes

- $\quad$ RSOFC dual mode operation of 1500 hours with more than ten SOFC/SOEC transitions

- Operating current density of more than $300 \mathrm{~mA} / \mathrm{cm}^{2}$ in both SOFC and SOEC modes

- Overall decay rate of less than $4 \%$ per 1000 hours of operation

\section{Project Potential}

A significant issue associated with some renewable energy sources, such as wind turbines or photovoltaic systems, is intermittency. There are a number of storage options to address renewable energy's intermittency such as batteries, thermal storage, etc. An RSOFC system, combined with hydrogen storage, is one of these energy storage options. Energy storage enables an intermittent renewable energy source to be better matched to the demands of either the electric grid it supplies or, in the case of distributed renewable energy installations, local energy demands. In either case, an arbitrage opportunity arises as renewable energy captured at grid non-peak times can be delivered to the grid during peak times or offset peak demand in distributed generation applications. Additionally, where large amounts of intermittent renewable energy have been installed, electric grid stability issues have arisen due to this intermittency. Energy storage deployed with intermittent renewables provides an energy delivery buffer that can smooth out delivery profiles and help mitigate grid stability issues.

Furthermore, in a number of remote applications it is difficult to bring traditional power sources (electricity, natural gas, etc.) economically to the location. These applications include communication towers, agricultural water distribution, road-side signage, and others. In these applications, an RSOFC with hydrogen storage would be teamed with a renewable power source such as wind turbines or photovoltaic systems. Generally, the overall size of these systems is anticipated to be in the tens of kW.

Where inexpensive off-peak electricity is available, an RSOFC system could be deployed to provide a hydrogen supply-e.g., for vehicle fueling - with the RSOFC supplying local electric power. Due to the pace of fuel cell vehicle development and deployment and the geographic constraint of the availability of inexpensive off-peak electricity, it is expected that this will be a limited market in the near term.

This effort, leveraging VPS's years of development experience, has the potential to bring renewable energy RSOFC storage systems significantly closer to commercial viability through improvements in RSOFC durability, performance, and cost. When unitized and deployed in renewable solar and wind installations, the VPS RSOFC system can enable higher availability for intermittent renewable resources, thereby improving the commercial viability of these types of energy resources.

\section{Project Overview}

The objective of the project is to advance RSOFC cell stack technology in the areas of durability and performance. In order to address key technical and cost barriers, the following approaches were taken in the project:

- Building on VPS's strong SOFC cell and stack baseline

- Leveraging cell and stack advancements from the parallel DOE SECA project

- Addressing RSOFC degradation mechanisms in SOEC mode with innovative cell and stack repeat unit configurations 
- Conducting parallel materials development activities and integrating them with cell production technology development

- Completing RSOFC stack and process designs to address durability, performance, and cost in both SOFC and SOEC operating modes

The project was executed with the following tasks structure:

- Task 1 Degradation Mechanism Study for RSOFC

- Task 2 Cell Materials Development

- Task 3 Interconnect Materials Development

- Task 4 Stack Design and Demonstration

- Task 5 Project Management

A stage-gate project management process was employed throughout the project. Figure 3 presents a high level project schedule. Accordingly, research and development activities were grouped in parallel as interlinked tasks and sub-tasks. Key development milestones were marked along with one project Go/No-Go decision point. Five technical milestones were tracked and measured throughout the project:

- Milestone 1: Completion of degradation mechanisms study of baseline cells ( $4^{\text {th }}$ quarter)

- Milestone 2: Completion of RSOFC cell materials selection ( $6^{\text {th }}$ quarter)

- Milestone 3: Completion of RSOFC interconnect materials selection ( $6^{\text {th }}$ quarter)

- Milestone 4: Completion of RSOFC stack design ( $7^{\text {th }}$ quarter)

- Milestone 5: Starting end of the project RSOFC stack metrics test ( $8^{\text {th }}$ quarter)

All the milestones were completed on time.

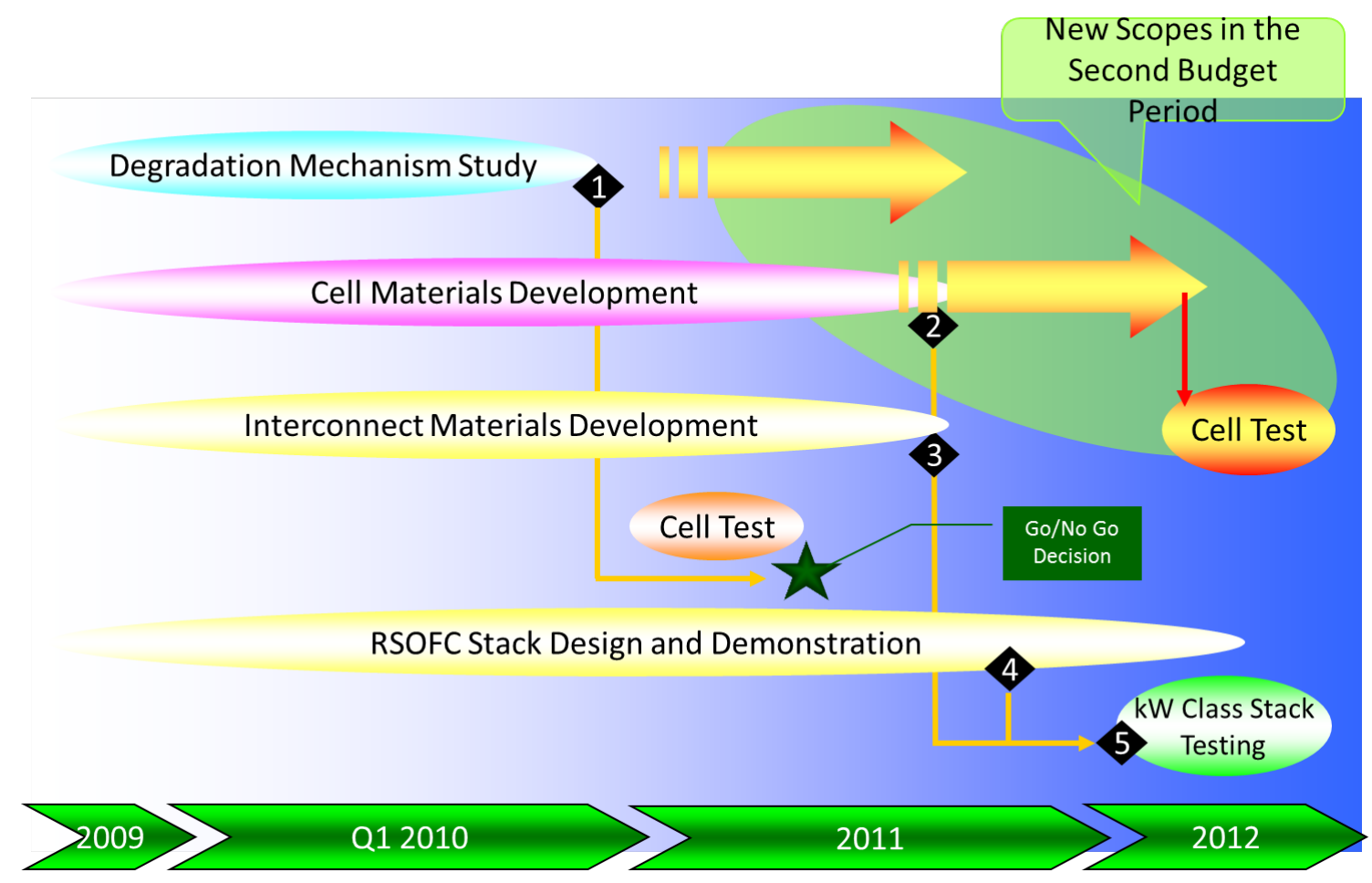

Figure 3. High Level Project Schedule 
The development path for RSOFC can be summarized in Figure 4. Prior to the current project, three cell types-EC-1, EC-2, and EC-3-were developed based on the baseline TSC-2 cell. The cell development has been accelerated since the beginning of the project. The early development was focused on a new air electrode - four RSOFC (1-4) cell types were developed from the base EC-1 and EC-2 cells. After that, two additional cell types-MAC-RSOFC-1 and MAC-RSOFC-5- were developed with innovative fuel electrode contact designs. The parallel development activities were focused on fuel electrode development with an EC-3 air electrode. This development path led to four new cell designs: RSOFC-6, RSOFC-7, RSOFC-8, and RSOFC-9.

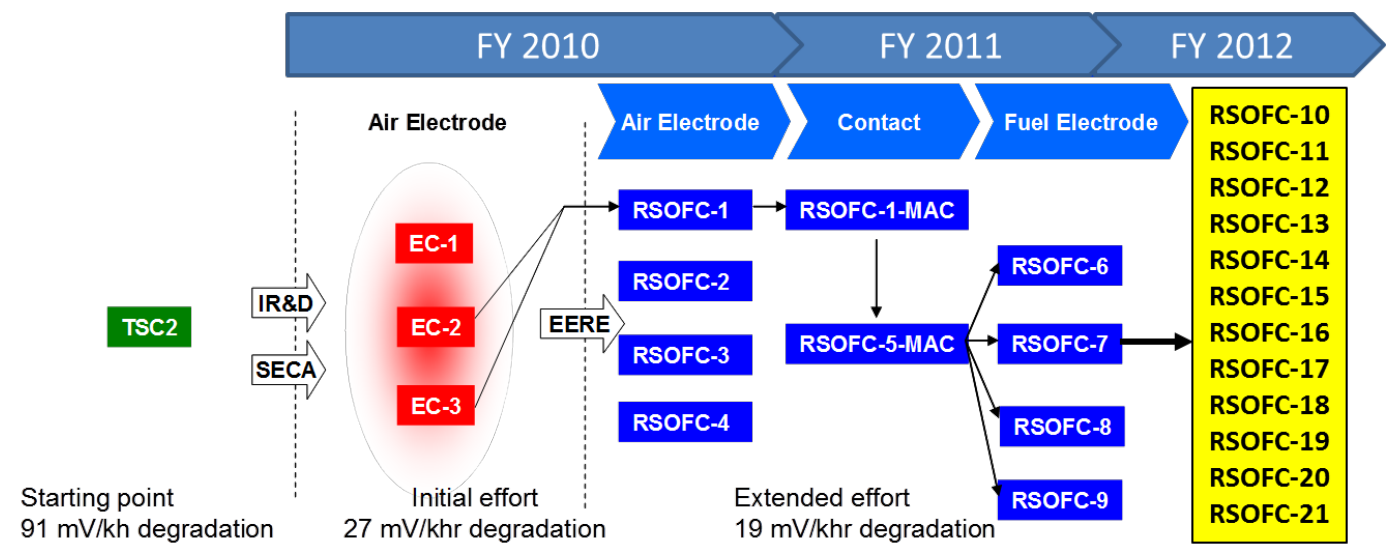

Figure 4. RSOFC Cell Development Path at VPS

At month 15, a go/no-go decision point was passed based on a 1000 hour single cell test relative to the following performance and endurance metrics:

- RSOFC area specific resistance of less than $300 \mathrm{~m} \Omega-\mathrm{cm}^{2}$ in both SOFC and SOEC operating modes

- Operating current density of more than $300 \mathrm{~mA} / \mathrm{cm}^{2}$ in both SOFC and SOEC modes

- Overall decay rate of less than $4 \%$ per 1000 hours of operation

As shown in Table 1, a single-cell test based on an RSOFC-7 cell surpassed all technical metrics in the Go/No-Go decision test.

Table 1. Summary of Go/No-Go Decision Points

\begin{tabular}{|lll|}
\hline \multicolumn{1}{|c|}{} & \multicolumn{1}{c|}{ Targets } & \multicolumn{1}{c|}{ Results } \\
Performance & $<300 \mathrm{~m} \Omega-\mathrm{cm}^{2}$ in SOEC & $223 \mathrm{~m} \Omega-\mathrm{cm}^{2}$ in SOEC \\
& $<300 \mathrm{~m} \Omega-\mathrm{cm}^{2}$ in SOFC & $224 \mathrm{~m} \Omega-\mathrm{cm}^{2}$ in SOFC \\
\hline Degradation & $<4 \%$ per 1000 hours & $1.5 \%$ per 1000 hours \\
\hline Operating Duration & $>1000$ hours & $>1000$ hours \\
\hline Operating Current & $>300 \mathrm{~mA} / \mathrm{cm}^{2}$ & $500 \mathrm{~mA} / \mathrm{cm}^{2}$ \\
\hline
\end{tabular}

Following the successful completion of the original scope of work for this task, it was agreed to continue cell development to further improve steady-state electrolysis performance and cyclic RSOFC operation based on RSOFC-7 materials systems. In total, 23 materials systems were evaluated for initial performance in SOFC and SOEC modes, with four cell materials systems tested for significant time periods under SOFC/SOEC cyclic conditions. Two materials systems achieved ASR less than $300 \mathrm{~m} \Omega-\mathrm{cm}^{2}$ 
for both SOEC and SOFC operation even at $700^{\circ} \mathrm{C}$. One of the tests completed over 14,500 hours with over 600 daily SOFC/SOEC cycles. The degradation rate was less than $0.7 \%$ per 1000 hours in fuel cell mode and less than $1.5 \%$ per 1000 hours in electrolysis mode. In another cyclic test, over 5800 cycles were completed in accelerated 20-minute SOFC/SOEC cycles. This compares favorably to current battery technologies.

RSOFC stack development, based on a strong VPS SOFC stack baseline design, started in parallel to cell development. A number of stacks were built and tested throughout the project in order to

- Explore the stack design options

- Compare to stack modeling results

- Validate the materials development inputs from Task 1, 2, and 3

- Develop the reversible capability of the stack design

In one kW-class stack test, over 5000 hours of continuous steady-state electrolysis operation was achieved with less than $3 \%$ per 1000 hours degradation. Another $\mathrm{kW}$-class stack was tested over 100 SOFC/SOEC cycles. As a demonstration of the overall RSOFC materials development and stack development, a final kW-class RSOFC stack test was conducted at the end of the project to meet the following technical metrics:

- $\quad$ RSOFC area specific resistance of less than $300 \mathrm{~m} \Omega-\mathrm{cm}^{2}$ in both SOFC and SOEC operating modes

- RSOFC dual mode operation of 1500 hours with more than ten SOFC/SOEC transitions

- Operating current density of more than $300 \mathrm{~mA} / \mathrm{cm}^{2}$ in both SOFC and SOEC modes

- Overall decay rate of less than $4 \%$ per 1000 hours of operation

A kW-class stack with scale-up 25 by $25 \mathrm{~cm}\left(550 \mathrm{~cm}^{2}\right.$ active area) was constructed for this test. As shown in Table 2, the test met most of the technical metrics except overall degradation rate due to thermal management issues in SOFC/SOEC transients.

Table 2. kW-Class RSOFC Stack Metric Test Summary

\begin{tabular}{|lll|}
\multicolumn{1}{|c}{} & \multicolumn{1}{c|}{ Targets } & \multicolumn{1}{c|}{ Results } \\
\hline \multirow{2}{*}{ Performance } & $<300 \mathrm{~m} \Omega-\mathrm{cm}^{2}$ in SOEC & $223 \mathrm{~m} \Omega-\mathrm{cm}^{2}$ in SOEC \\
& $<300 \mathrm{~m} \Omega-\mathrm{cm}^{2}$ in SOFC & $224 \mathrm{~m} \Omega-\mathrm{cm}^{2}$ in SOFC \\
\hline Degradation & $<4 \%$ per 1000 hours & $5.3 \%$ per 1000 hours \\
\hline \multirow{2}{*}{ Operating Duration } & $>1500$ hours with 10 & $>1500$ hours with 10 \\
& SOFC/SOEC transients & SOFC/SOEC transients \\
\hline Operating Current & $>300 \mathrm{~mA} / \mathrm{cm}^{2}$ & $364 \mathrm{~mA} / \mathrm{cm}^{2}$ \\
\hline
\end{tabular}

In the following sections, the development activities and results in each task will be discussed in detail.

\section{Task 1: Degradation Mechanism Study for RSOFC}

According to the literature, a number of degradation mechanisms under SOEC conditions were observed, depending on the materials system used in the cell and the operating conditions chosen. At higher operating temperatures (over $850^{\circ} \mathrm{C}$ ), nickel coarsening is proposed as a key degradation 
mechanism for the anode in one study, while other studies compare a range of perovskite cathodes showing that different chemistries result in different performance and degradation rates. While studies were found using the same fuel electrode chemistry as VPS cells, no studies were found using the VPS air electrode materials, and only limited recent studies were found using any SOEC tests with operating temperatures under $800^{\circ} \mathrm{C}$ (the preferred VPS operating temperature range is 700 to $800^{\circ} \mathrm{C}$ ). In both studies the materials system was different, hence as far as current published literature is concerned this project is unique. Several papers have arisen from a Ph.D. thesis from Hauch ${ }^{8}$ at Ris $\varnothing$ National Labs, detailing testing of fuel electrode-supported cells in the temperature range 650 to $950^{\circ} \mathrm{C}$. The conclusion is that the fuel electrode is responsible for most of the degradation in SOEC mode. Impurity phases at the triple phase boundary (including silicates, alumino-silicates, and sodium alumino-silicates) are thought to be the cause of degradation (presumably from the glass-ceramic seal used). It is hard to imagine where such impurities would arise in a VPS stack repeat unit that does not use glass-ceramic seals.

Prior to this project, VPS had already tested standard baseline TSC-2 cells in a stack repeat unit configuration for more than 1000 hours with an innovative test configuration that allowed separation of interconnect-to-contact interface degradation (anode and cathode) from cell degradation. The results showed that less than $10 \%$ of the total degradation was due to interconnect-to-contact interfaces and over $90 \%$ could be directly attributed to the cell itself. EIS analysis showed that the degradation was not due to diffusion limitations but was related to charge transfer processes at the electrodes. The key cause of degradation also affects an electrochemical process that is fully reversible (the degradation of performance is the same in SOFC as SOEC operation), but it only occurs during operation in SOEC mode (the degradation rate is under $0.3 \%$ per 1000 hours running in SOFC mode only). This suggests the most likely causes are microstructural changes or impurity effects at the triple phase boundary. SEM analysis revealed no clear large-scale microstructural changes at the fuel or air electrodes and no build-up of impurities within the resolution of EDX. In order to better determine the mechanism, more sophisticated microstructural and micro-analytical techniques were applied.

The work therefore focused on lowering steady-state electrolysis degradation. Previous work at VPS had shown that the majority of degradation in electrolysis mode is likely related to the cell air electrode using standard VPS TSC-2 cells. Cells were therefore prepared and tested using modified air electrode (EC-1 and EC-2), but keeping the rest of the cell materials and microstructure the same. A comparison of the steady-state electrolysis tests from a TSC-2 cell (GLOB 101670), an EC-1 cell (GLOB 101695), and an EC-2 cell (GLOB 101706 and GLOB 101726) can be seen in Figure 5. This comparison shows clearly the change in degradation rate as well as the difference performance in initial cell voltage at the same electrolysis operating conditions. 


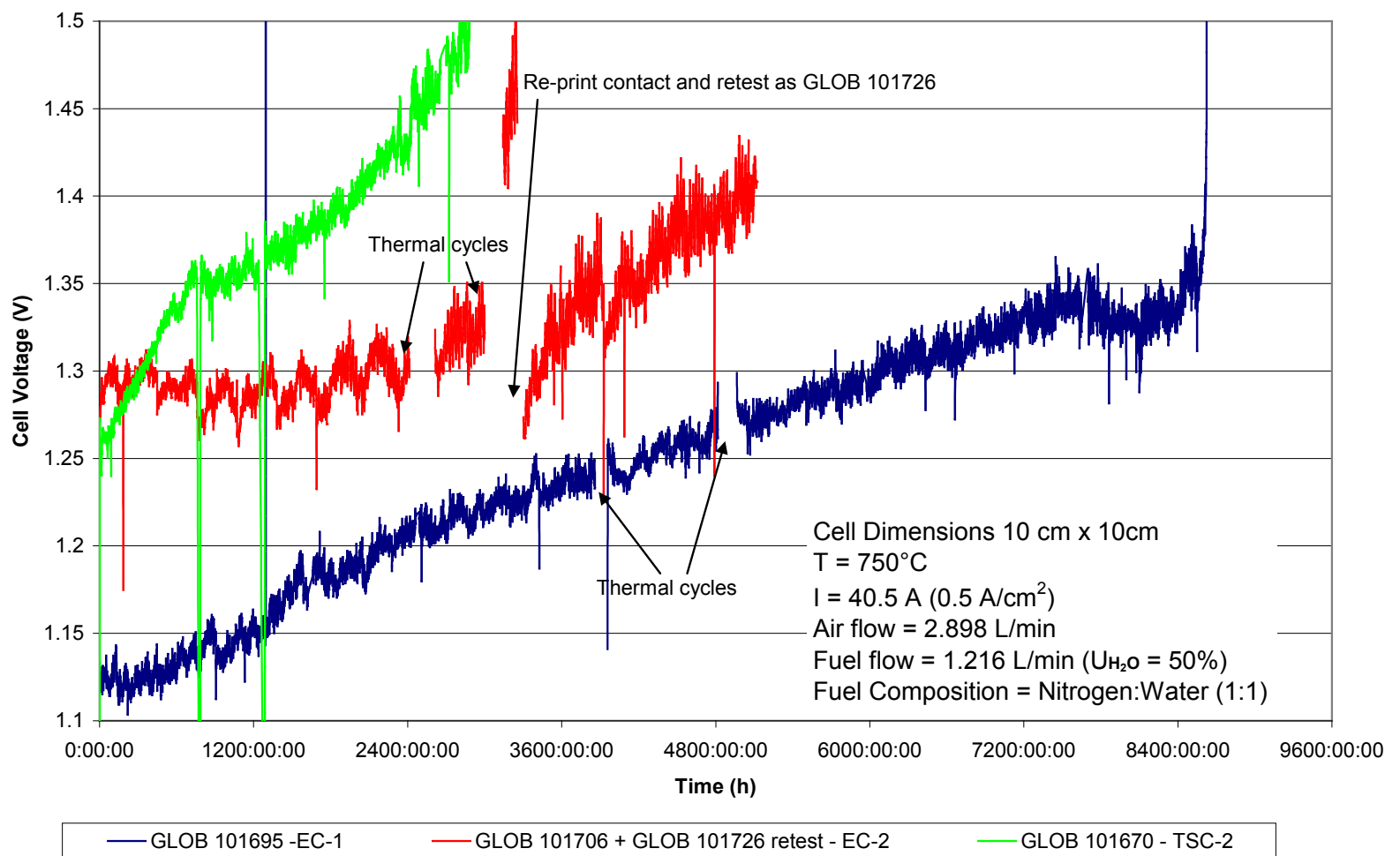

Figure 5. Comparison of Steady-State Electrolysis Tests GLOB 101670, GLOB 101695, and GLOB 101706 (GLOB 101726)

As shown in Figure 5, the EC-2 cell ran for about 2400 hours with no measurable degradation. The air electrode of this cell was modified in an attempt to resolve cathode delamination problems encountered with the TSC- 2 cell. However, this cell had lower performance than the TSC- 2 and EC- 1 cells in both electrolysis and fuel cell mode. It is worth noting that all of these cells tested had nominally the same fuel electrode and electrolyte compositions and microstructure. This indicated that these layers were most likely not contributing to degradation in the first 2400 hours of operation. After that, facilities issues caused large performance losses and a significant increase in degradation rate. The test was stopped after around 3200 hours and the contact layer at air electrode side was found to be delaminated during autopsy. The layers were re-produced and cell performance went back to the initial level. However, the degradation rate was high for the remaining 1700 hours of the test. This demonstrated that for this type of air electrode, full performance can be restored after this degradation by replacing the contact layers that delaminated. Unfortunately, the cell was broken after autopsy the second time and could not be used again for further testing. While of very poor SOFC performance and relatively low electrolysis performance, this test of an EC-2 cell did provide some very useful information regarding degradation mechanisms.

In comparison, another single cell test with EC-1 cells was performed for 8465 hours in SOEC mode. Although it demonstrated excellent performance and a lower degradation rate ( $27 \mathrm{mV}$ per 1000 hours), the test was terminated due to an abrupt voltage runaway to more than $1.6 \mathrm{~V}$. Figure 6 and Figure 7 show power curves at the start and end of the test at 50\% humidity (SOFC and SOEC mode), respectively. 
The power curve comparisons at test start and end showed significant activation and ohmic losses . In addition, the EIS comparisons showed very significant ohmic loss increases as well as significant charge transfer resistance increases (high frequency arcs), with little change in the diffusion resistance. This suggested that electrode densification was unlikely to be a degradation mechanism, but with both ohmic and charge transfer losses increasing significantly, the key cause of degradation was not clear from the data alone.

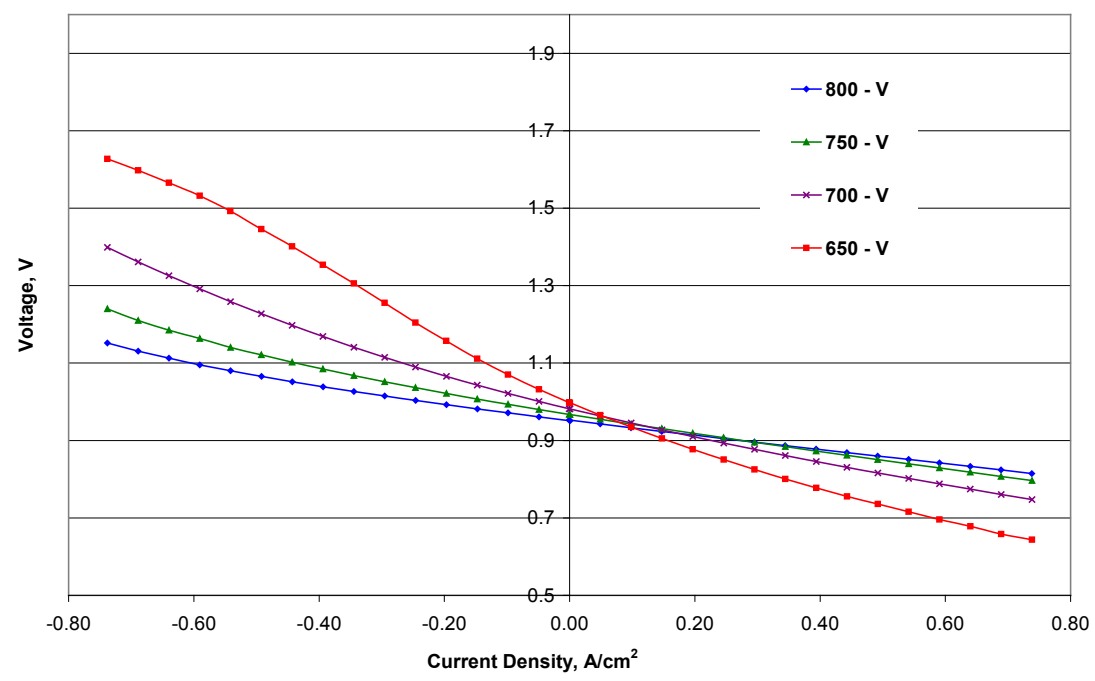

Figure 6. SOFC and SOEC Power Curves at 50\% Humidity for GLOB 101695 at Test Start

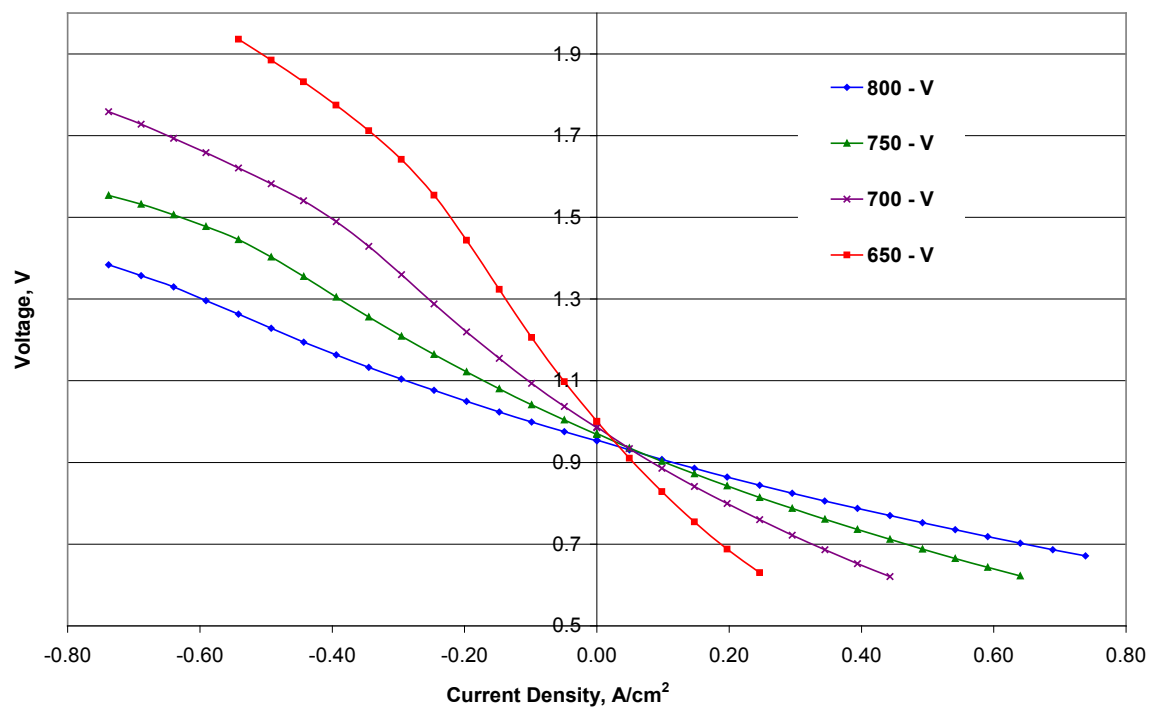

Figure 7. SOFC and SOEC Power Curves at 50\% Humidity for GLOB 101695 at Test End

Post-test analysis was conducted after the electrochemical test. The single-cell test assembly was taken apart following a standard autopsy. Although some oxidation of the $\mathrm{Ni} / Y S Z$ fuel electrode was observed 
at the steam inlet corners as shown in Figure 8, no other obvious damage of the cell could be found. In addition, contact was good on the anode side.

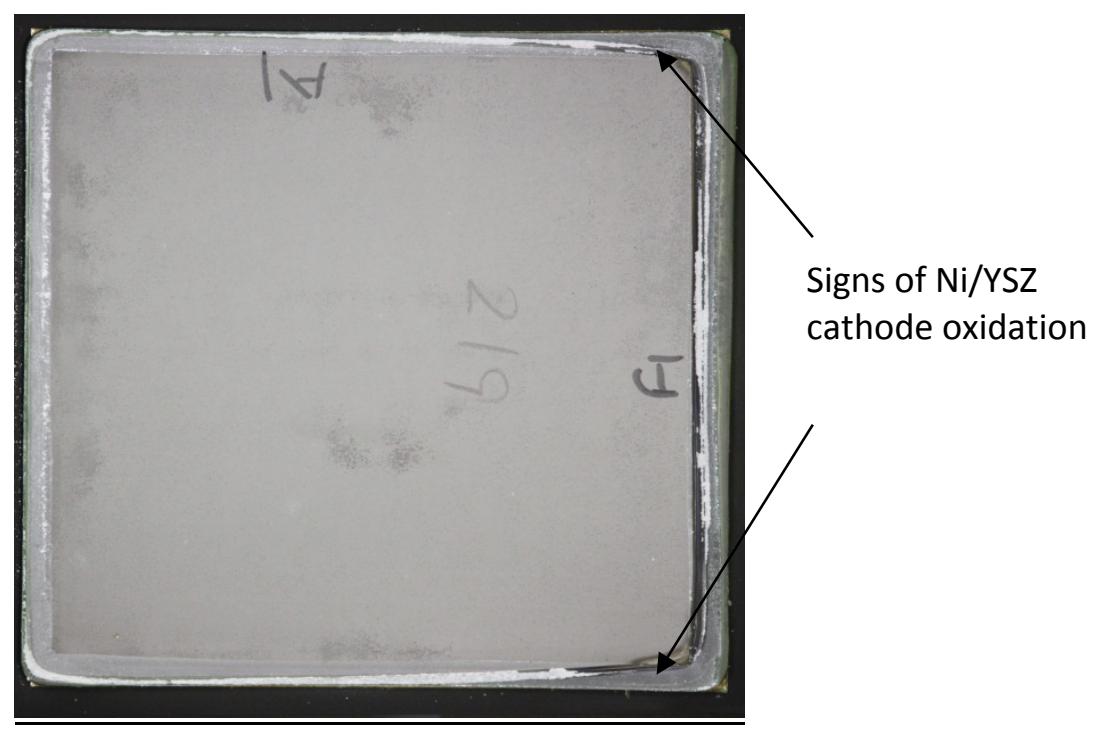

Figure 8. Fuel Cell Anode Side after Test

The interconnect jigs were prepared for detailed microscopic analysis. The oxide thickness and composition on the interconnect were analyzed by SEM. On the fuel electrode side (Figure 8), the oxide was thicker (up to 5 micron) in the center and by the fuel outlet (FO). On the air electrode side (Figure 10), the oxide was thin and even at around 1 micron. The oxide composition was as expected-mainly chromia with CrMn spinel as an outer layer. There was no obvious cause for the sudden voltage run up at the end of the test.

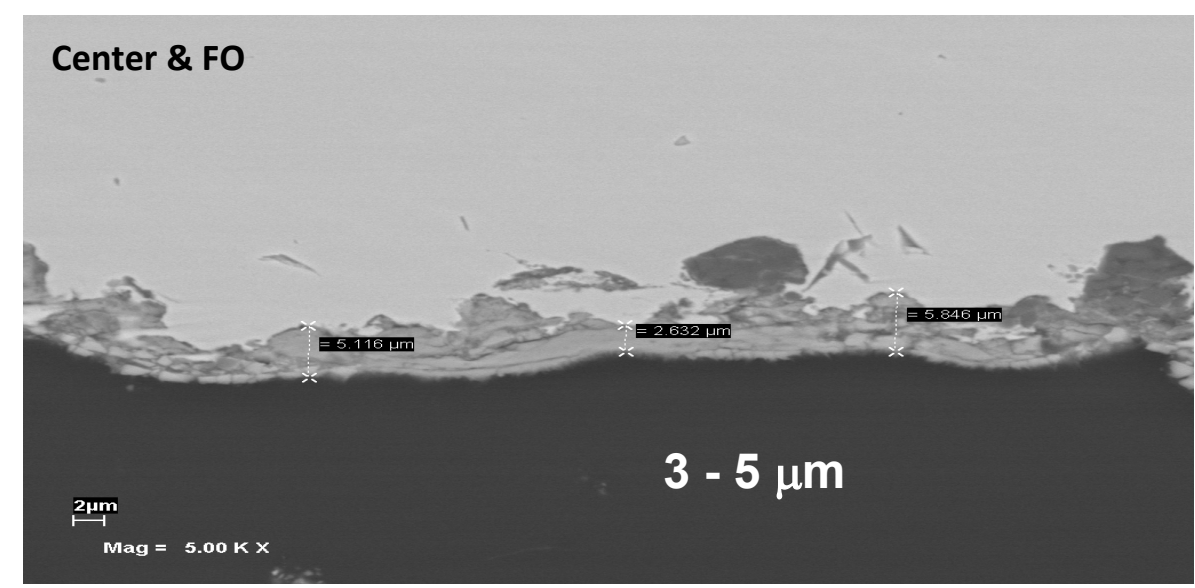

Figure 9. Cross-Section SEM Image of Interconnect Oxidation at Fuel Electrode after 8465 Hours SOEC Operation 


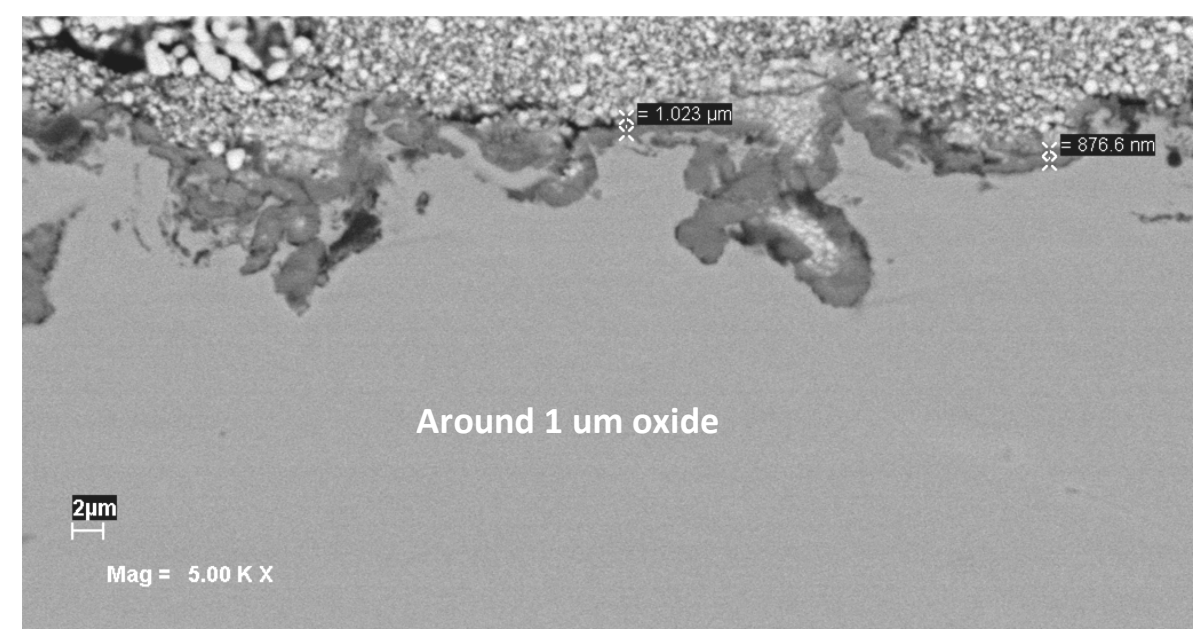

Figure 10. Cross-Section SEM Image of Interconnect Oxidation at Air Electrode after 8400 Hours SOEC Operation

After autopsy, the cell used in test GLOB 101695 was retested as GLOB 101753 since there was no obvious visible cause of the voltage runaway observed right at the end of the test. Figure 11 shows cell voltage against time for GLOB 101695 with the retest data (GLOB 101753) at the same test conditions added on to the end of the test for comparison. The cell voltage was the same as after about 4370 hours of the original test, significantly lower than at the end of the previous test and approximately half way between the initial cell voltage and the voltage at 8465 hours (just before the cell voltage increased dramatically to over $1.6 \mathrm{~V}$ ). This could indicate that the final catastrophic event was related to loss of contact, which (in addition to interconnect oxidation) could also be linked to half of the degradation rate observed in the first 8465 hours. Using the same cell with new contact and interconnects gave an initial voltage of $1.26 \mathrm{~V}$ compared to the end of test voltage for GLOB101695 of greater than $1.6 \mathrm{~V}$ and about $1.35 \mathrm{~V}$ after 8465 hours. Based on autopsy and cell retest result, the leading cause of the final voltage run up might be fuel electrode contact related.

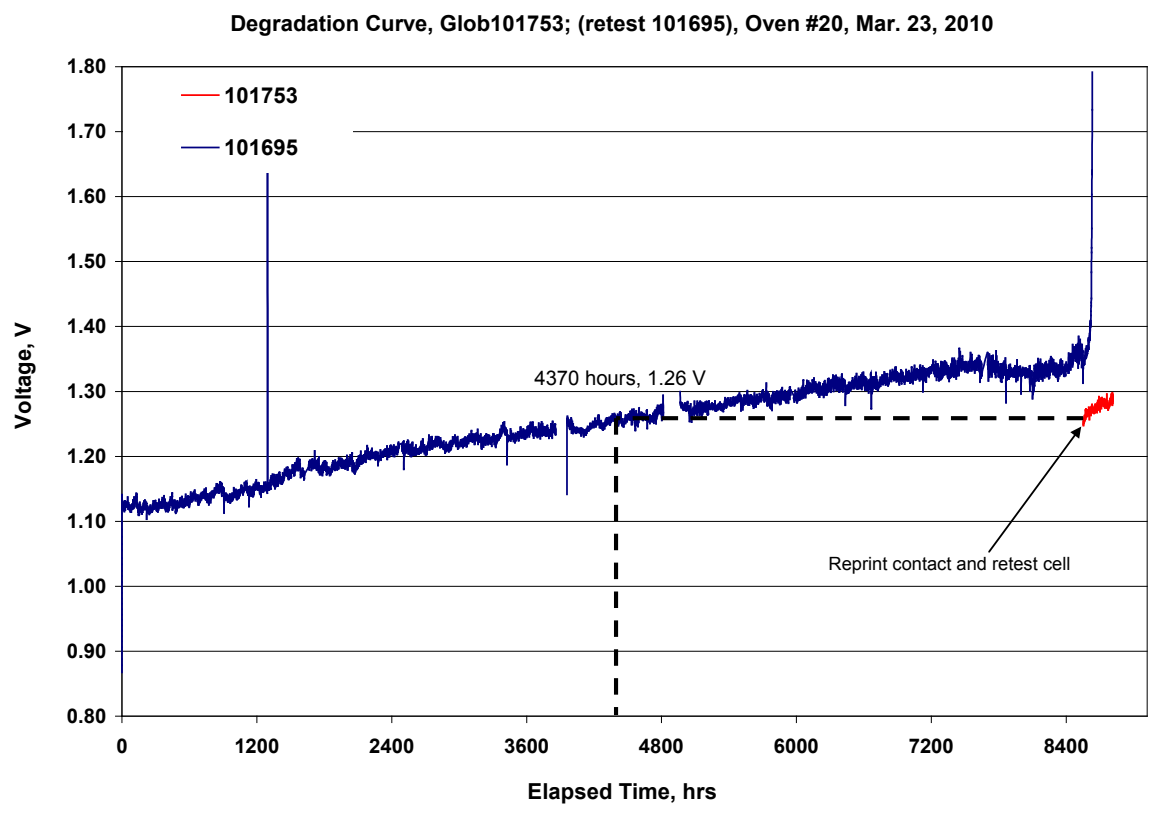

Figure 11. Cell Voltage over Time under Electrolysis Hold Conditions for GLOB 101695 and Retest GLOB 101753 
Although the initial performance of the retested cell (GLOB 101753) is good, the degradation at the same steady-state SOEC operation as the original test (GLOB 101695) was much higher. It was determined that the final voltage run up had caused this significant change in degradation rate. The test was shut down for a detailed post analysis on cell. The observation from the cross section sample of the cell showed two features: a slight densification of the fuel cell anode and a partial delamination at fuel electrode functional layer/electrolyte interface. However, both features could be the result of the final electrolysis voltage run away of over $1.8 \mathrm{~V}$, which caused a redox cycle for the $\mathrm{Ni} / \mathrm{YSZ}$ fuel electrode.

The cell was sent to in-depth TEM analysis, since SEM analysis of the cell after testing did not reveal any conclusive degradation mechanisms. Figure 12 shows a TEM image of the cell showing all interfaces are intact with no interface contamination under high spatial resolution analysis. However, some microstructure changes in fuel electrode due to Ni migration to YSZ were found.

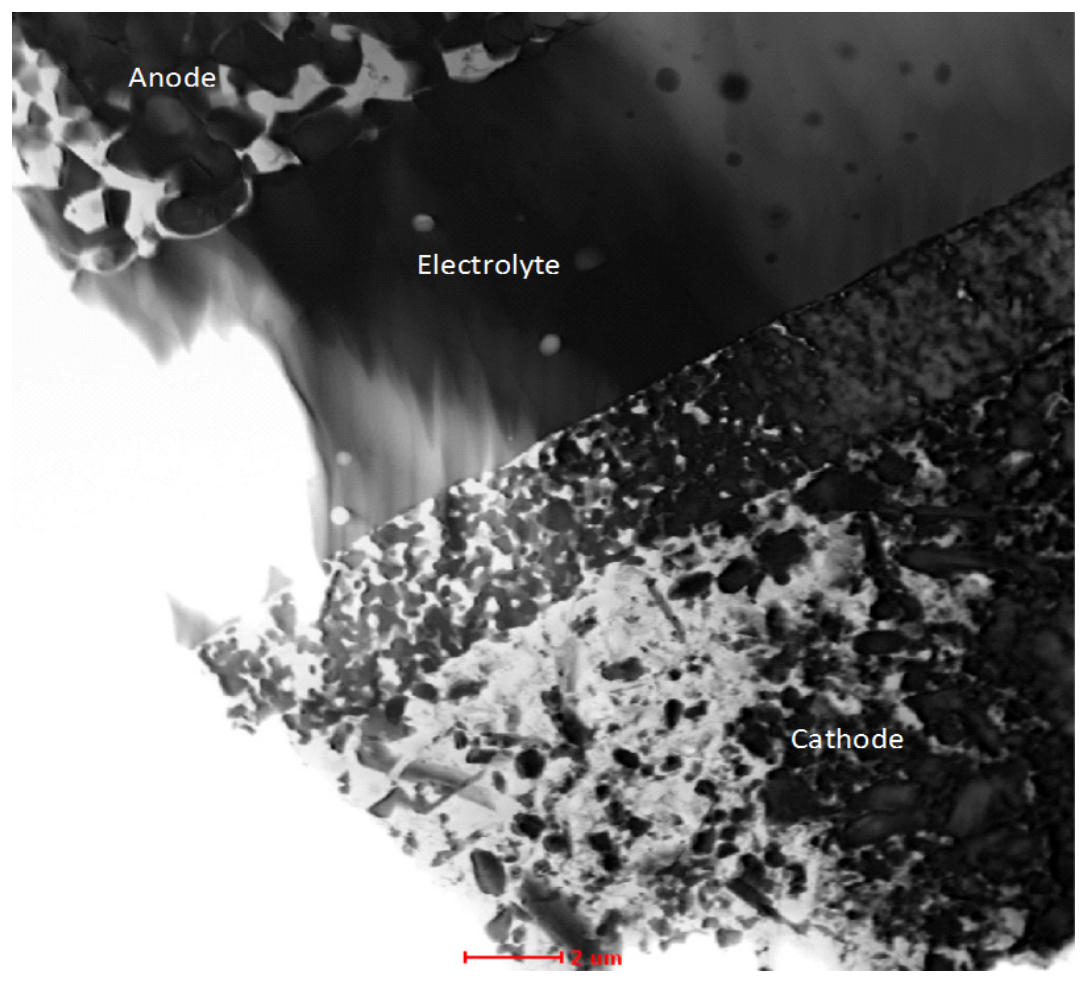

Figure 12. TEM Image of an RSOFC Cell Showing All Interfaces Intact with no Interface Contamination (Anode and Cathode of Fuel Cell Mode)

The post-test analysis of contact loss and microscopic observation of the fuel electrode led to further investigation in contact and fuel electrode. A group of new materials systems range from RSOFC-1 to RSOFC-9 were developed and tested in single cell arrangement.

Table 3 shows degradation rates in electrolysis mode at fixed operating conditions $\left(750^{\circ} \mathrm{C}, 0.5 \mathrm{~A} / \mathrm{cm}^{2}\right.$ and $50 \%$ steam utilization) in both $\mathrm{mV}$ and percent per 1000 hours (percentages were calculated using a fixed reference voltage of $1.25 \mathrm{~V}$ ). 
Table 3. Summary of Cell Degradation Rates under Fixed SOEC Operation

\begin{tabular}{|c|ccc|c|}
\hline \multirow{2}{*}{ Tell Type } & \multicolumn{3}{|c|}{ Electrolysis (SOEC) } & \multirow{2}{*}{ Test No. } \\
\cline { 2 - 4 } & $\mathrm{mV} / \mathbf{1 0 0 0}$ hours & $\mathbf{\%} / \mathbf{1 0 0 0}$ hours & Test duration (hrs) & \\
\cline { 2 - 4 } TSC-2 & $<\mathbf{5 0}$ & $<4$ & $\mathbf{1 0 0 0}$ & 101670 \\
\hline EC-1 & 91 & 7.3 & 2893 & 101695 \\
\hline EC-2 & 27 & 2.2 & 8465 & 101706 \\
\hline EC-3 & $\sim 0$ & 0 & 2400 & 101728 \\
\hline RSOFC-1 & 72 & 5.8 & 1792 & 101737 \\
\hline RSOFC-2 & 35 & 2.8 & 6472 & 101738 \\
\hline RSOFC-3 & 120 & 9.6 & 1152 & 101741 \\
\hline RSOFC-4 & 42 & 3.4 & 2653 & 101744 \\
\hline MAC-RSOFC-5 & 24 & 1.9 & 3618 & 101758 \\
\hline RSOFC-6 & 51 & 4.1 & 1059 & 101779 \\
\hline RSOFC-7 & 31 & 2.5 & 689 & 101782 \\
\hline RSOFC-8 & 18 & 1.5 & 1071 & 101782 \\
\hline RSOFC-9 & 24 & 1.9 & 498 & 101784 \\
\hline
\end{tabular}

Based on these long-term steady-state SOEC tests, it is clear that the degradation target of $4 \%$ per 1000 hours can be achieved mainly through air electrode development in nine cell types. The lowest degradation rates are for the EC-2 cell. However, the EC-2 cell did not meet performance targets in both fuel cell and electrolysis mode and was mainly designed to help confirm the air electrode as the key cause of high electrolysis degradation rates.

In order to understand the operating window better, single-cell tests were conducted to study the effect of operating conditions (such as temperature, current densities, and steam utilization) on degradation rates. MAC-RSOFC- 5 cells with an average degradation rate of around $4 \%$ were selected for the study. Figure 13 shows the effect of temperature on performance and degradation rate. The test ran for over 3300 hours at 700,750 , and $800^{\circ} \mathrm{C}$. The degradation rates were similar at $5.5 \%, 4.1 \%$, and $4.8 \%$, respectively. 


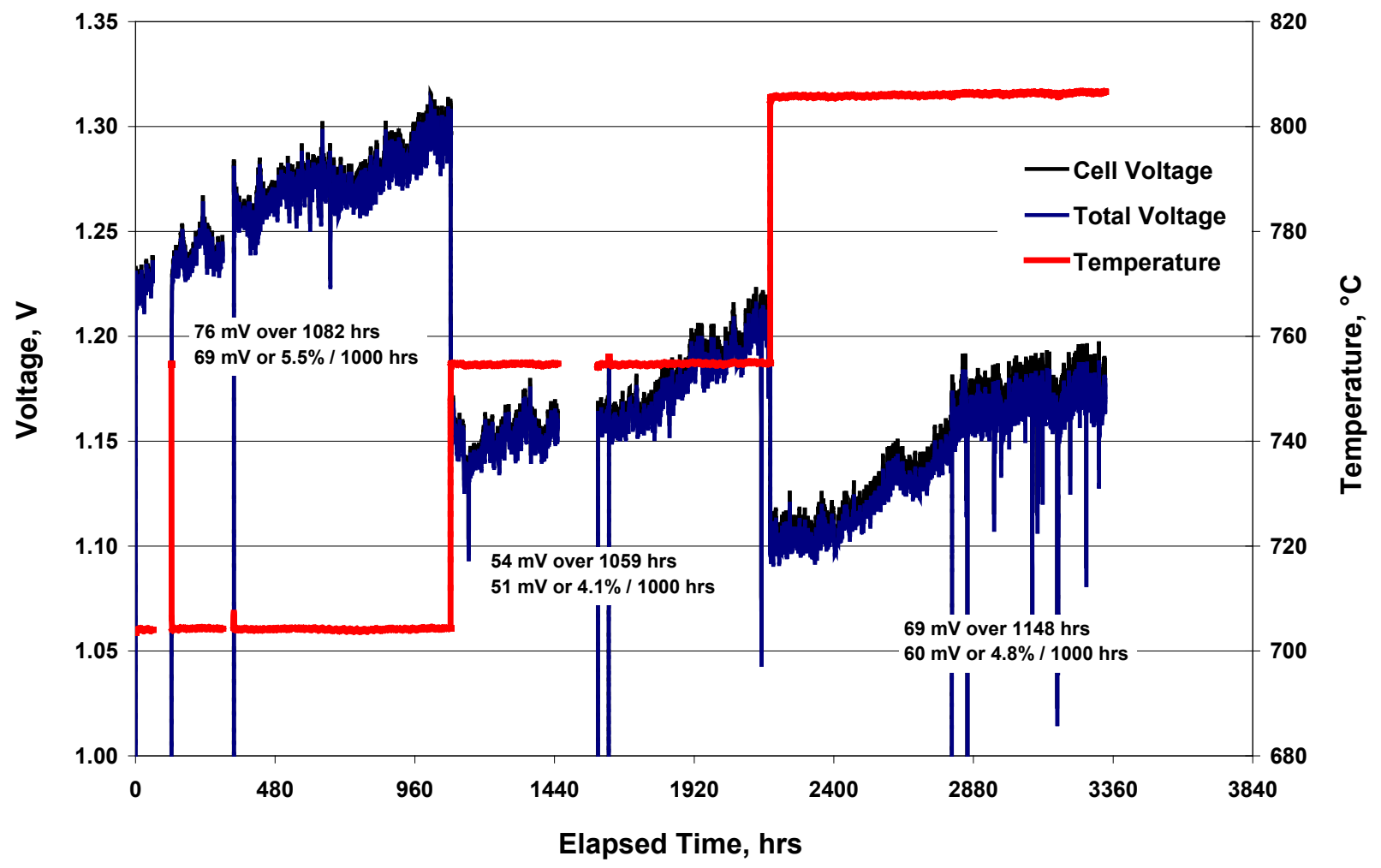

Figure 13. Cell Voltage over Time under Electrolysis Hold Conditions for GLOB 101758 (MAC-RSOFC-5 Cell) at Different Temperatures

Figure 14 shows the effect of current density on performance and degradation rate at a constant furnace temperature of $750^{\circ} \mathrm{C}$. The test ran for over 3300 hours at $0.25,0.5$, and $0.75 \mathrm{~A} / \mathrm{cm}^{2}$. The degradation rate was significantly lower at the lower current density of $0.25 \mathrm{~A} / \mathrm{cm}^{2}$. Increasing the current density from 0.25 to $0.5 \mathrm{~A} / \mathrm{cm}^{2}$ increased the degradation rate from $1.1 \%$ to $6.9 \%$ per 1000 hours. However, increasing the current density further from 0.5 to $0.75 \mathrm{~A} / \mathrm{cm}^{2}$ did not increase degradation rate but increased the voltage noise significantly.

Figure 15 shows the effect of steam utilization on performance and degradation rate at constant furnace temperature of $750^{\circ} \mathrm{C}$ and constant current density of $0.5 \mathrm{~A} / \mathrm{cm}^{2}$. The test ran for over 1300 hours at 25 , 50 , and $75 \%$ steam utilization. This test yielded most conclusive results. Both degradation rates and voltage noise increased significantly with increased steam utilization at the fuel electrode from $1.6 \%$ per 1000 hours at $25 \%$ steam utilization to $5.6 \%$ per 1000 hours at $50 \%$ steam utilization to $16 \%$ per 1000 hours at $75 \%$ steam utilization. 


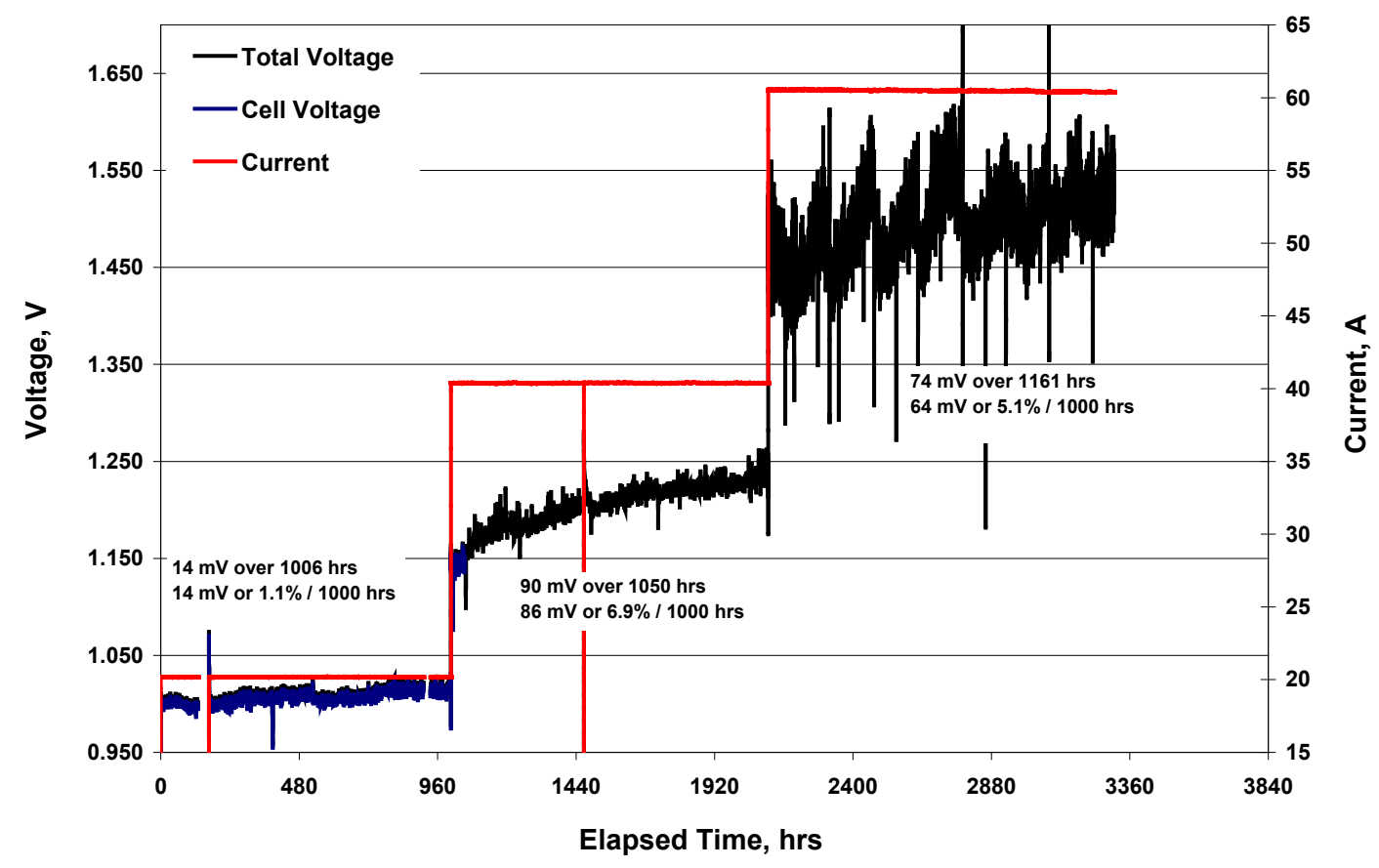

Figure 14. Cell Voltage over Time under Electrolysis Hold Conditions for GLOB 101760 (MAC-RSOFC-5 Cell) at Different Current Densities

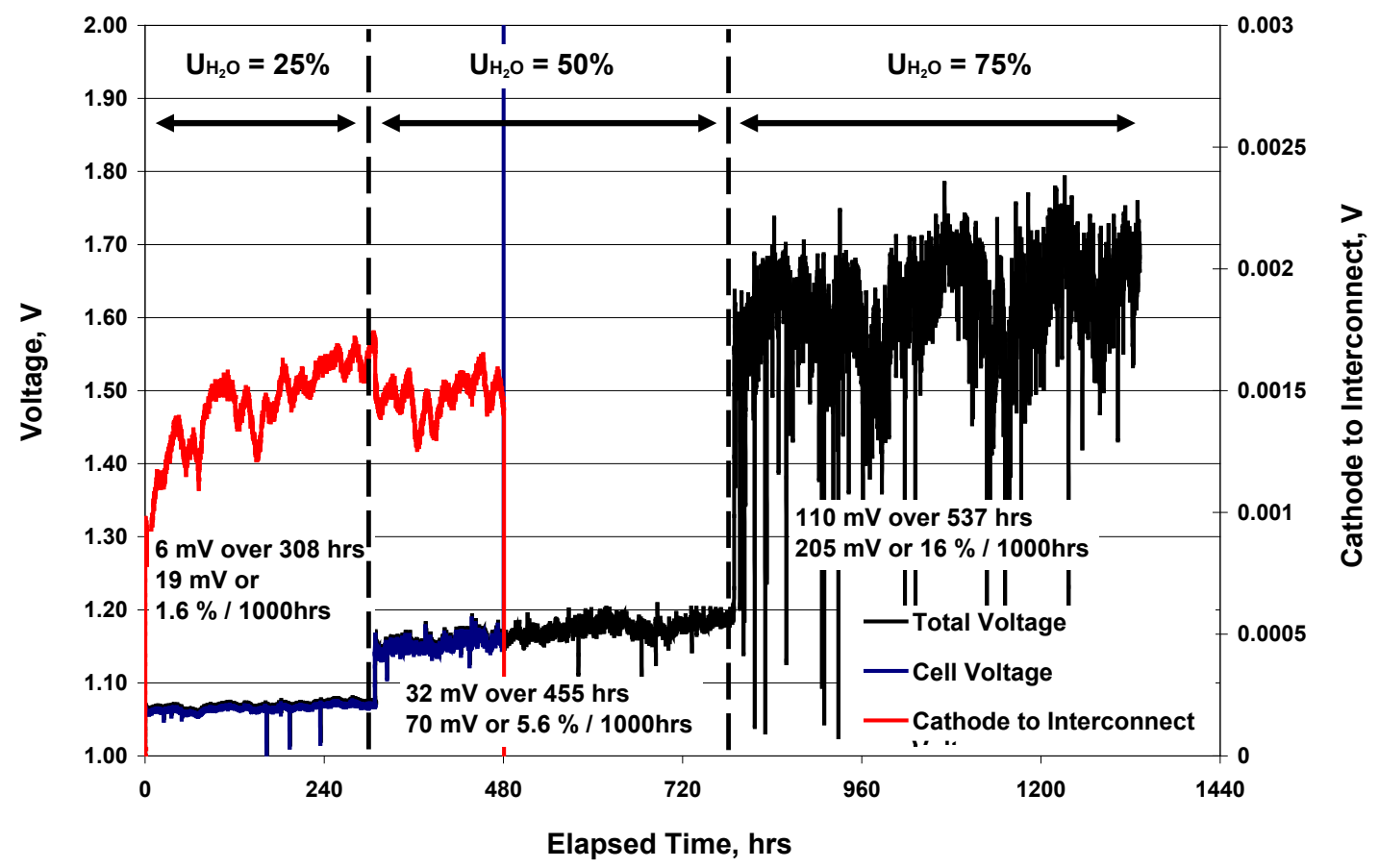

Figure 15. Cell Voltage over Time under Electrolysis Hold Conditions for GLOB 101773 (MAC-RSOFC-5 Cell) at Different Steam Utilizations 
In summary, key findings from electrochemical testing are:

- Majority of the degradation in RSOFC operation was from steady state SOEC operation

- Decay mechanisms were mainly cell related

- No strong evidence of sealing decay

- Limited degradation from interconnect

- Decay rate in SOEC mode was operating condition related

- Higher decay rate at higher operating current

- Higher decay rate at higher steam utilization

- Weak temperature dependence in the operating window of 700 to $800^{\circ} \mathrm{C}$

- Degradation in steady-state SOEC was mainly related to ohmic resistance and activation polarization increase

Key findings from post-test analysis are:

- No evidence of air electrode delamination

- No conclusive evidence of fuel electrode coarsening

- No evidence electrode poisoning and contamination

- Key microstructure changes in fuel electrode due to Ni migration to YSZ

\section{Task 2: Cell Development}

Task 2 focused on developing overall RSOFC cell technology to meet the following performance and endurance metrics:

- RSOFC area specific resistance of less than $300 \mathrm{~m} \Omega-\mathrm{cm}^{2}$ in both SOFC and SOEC operating modes

- Operating current density of more than $300 \mathrm{~mA} / \mathrm{cm}^{2}$ in both SOFC and SOEC modes

- Overall decay rate of less than $4 \%$ per 1000 hours of operation at SOEC mode

Progress made in Task 1 towards understanding the key causes of degradation in SOEC mode guided the development in Task 2 during the first year of the project. Figure 16 summarizes the performance and endurance improvement made in the project. All three tests were conducted at the same SOEC operating condition. The lower starting voltages and the smaller slopes of voltage trends over the time demonstrated both performance enhancement and degradation reduction from baseline TSC- 2 cell through EC-1 cell to RSOFC-7 cell. 


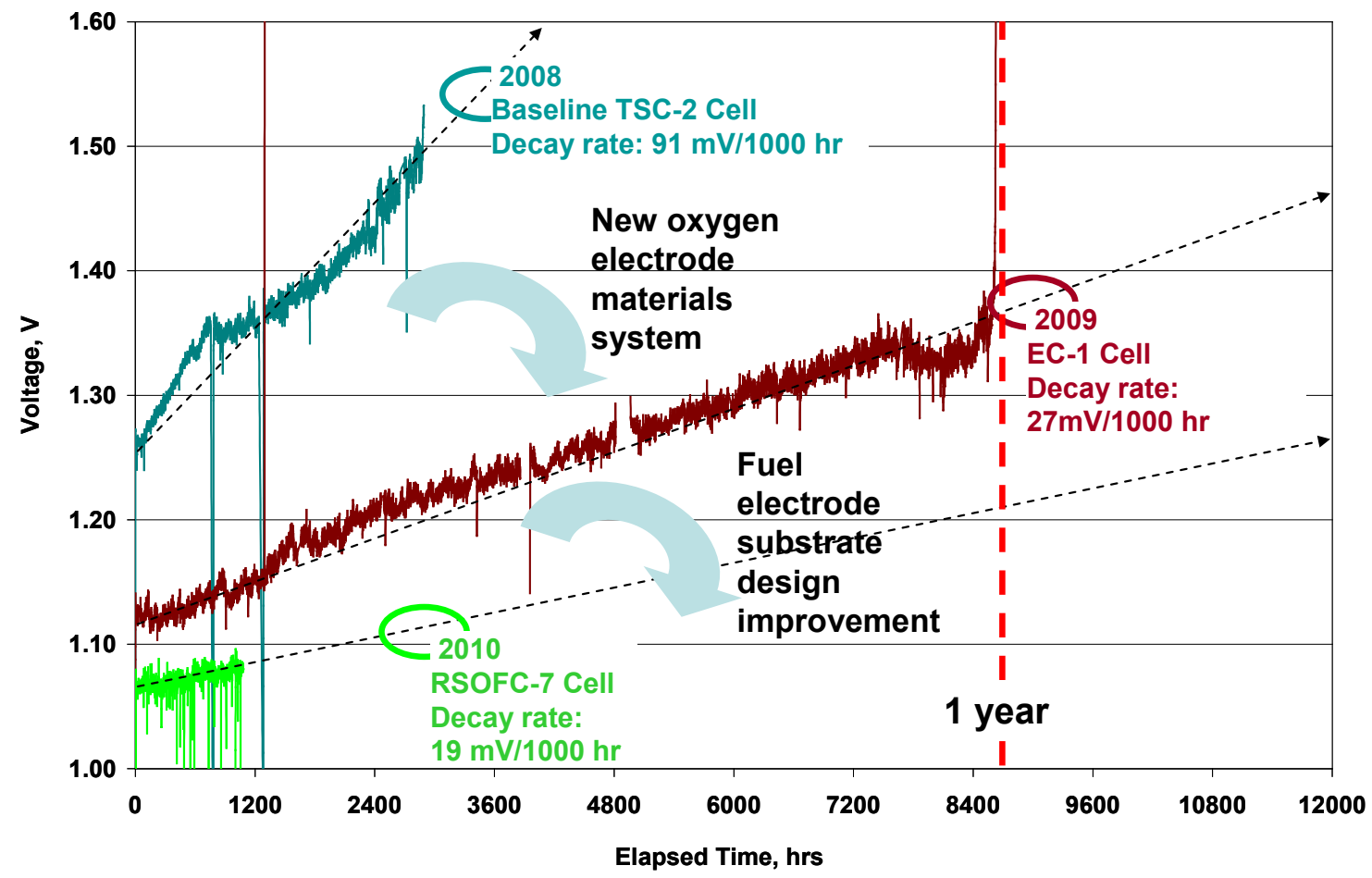

Figure 16. Summary of Cell Performance and Endurance Improvement in Electrolysis Mode

At the project go/no-go milestone test, as shown in Figure 17, the best cell materials systemRSOFC-7-demonstrated 223 and $224 \mathrm{~m} \Omega-\mathrm{cm}^{2}$ ASR values in electrolysis and fuel cell modes, respectively, at $750^{\circ} \mathrm{C}$ compared with the target of less than $300 \mathrm{~m} \Omega-\mathrm{cm}^{2}$. 


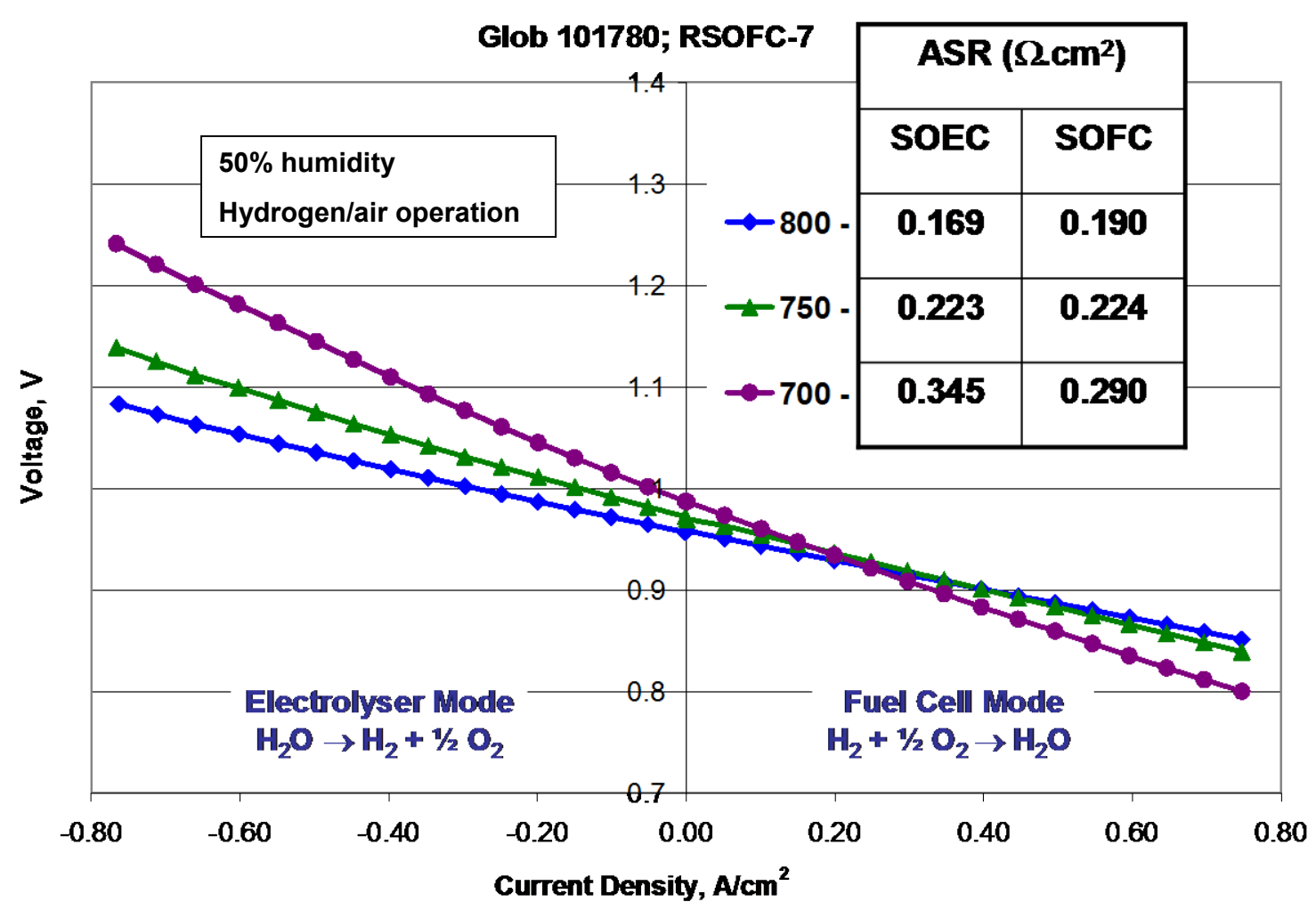

Figure 17. Performance of RSOFC-7 Cells in Both Fuel Cell Mode and Electrolysis Mode

It also demonstrated $1.5 \%$ per 1000 hours degradation rate in a steady-state electrolysis test of over 1000 hours as shown in Figure 18.

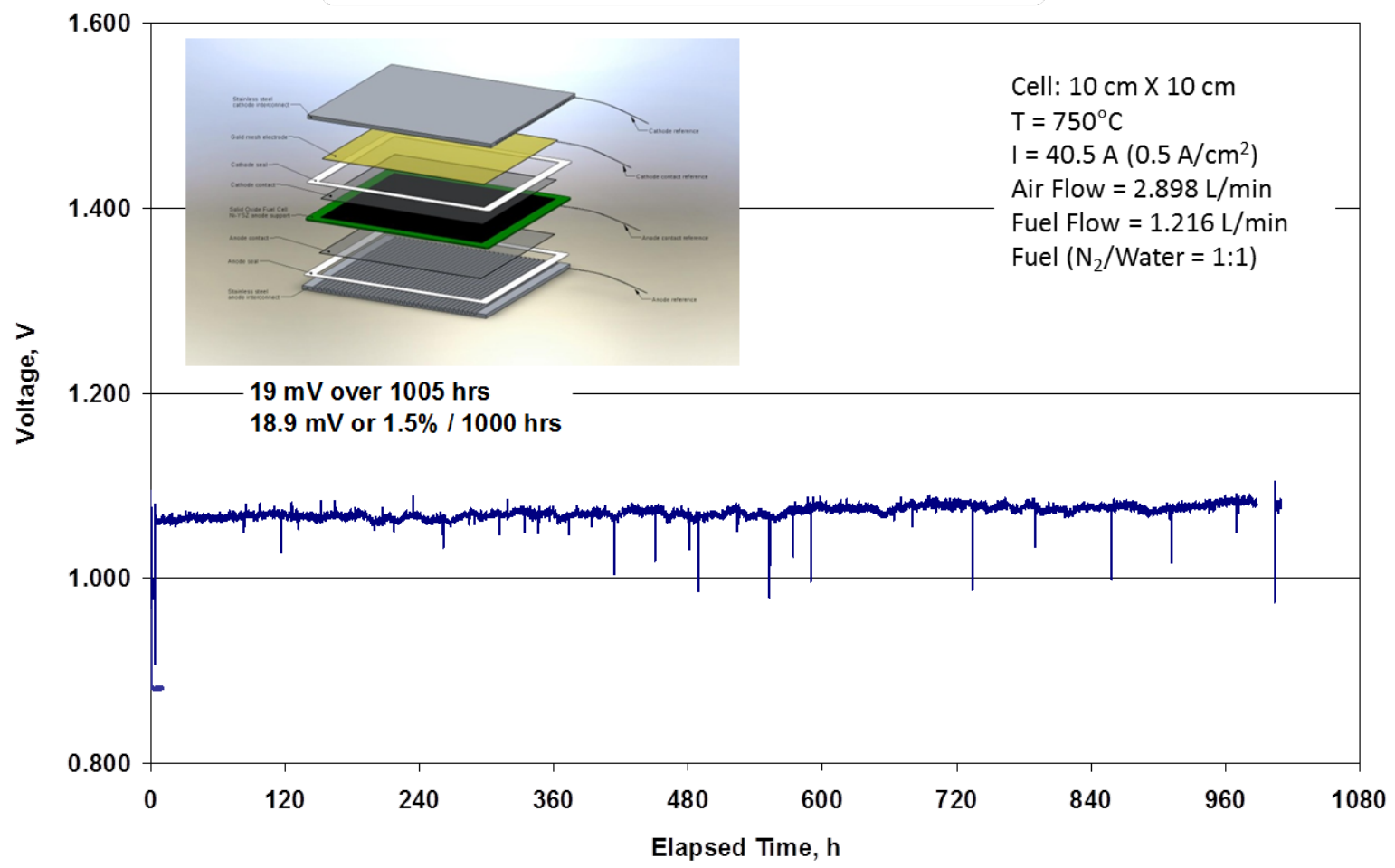

Figure 18. Single-Cell Steady-State Electrolysis Test of an RSOFC-7 Cell for the Go/No-Go Decision 
To further explore the performance capability in electrolysis mode, a single stack repeat unit with one RSOFC-7 was tested to ultra-high electrolysis current. DOE's 2017 water electrolysis efficiency target of $75 \%$ was used to establish the electrolysis operating voltage of $1.67 \mathrm{~V}$. As shown in Figure 19, the cell demonstrated excellent performance exceeding $3 \mathrm{~A} / \mathrm{cm}^{2}$ at $75 \%$ water electrolysis efficiency.

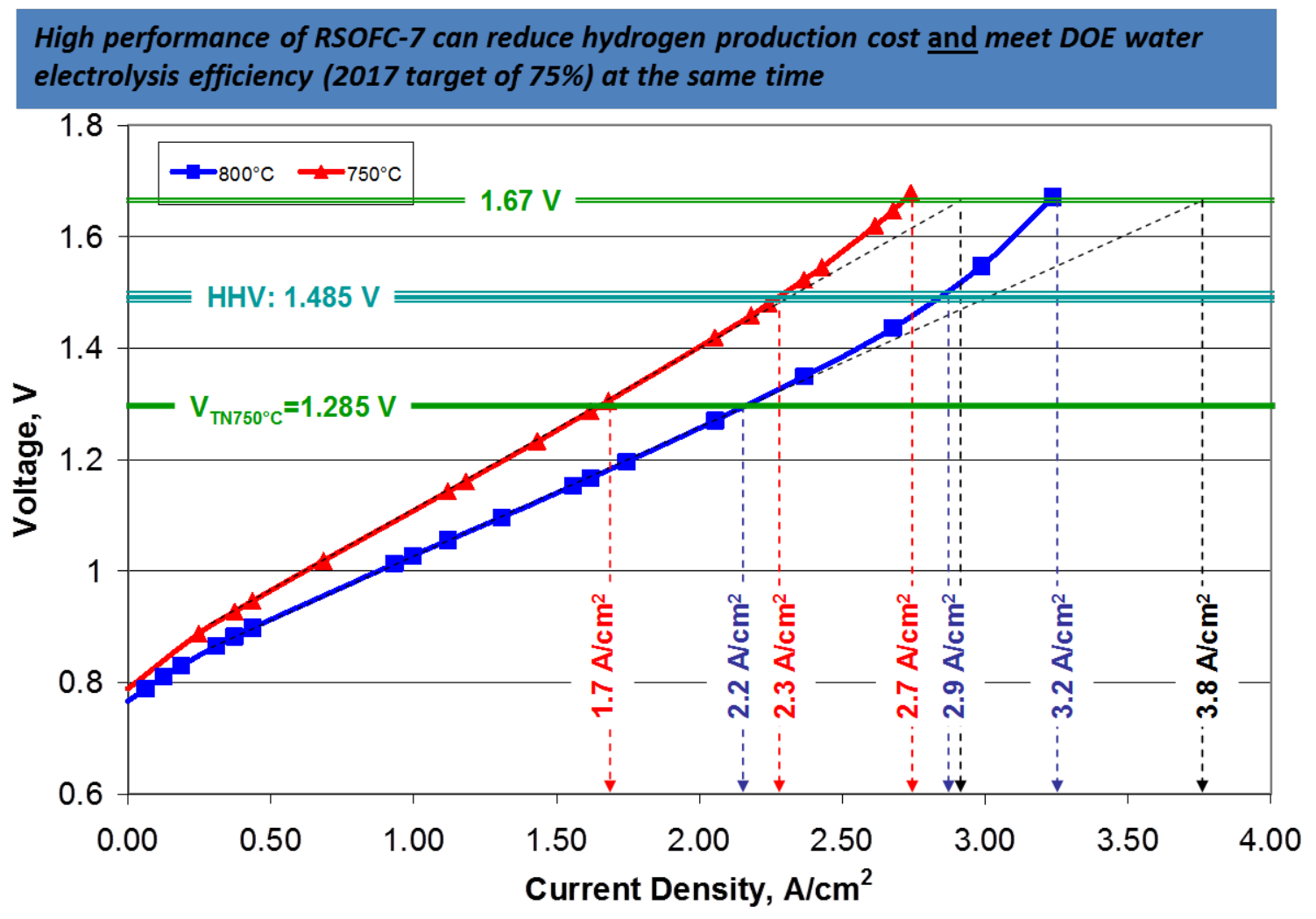

Figure 19. Single Cell Test of RSOFC-7 Cell Performance at Ultra-High Electrolysis Current Density

Following the successful completion of the original scope of work for this task, it was agreed to continue cell development to further improve steady-state electrolysis performance and cyclic RSOFC operation based on RSOFC-7 materials systems. In total, 23 materials systems have been evaluated for initial performance in SOFC and SOEC modes, with twelve systems tested for significant time periods under steady-state electrolysis conditions. Table 4 summarizes cell voltages under electrolysis and fuel cell conditions at a range of temperatures (low utilizations) for these cells, including RSOFC- 6 to RSOFC-21 with modified anodes. One of the key targets for this task is to achieve RSOFC area specific resistances of less than $300 \mathrm{~m} \Omega-\mathrm{cm}^{2}$ in both SOFC and SOEC modes. 
Table 4. Summary of Cell Performances under SOFC and SOEC Operation

\begin{tabular}{|c|c|c|c|c|c|c|c|c|}
\hline \multirow{3}{*}{ Cell Type } & \multirow{2}{*}{\multicolumn{4}{|c|}{$\begin{array}{l}\text { Electrolysis (SOEC) - } 50 \% \text { humidity } \\
\text { Peak Performance at } 0.74 \mathrm{~A} / \mathrm{cm}^{2}(\mathrm{mV})\end{array}$}} & \multirow{2}{*}{\multicolumn{4}{|c|}{$\begin{array}{c}\text { Fuel Cell (SOFC) - 3\% humidity } \\
\text { Peak Performance at } 0.74 \mathrm{~A} / \mathrm{cm}^{2}(\mathrm{mV})\end{array}$}} \\
\hline & & & & & & & & \\
\hline & $650^{\circ} \mathrm{C}$ & $700^{\circ} \mathrm{C}$ & $750^{\circ} \mathrm{C}$ & $800^{\circ} \mathrm{C}$ & $650^{\circ} \mathrm{C}$ & $700^{\circ} \mathrm{C}$ & $750^{\circ} \mathrm{C}$ & $800^{\circ} \mathrm{C}$ \\
\hline TSC-2 & -------- & 1469 & 1352 & 1271 & 623 & 767 & 832 & 879 \\
\hline EC-1 & 1624 & 1398 & 1239 & 1153 & 684 & 786 & 838 & 862 \\
\hline EC-2 & -------- & 1514 & 1366 & 1277 & -------- & -------- & 621 & 702 \\
\hline EC-3 & 1487 & 1297 & 1178 & 1128 & 740 & 825 & 864 & 882 \\
\hline RSOFC-1 & 1533 & 1335 & 1213 & 1152 & 752 & 832 & 870 & 884 \\
\hline MAC-RSOFC-1 & 1444 & 1245 & 1137 & 1078 & 756 & 831 & 869 & 880 \\
\hline RSOFC-2 & 1514 & 1302 & 1189 & 1129 & 689 & 758 & 838 & 859 \\
\hline RSOFC-3 & 1635 & 1420 & 1261 & 1162 & 666 & 777 & 839 & 858 \\
\hline RSOFC-4 & 1484 & 1297 & 1177 & 1108 & 757 & 839 & 877 & 890 \\
\hline MAC-RSOFC-5 & 1559 & 1368 & 1223 & 1141 & 744 & 816 & 857 & 874 \\
\hline RSOFC-6 & 1494 & 1270 & 1157 & 1098 & 724 & 820 & 868 & 884 \\
\hline RSOFC-7 & 1442 & 1241 & 1139 & 1083 & 738 & 842 & 888 & 904 \\
\hline RSOFC-8 & 1379 & 1192 & 1102 & 1051 & 750 & 846 & 890 & 906 \\
\hline RSOFC-9 & 1394 & 1217 & 1128 & 1068 & 748 & 845 & 895 & 908 \\
\hline RSOFC-10 & ------- & ------- & ------- & ------- & 729 & 827 & 874 & 890 \\
\hline RSOFC-11 & ------- & ------- & ------- & ------- & 810 & 884 & 912 & 920 \\
\hline RSOFC-7 & 1423 & 1231 & 1137 & 1082 & 760 & 850 & 890 & 899 \\
\hline RSOFC-12 & ------- & ------- & ------- & ------- & 624 & 767 & 834 & 861 \\
\hline RSOFC-13 & 1448 & 1212 & 1112 & 1057 & 779 & 866 & 904 & 916 \\
\hline RSOFC-14 & 1512 & 1273 & 1155 & 1091 & 697 & 815 & 870 & 890 \\
\hline RSOFC-15 & 1431 & 1231 & 1132 & 1068 & 729 & 832 & 875 & 890 \\
\hline RSOFC-16 & 1374 & 1196 & 1108 & 1060 & 789 & 871 & 906 & 918 \\
\hline RSOFC-17 & 1347 & 1177 & 1094 & 1047 & 787 & 869 & 902 & 913 \\
\hline RSOFC-18 & 1467 & 1271 & 1156 & 1088 & 783 & 865 & 900 & 912 \\
\hline RSOFC-19 & 1477 & 1224 & 1121 & 1062 & 783 & 867 & 903 & 915 \\
\hline RSOFC-7p & 1514 & 1282 & 1158 & 1096 & 740 & 835 & 874 & 887 \\
\hline RSOFC-20 & 1396 & 1204 & 1111 & 1060 & 765 & 858 & 895 & 907 \\
\hline RSOFC-21 & 1542 & 1301 & 1176 & 1113 & 718 & 819 & 864 & 880 \\
\hline
\end{tabular}

Table 5 shows the performance for each of the cell materials systems against these ASR targets demonstrating that most of these materials systems are capable of meeting the ASR targets at $800^{\circ} \mathrm{C}$. The best ASR values were obtained from RSOFC-16 and RSOFC-17. Both cells will meet project stated ASR targets for both SOFC and SOEC at $700^{\circ} \mathrm{C}$ 
Table 5. Summary of Cell ASR under SOFC and SOEC Operation

\begin{tabular}{|c|c|c|c|c|c|c|c|c|}
\hline \multirow{3}{*}{ Cell Type } & \multicolumn{4}{|c|}{ Electrolysis (SOEC) - $\mathbf{5 0 \%}$ humidity } & \multicolumn{4}{|c|}{ Fuel Cell (SOFC) - 3\% humidity } \\
\hline & \multicolumn{4}{|c|}{ ASR $\left(m \Omega-\mathrm{cm}^{2}\right)$} & \multicolumn{4}{|c|}{ ASR $\left(\mathrm{m} \Omega-\mathrm{cm}^{2}\right)$} \\
\hline & $650^{\circ} \mathrm{C}$ & $700^{\circ} \mathrm{C}$ & $750^{\circ} \mathrm{C}$ & $800^{\circ} \mathrm{C}$ & $650^{\circ} \mathrm{C}$ & $700^{\circ} \mathrm{C}$ & $750^{\circ} \mathrm{C}$ & $800^{\circ} \mathrm{C}$ \\
\hline Target & \multicolumn{4}{|c|}{$\leq \mathbf{3 0 0}$} & \multicolumn{4}{|c|}{$\leq \mathbf{3 0 0}$} \\
\hline TSC-2 & 547 & 372 & 275 & 241 & 501 & 359 & 269 & 182 \\
\hline EC-1 & 954 & 587 & 366 & 266 & 474 & 350 & 281 & 241 \\
\hline EC-2 & --------- & 526 & 362 & 284 & --------- & 521 & 393 & 374 \\
\hline EC-3 & 726 & 422 & 278 & 221 & 425 & 311 & 251 & 218 \\
\hline RSOFC-1 & 784 & 466 & 308 & 245 & 405 & 298 & 245 & 214 \\
\hline MAC-RSOFC-1 & 671 & 383 & 251 & 189 & 392 & 290 & 229 & 204 \\
\hline RSOFC-2 & 754 & 422 & 285 & 229 & 502 & 365 & 295 & 254 \\
\hline RSOFC-3 & 1003 & 623 & 386 & 279 & 495 & 359 & 283 & 238 \\
\hline RSOFC-4 & 711 & 413 & 268 & 203 & 397 & 293 & 238 & 207 \\
\hline MAC-RSOFC-5 & 957 & 530 & 341 & 254 & 404 & 304 & 253 & 218 \\
\hline RSOFC-6 & 741 & 412 & 271 & 208 & 429 & 308 & 242 & 209 \\
\hline RSOFC-7 & 629 & 345 & 223 & 169 & 422 & 290 & 224 & 190 \\
\hline RSOFC-8 & 554 & 301 & 194 & 146 & 406 & 285 & 223 & 189 \\
\hline RSOFC-9 & 572 & 330 & 230 & 166 & 405 & 289 & 219 & 186 \\
\hline RSOFC-10 & ------- & ------- & ------- & ------- & 418 & 301 & 234 & 199 \\
\hline RSOFC-11 & ------- & ------- & ------- & ------- & 340 & 245 & 197 & 173 \\
\hline RSOFC-7 & 592 & 349 & 236 & 181 & 369 & 273 & 212 & 190 \\
\hline RSOFC-12 & ------- & ------- & ------- & ------- & 509 & 359 & 281 & 235 \\
\hline RSOFC-13 & 645 & 329 & 208 & 153 & 352 & 258 & 205 & 177 \\
\hline RSOFC-14 & 734 & 415 & 265 & 192 & 440 & 321 & 250 & 214 \\
\hline RSOFC-15 & 629 & 355 & 233 & 169 & 446 & 313 & 247 & 206 \\
\hline RSOFC-16 & 540 & 300 & 196 & 150 & 343 & 250 & 198 & 171 \\
\hline RSOFC-17 & 509 & 282 & 188 & 140 & 361 & 259 & 205 & 181 \\
\hline RSOFC-18 & 667 & 402 & 259 & 184 & 363 & 264 & 212 & 186 \\
\hline RSOFC-19 & 694 & 347 & 218 & 157 & 361 & 263 & 207 & 179 \\
\hline RSOFC-7p & 789 & 464 & 296 & 226 & 399 & 297 & 239 & 211 \\
\hline RSOFC-20 & 583 & 321 & 208 & 156 & 370 & 268 & 215 & 187 \\
\hline RSOFC-21 & 812 & 488 & 318 & 244 & 404 & 291 & 232 & 204 \\
\hline
\end{tabular}

\section{Reversible SOFC Cyclic Capability Development}

Developing and validating cell RSOFC cyclic capability was the main focus in the second half of the project. A cyclic test profile as shown in Table 6 simulates a likely operational scenario for an RSOFC combined with solar power. The test runs a 24-hour cycle with 10.5 hours electrolysis, 12.5 hours fuel cell operation, and the balance for transitions. 
Table 6. Summary of RSOFC Test Profile for Cyclic Operation

\begin{tabular}{|c|c|c|}
\hline Condition & Unit & Test Condition \\
\hline Cell size & $\mathrm{cm}^{2}$ & 81 \\
\hline Fuel stream & & Hydrogen + steam \\
\hline Oxidant stream & & Air flow-through \\
\hline FC current & $\mathrm{A} / \mathrm{cm}^{2}$ & 0.25 \\
\hline EL current & $\mathrm{A} / \mathrm{cm}^{2}$ & 0.5 \\
\hline EL Humidity & $\%$ & $50 \%$ \\
\hline FC humidity & $\%$ & Nearly dry \\
\hline Steam utilization (EL) & $\%$ & $50 \%$ \\
\hline Temperature & ${ }^{\circ} \mathrm{C}$ & 750 \\
\hline
\end{tabular}

Figure 20 shows the cell voltage against time over 600 simulated day-night cycles of electrolysis and fuel cell operation. An RSOFC-7 cell combined with the modified anode contact was employed in this test. For the first two cycles, electrolysis operation was initially causing cell voltages to spike up to around 1.6 $\checkmark$ with large fluctuations in cell voltage. Problems with the trace-heating of the inlet and outlet gas lines were discovered, and after these were rectified, cell voltages did not exceed $1.3 \mathrm{~V}$ on initial electrolysis loading. The cycle immediately following this was taken as the first cycle and degradation was calculated from fuel cell operation (as electrolysis operation may not be as crucial for a realistic device of this type operating below the thermally neutral voltage).

Calculated from fuel cell mode, the performance decay was $94 \mathrm{mV}$ over 14,500 hours. The test continues to operate at the time of this report, approaching two years of operation with a less than 7 $\mathrm{mV}$ per 1000 hours degradation rate in SOFC mode. Calculating from electrolysis mode is more difficult due to voltage noise. Based on an estimated decay of 200 to $280 \mathrm{mV}$, the corresponding degradation rate was 1.1 to $1.5 \%$ per 1000 hours. 


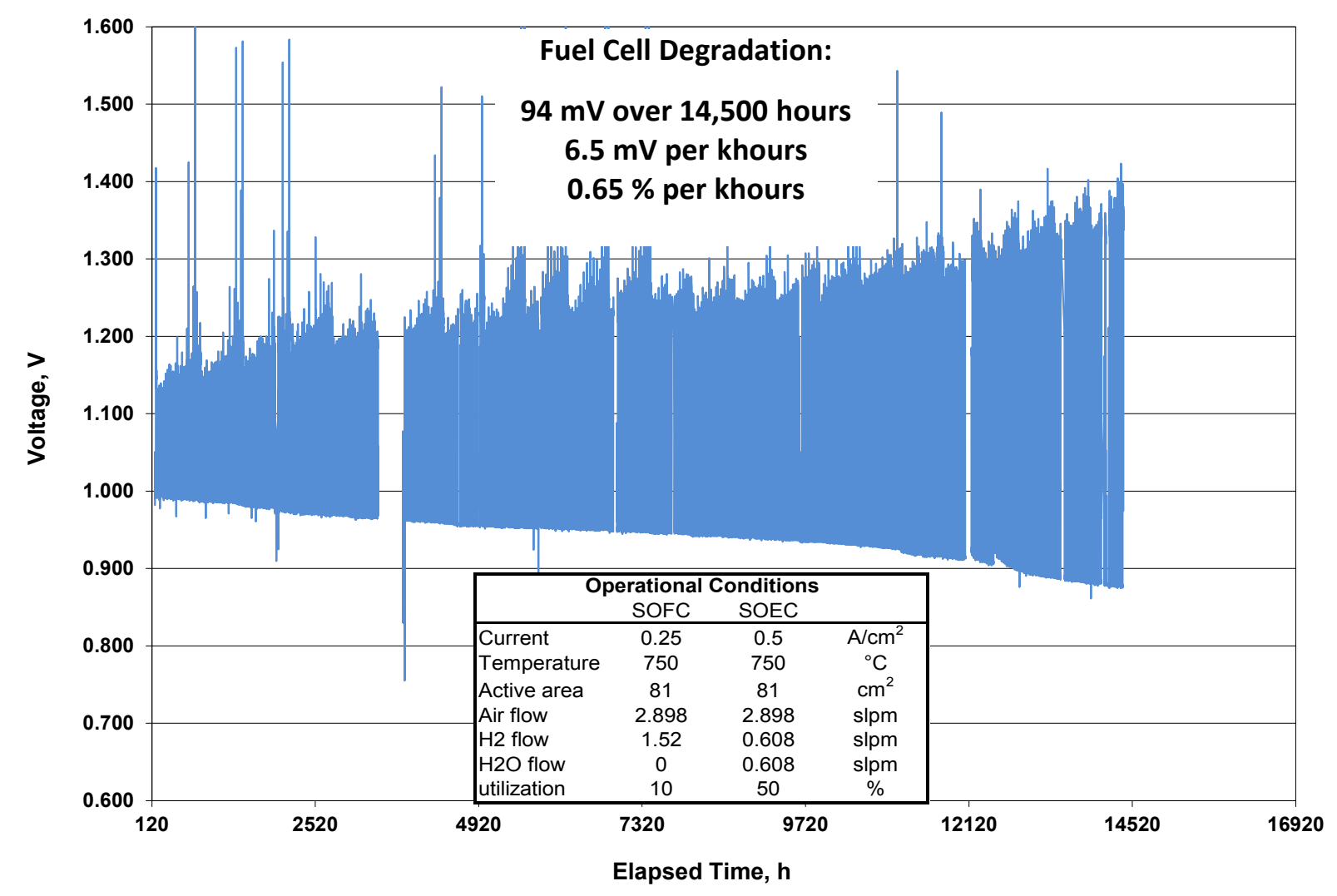

Figure 20. Fuel Cell and Electrolysis Cyclic Testing of an RSOFC-7 Cell

At the end of the project, three more cyclic RSOFC cell tests were conducted with an RSOFC-7p cell, an RSOFC- 20 cell, and an RSOFC - 21 cell. Figure 21 shows the cell voltage against time over more than 140 simulated day-night cycles of electrolysis and fuel cell operation for RSOFC-7p. This was a repeat test of RSOFC-7 cells with some pilot plant modifications for ease of processing. Degradation rate is very similar to the first RSOFC-7 cell test. 


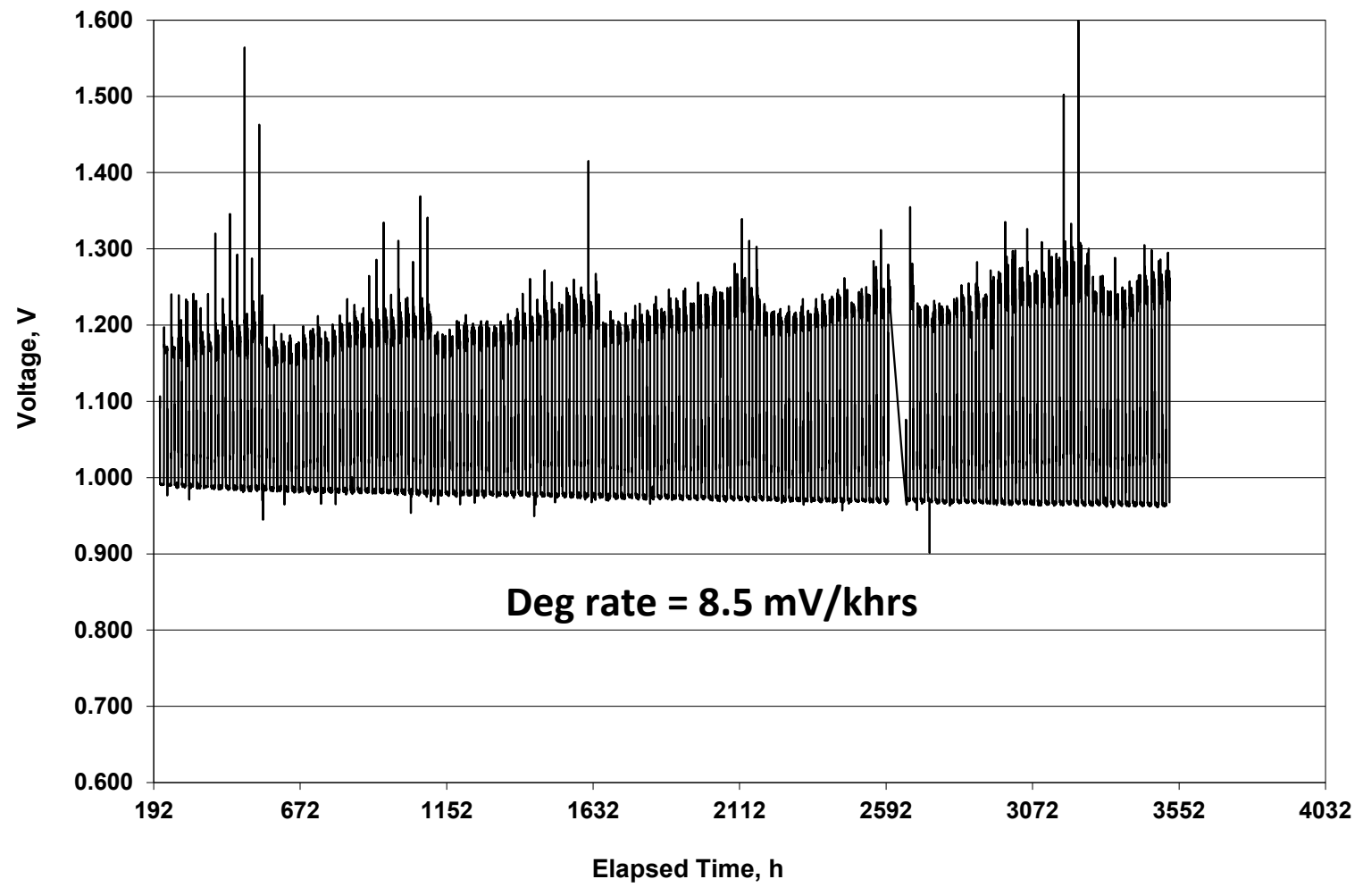

Figure 21. RSOFC-7p Cell Cyclic Test

Figure 22 shows the cell voltage against time over more than 100 simulated day-night cycles of electrolysis and fuel cell operation for RSOFC-20. RSOFC-20 has higher performance and similar degradation rate to RSOFC-7 materials. This materials system hints strongly at a future direction towards even higher performance with similar degradation rates than achieved in this project so far and will be pursued further. 


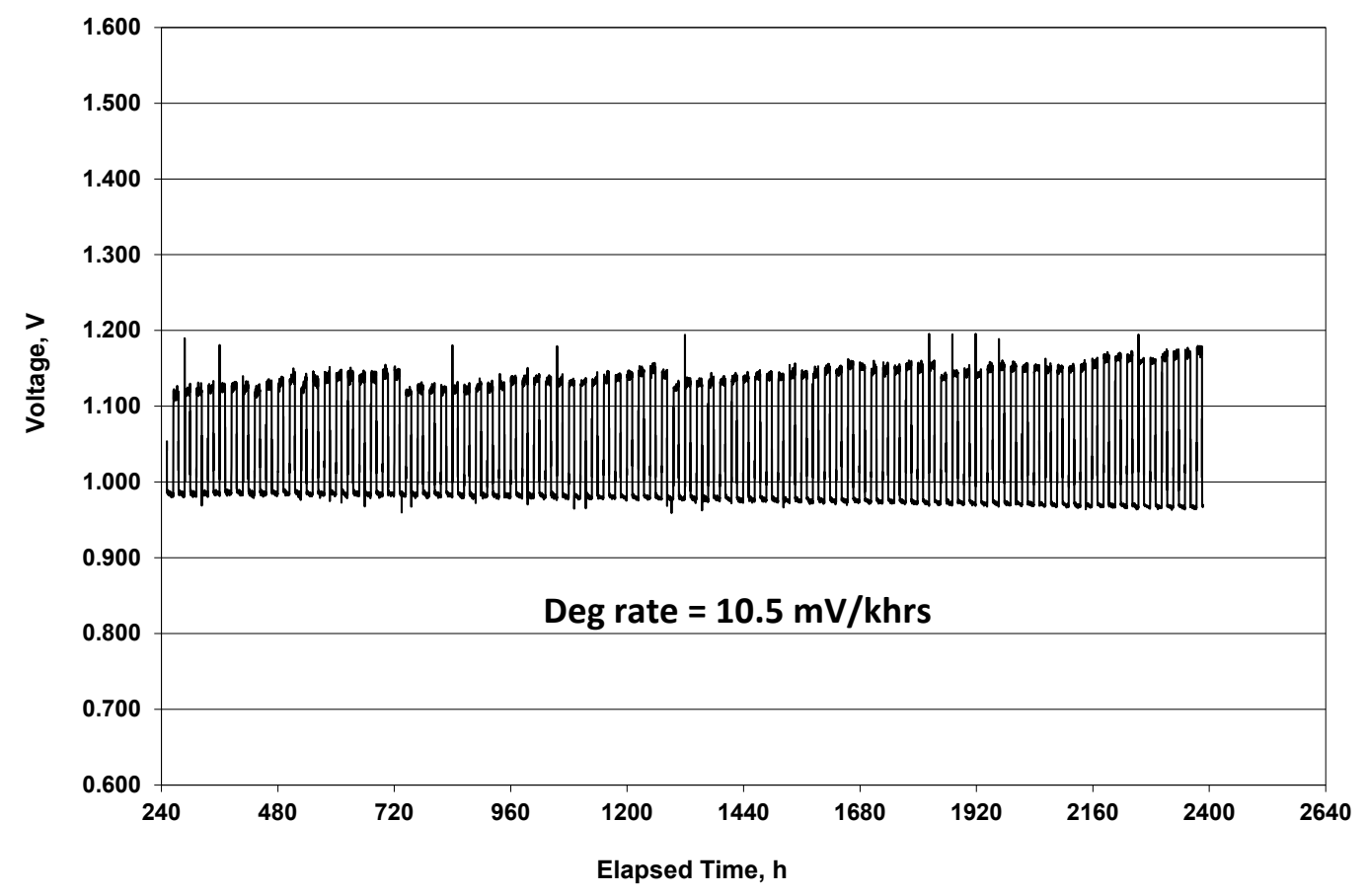

Figure 22. RSOFC-20 Cell Cyclic Test

In addition, one accelerated RSOFC cyclic test was conducted at three temperatures: $750^{\circ} \mathrm{C}, 700^{\circ} \mathrm{C}$, and $800^{\circ} \mathrm{C}$ as shown in Figure 23. Each cycle was 4 hours with 1.6 hours in SOFC and SOEC modes.

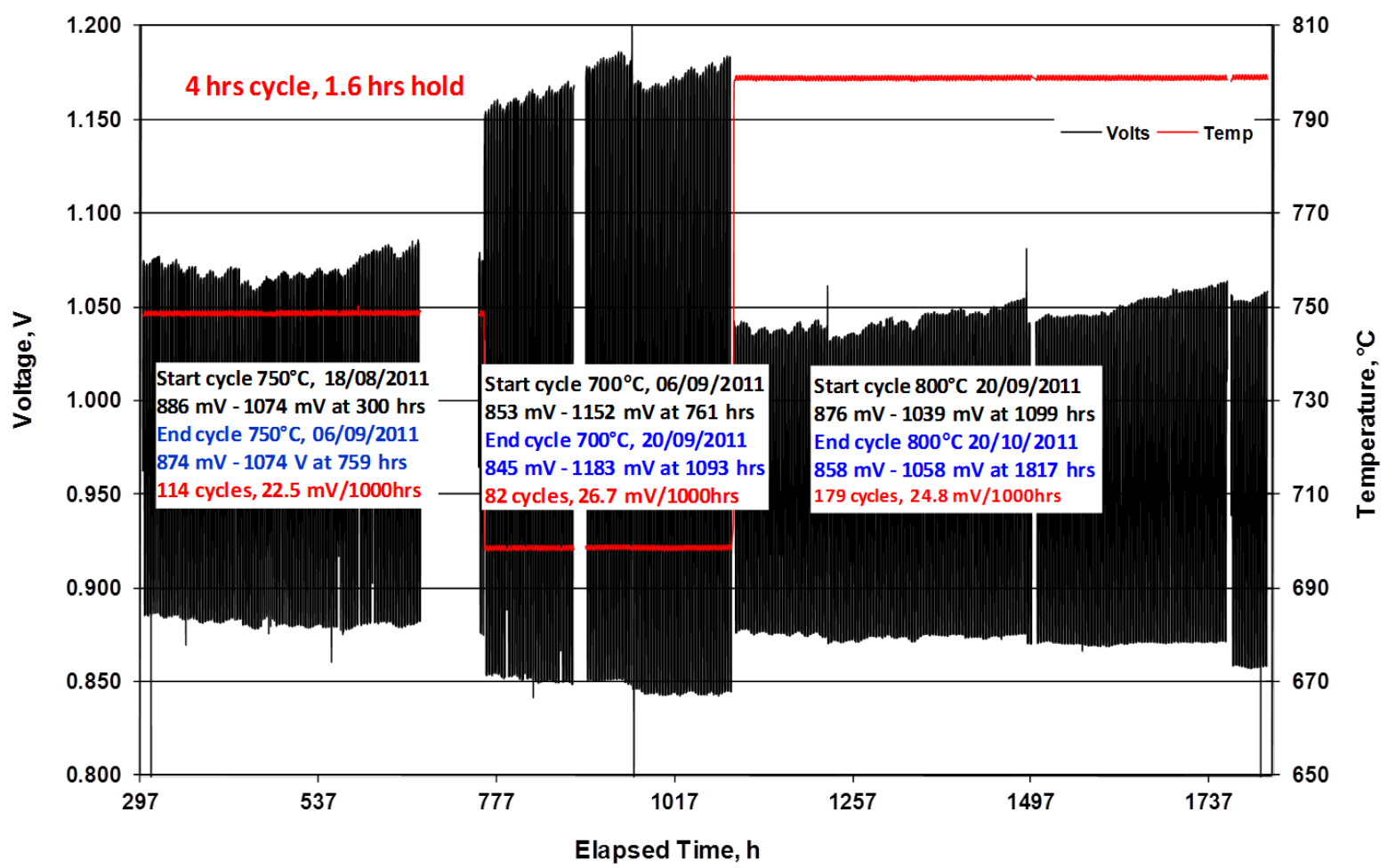

Figure 23. Accelerated RSOFC Cyclic Test at Three Temperatures: $750^{\circ} \mathrm{C}, 700^{\circ} \mathrm{C}$, and $800^{\circ} \mathrm{C}$ 
To further demonstrate the cyclic capability, the cyclic frequency was further increased to 20 minutes per cycle as shown in Figure 24 . A total of 5880 cycles were run at $800^{\circ} \mathrm{C}$. This represents more than 15 years of daily cycles and compares favorably to current battery technology.

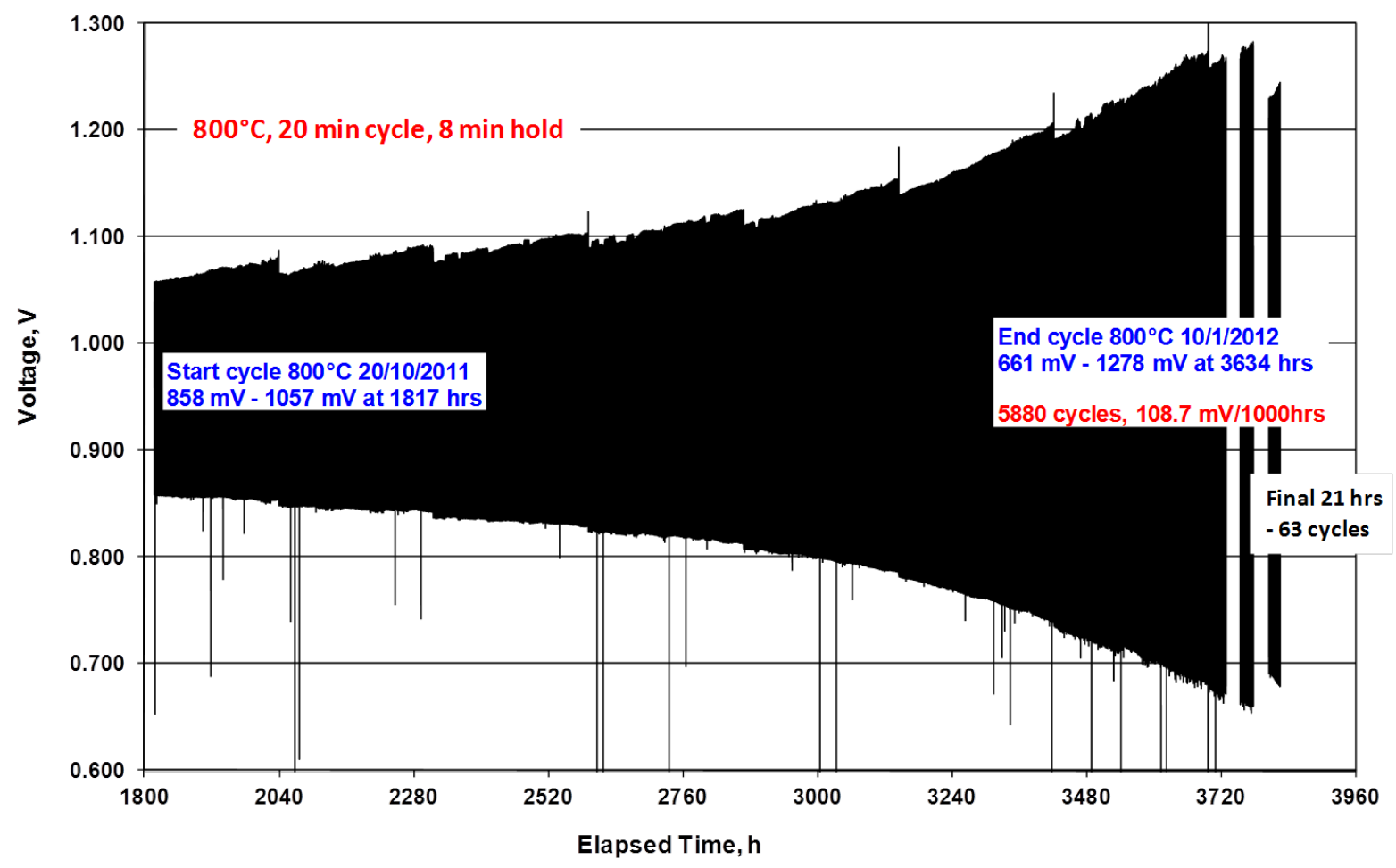

Figure 24. Accelerated RSOFC Cyclic Test with 20 Minute Cycles

\section{Task 3: Interconnect Materials Development}

Operating in RSOFC mode brings new challenges to the interconnect material: high humidity on the anode side and pure oxygen on the cathode side. The interconnect alloy has to resist this dual environment at temperature over time without significant oxide build-up and loss of electrical conductivity. Other properties are also of importance such as mechanical stability and creep resistance. To overcome these challenges, the selected material could be made of a single alloy, combination of alloys, or any of those options with surface coatings. The interconnect material development activity had three phases:

- Literature survey on materials oxidation in pure oxygen or high humidity environment at high temperature

- Coupon testing of selected materials in each of those two environments

- Testing of candidate materials in RSOFC operation

VPS has collected a large amount of testing data on stainless steels and other alloys. The historical VPS data along with a literature survey provided guidance on materials to be selected for testing. Coupon interconnect samples were tested in a thermal mass analyzer and/or tube furnace to collect data of weight gain over time at $800^{\circ} \mathrm{C}$. Tested samples were analyzed to determine the nature of formed oxides and their thicknesses. Upon completion of coupon testing, a short list of material candidates was 
suggested for in-situ testing in RSOFC operation in a single cell setting. The best interconnect materials system was recommended for stack development and validation testing.

\section{Literature Survey}

An extensive literature survey was performed and is summarized as follows.

\section{Oxidation in Water Vapor}

The effect of water vapor on accelerating the oxidation of steels is quite complicated and not consistent. The addition of water vapor increases the oxidation rate compared with conditions in dry conditions for Fe-Cr stainless steels. The mechanism proposed by the different researchers between iron-based and nickel-based alloy suggests that the inability to form chromia as a result of scale cracking or volatilization is compounded in the case of a iron-based system by a further water vapor induced acceleration of oxidation for the iron oxides which does not occur for the nickel system. ${ }^{9}$ Water vapor up to $43 \%$ at $1000^{\circ} \mathrm{C}$ has little effect on the oxidation of pure $\mathrm{Ni}$. It is noted that alumina or nickel oxide forming materials are the exception. Their rate of oxidation does not increase in water vapor.

Different mechanisms have been proposed for water vapor accelerated oxidation. The water vapor may promote the formation of volatile oxy-hydroxides and so increase the oxidation rate. Hydrogen protons from water vapor may dissolve in the oxide and concentrate in the grain boundaries affecting the diffusion through the oxides. A new proposed mechanism suggests that water molecules diffuse through cracks and pores towards the metal surface where chromium is depleted and release hydrogen following this reaction $3 \mathrm{H}_{2} \mathrm{O}+2 \mathrm{Fe} \rightarrow \mathrm{Fe}_{2} \mathrm{O}_{3}+3 \mathrm{H}_{2}$. The local presence of hydrogen may react with chromium and reduces it as follows $3 \mathrm{H}_{2}+\mathrm{Cr}_{2} \mathrm{O}_{3} \rightarrow 2 \mathrm{Cr}+3 \mathrm{H}_{2} \mathrm{O}$. So as soon as there are micro-cracks in the oxide, there will be a breakaway oxidation. ${ }^{10}$ The breakaway oxidation is the formation of a layer of iron oxide. This layer formation is accelerated by raising the temperature or increasing the water content. Addition of ceria particles onto the steel surface inhibits the breakaway oxidation.

Other experiments at $850^{\circ} \mathrm{C}$ demonstrated that 430 stainless steel oxidized by inward transport of water molecules in contrast to what is observed in air (oxygen-containing species). ${ }^{11}$ The steel composition, and more precisely its chromium content, determines the oxide structure. The high chromium content steel (above 15 weight percent) forms a chromium oxide that it is not very affected by the water vapor unless there is a crack or breakdown. The low chromium content (less than 15\%) Fe-Cr alloys form a bilayer iron oxide with a linear rate of oxidation at 800 to $1000^{\circ} \mathrm{C}^{12}$ In another study, chromium substitution of cobalt in the contact layer $(\mathrm{La}, \mathrm{Sr}) \mathrm{CoO}_{3}$ was significant enough to lower the conductivity of that layer in a stack that operated for 2000 hours in RSOFC. Chromium diffused as a vapor phase from the interconnect material tested in an RSOFC stack. ${ }^{13}$

The effect of water vapor presence on steel oxidation was also studied in SOFC mode when the steel is submitted to a dual environment. Supposedly there is hydrogen transport through the steel which combines with air to form water vapor clusters that results in localized anomalous oxidation. ${ }^{14}$ This effect was more pronounced for low-chromium steels and was almost nonexistent for $\mathrm{Ni}-\mathrm{Cr}$ and nickel alloys. ${ }^{15}$ For the ferritic steels an exposure to dual atmosphere and its effect can differ with a small composition change. A comparison between 441 and 430 demonstrated better oxidation resistance for 430 than 441 . When exposed to a dual atmosphere, 430 formed a spinel oxide with a presence of some iron in the oxide whereas 441 formed a multilayer oxide with chromium and a porous thick iron oxide layer that accelerated the oxidation rate. This difference could be due to presence of niobium in 441 steel. ${ }^{16}$ 


\section{Oxidation in Pure Oxygen}

There is only a limited a number of applications using pure oxygen at high temperatures. In those applications a high velocity or high pressure oxygen gas is used, while in the case of RSOFC, where the total volume of oxygen is small and oxygen gas is usually under atmospheric pressure.

The risk of material for ignition has been evaluated on several alloys under different conditions. In one particular study, copper alloys and nickel alloys have excellent oxygen compatibility which means they are difficult to ignite in oxygen service. In the same conditions, a velocity limit is imposed for carbon steel and stainless steel to avoid ignition. An extended fire triangle is shown in Figure 25 to sum up all the parameters that influence the risk of ignition in oxygen for a particular material. ${ }^{17}$

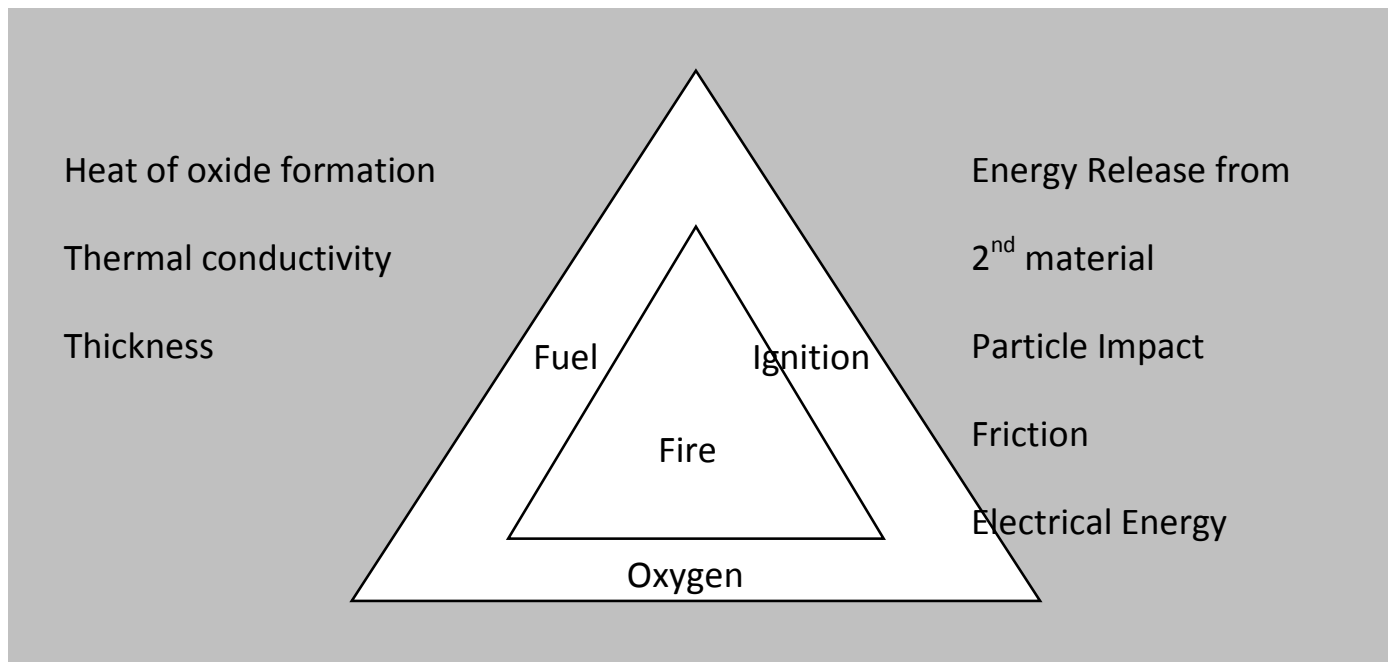

Figure 25. Extended Fire Triangle

In pressurized high temperature oxygen applications, a few considerations are of importance. ${ }^{18}$ This may also apply to non-pressurized case as in RSOFC:

- All systems should be cleaned for oxygen service (no debris or loose particles)

- Safety factors should be considered (oxygen purity, material thickness, etc.)

In addition to material ignition, flammability was considered for oxygen service. Flammability is defined as the minimum pressure that enables equilibrium combustion of that particular material. ${ }^{19}$ As for the ignition test, copper and Monel alloys did not combust up to $10.34 \mathrm{MPa}$. Conversely, carbon steel and aluminum alloys burnt at low pressures $(0.17 \mathrm{MPa})$ whereas stainless steels had an intermediate behavior. In those tests, it was also confirmed that the geometry of the sample was also of importance.

In summary, high water vapor concentration could accelerate the material oxidation if not protected by a compact oxide. Stainless steels with more than 15 weight percent chromium are suitable as well as nickel oxide forming alloys. The alumina forming alloys are not recommended due to their high electrical resistance oxide. In an oxygen environment, it is recommended to consider parameters such as cleanliness, material thickness, pressure, and temperature for RSOFC application. In the absence of high pressure, stainless steel could be suitable in this environment. Copper and Monel have good properties in oxygen but they will oxidize readily. 


\section{Metallic Coupon Tests}

Metal coupons were tested in a high steam environment to simulate the RSOFC environment. Coupons were cut of six alloys as shown in Table 4. Another coupon was made of cobalt coated Sanergy alloy. All seven samples were tested in a tube furnace at $750^{\circ} \mathrm{C}$ for over 1100 hours in an air stream with $50 \%$ steam. Upon completion of the test, the coupons' weight gains were determined. A thorough analysis of the surface oxide and oxide thickness in cross sections were carried out by scanning electron microscope (SEM).

Table 4. Composition of Tested Alloys

\begin{tabular}{|llcc|}
\hline Alloys & Composition & $\begin{array}{c}\text { High Steam } \\
\text { Test }\end{array}$ & $\begin{array}{c}\text { Pure } \mathrm{O}_{2} \\
\text { Test }\end{array}$ \\
\hline 430 & $\mathrm{Fe}, 16-18 \mathrm{Cr}, 1.00 \mathrm{Si}, 1.00 \mathrm{Mn}, 0.12 \mathrm{C}$ & $\mathrm{V}$ & \\
\hline 434LN2 & $\mathrm{Fe}, 19 \mathrm{Cr}, 0.25 \mathrm{Si}, 1.93 \mathrm{Mo}, 0.35 \mathrm{Nb}$, very low C & $\mathrm{V}$ & $\mathrm{V}$ \\
\hline Sanergy & $\mathrm{Fe}, 22 \mathrm{Cr}, 0.30 \mathrm{Si}, 0.50 \mathrm{Mn}, 1.0 \mathrm{Mo}, 0.75 \mathrm{Nb}, \mathrm{Ti}$, very low C & $\mathrm{V}$ & $\mathrm{V}$ \\
\hline $\begin{array}{l}\text { Co-coated } \\
\text { Sanergy }\end{array}$ & $\mathrm{Fe}, 22 \mathrm{Cr}, 0.30 \mathrm{Si}, 0.50 \mathrm{Mn}, 1.0 \mathrm{Mo}, 0.75 \mathrm{Nb}, \mathrm{Ti}$, very low C & $\mathrm{V}$ & $\mathrm{V}$ \\
\hline ZMG232 & $\mathrm{Fe}, 22 \mathrm{Cr}, 0.39 \mathrm{Si}, 0.26 \mathrm{Ni}, 0.46 \mathrm{Mn}, 0.23 \mathrm{Zr}, 0.05 \mathrm{La}$ & $\mathrm{V}$ & \\
\hline ZMG232L & $\mathrm{Fe}, 22 \mathrm{Cr}, 0.1 \mathrm{Si}, 0.26 \mathrm{Ni}, 0.45 \mathrm{Mn}, 0.21 \mathrm{Zr}, 0.03 \mathrm{La}$ & $\mathrm{V}$ & \\
\hline Haynes 230 & $\mathrm{Ni}, 22 \mathrm{Cr}, 0.4 \mathrm{Si}, 3 \mathrm{Fe}, 0.5 \mathrm{Mn}, 5 \mathrm{Co}, 2 \mathrm{Mo}, 14 \mathrm{~W}, 0.2 \mathrm{Al}, 0.2 \mathrm{La}$ & $\mathrm{V}$ & $\mathrm{V}$ \\
\hline
\end{tabular}

Weight gain results (Figure 9) after completion of the test show that Haynes 230 weight loss was likely due to some spallation. Its oxide was thin. Sanergy and 434LN2 had the lowest weight gain. 430 as the reference steel had the largest weight gain. Oxide surfaces were observed and analyzed by SEM. There were some notable differences between alloys. For example, Haynes 230 had a predominant CrNi oxide on the surface and $\mathrm{CrMnNi}$ oxide on the grain boundaries whereas 430 had predominant chromium with a small presence of $\mathrm{Mn}$ on the surface and nodules of $\mathrm{CrFe}$ oxide dispersed randomly. Cross sections on the tested coupons were prepared for detailed SEM analysis. Oxide thickness and its composition were measured on each coupon. For example, the 430 stainless had chromium oxide up to 3.0 microns thick on its surface. Haynes 230 had a discontinuous very thin oxide of $\mathrm{CrNi}$ oxide. Most of the Haynes oxidation was internal. Oxide thickness was measured on cross sections as shown in Table 4. It confirmed the trend of the weight gain. In order, the selected candidates for further analysis were: Haynes 230, 434LN2, Sanergy, and coated Sanergy. Coated Sanergy was selected despite its thick oxide because of the presence of Co oxide which has high conductivity. 


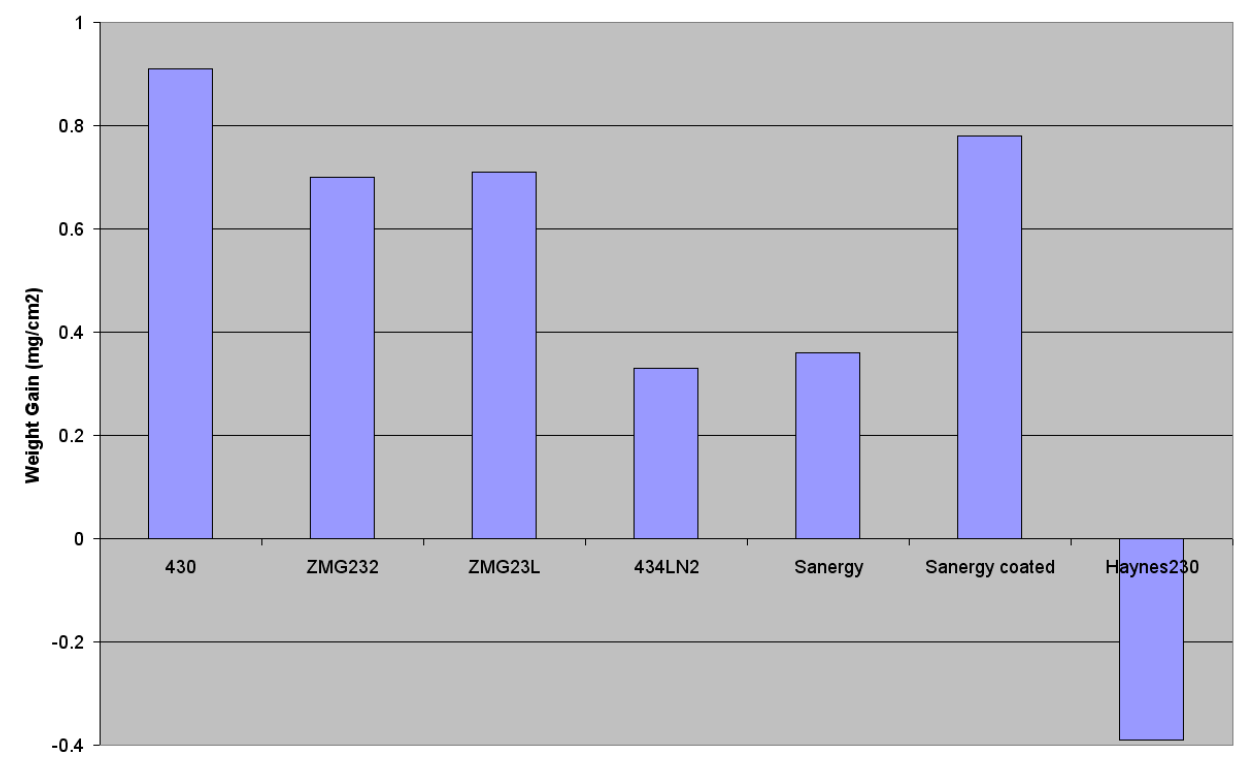

Figure 9. Weight Gain Results after 1150 Hours at $750^{\circ} \mathrm{C}$ in $50 \%$ Steam

Table 5. Oxide Thickness Measured on Cross Section of Tested Coupons in Steam

\begin{tabular}{|l|c|}
\multicolumn{1}{|c|}{ Alloys } & Oxide Thickness $(\mu \mathrm{m})$ \\
\hline 430 & 3.0 \\
\hline 434 LN2 & 1.0 \\
\hline ZMG232 & 4.6 \\
\hline ZMG232L & 6.5 \\
\hline Sanergy & 1.2 \\
\hline Co-Coated Sanergy & 3.5 \\
\hline Haynes 230 & $<0.5$ \\
\hline
\end{tabular}

Four of the seven metal coupons were further tested in a pure oxygen environment to simulate the RSOFC environment. Coupons were cut for $434 \mathrm{LN}$, Sanergy, Co-coated Sanergy, and Haynes 230. All four samples were tested in a thermo-gravimetric analyzer at $800^{\circ} \mathrm{C}$ for over 800 hours. Weight gain was monitored throughout the test. A thorough analysis of the surface oxide and oxide thickness in cross sections was carried out by scanning electron microscope (SEM).

All four tested alloys had a similar trend in weight gain but with a higher oxidation rate for Co-coated Sanergy as shown in Figure 26. As expected, the Co-coating will oxidize more rapidly at the beginning. 
Weight gain of $434 \mathrm{LN} 2$ in pure oxygen at $800^{\circ} \mathrm{C}$

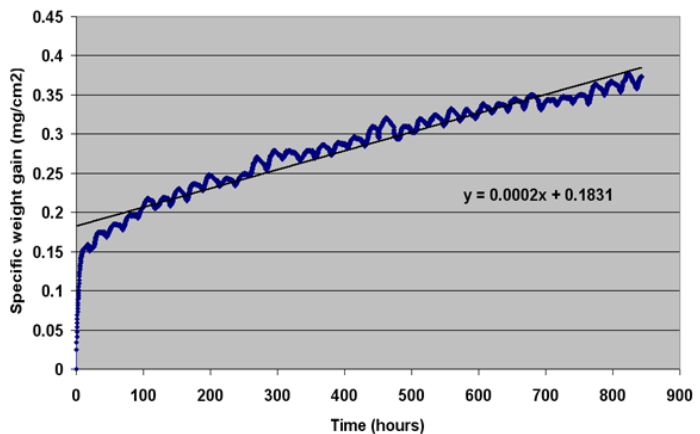

Weight gain of Sanergy in pure oxygen at $800^{\circ} \mathrm{C}$

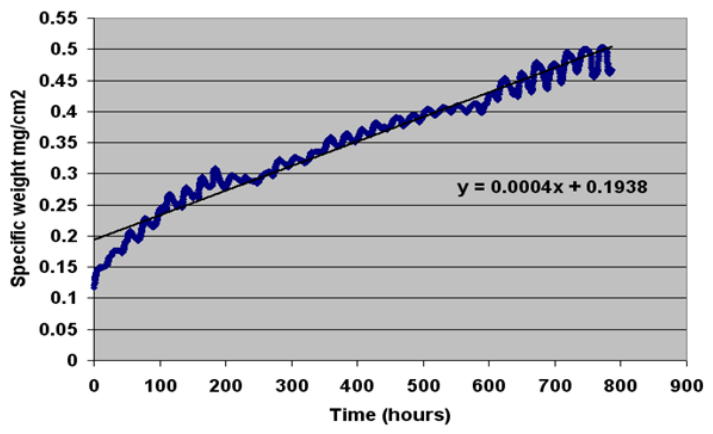

Specific Weight gain Haynes 230 in 02
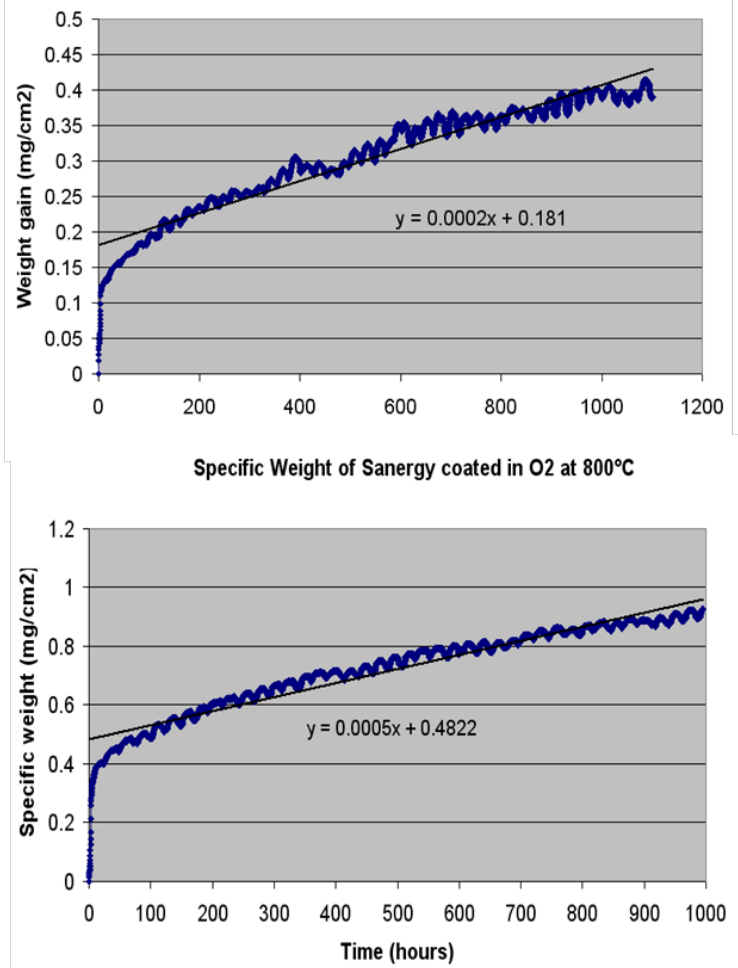

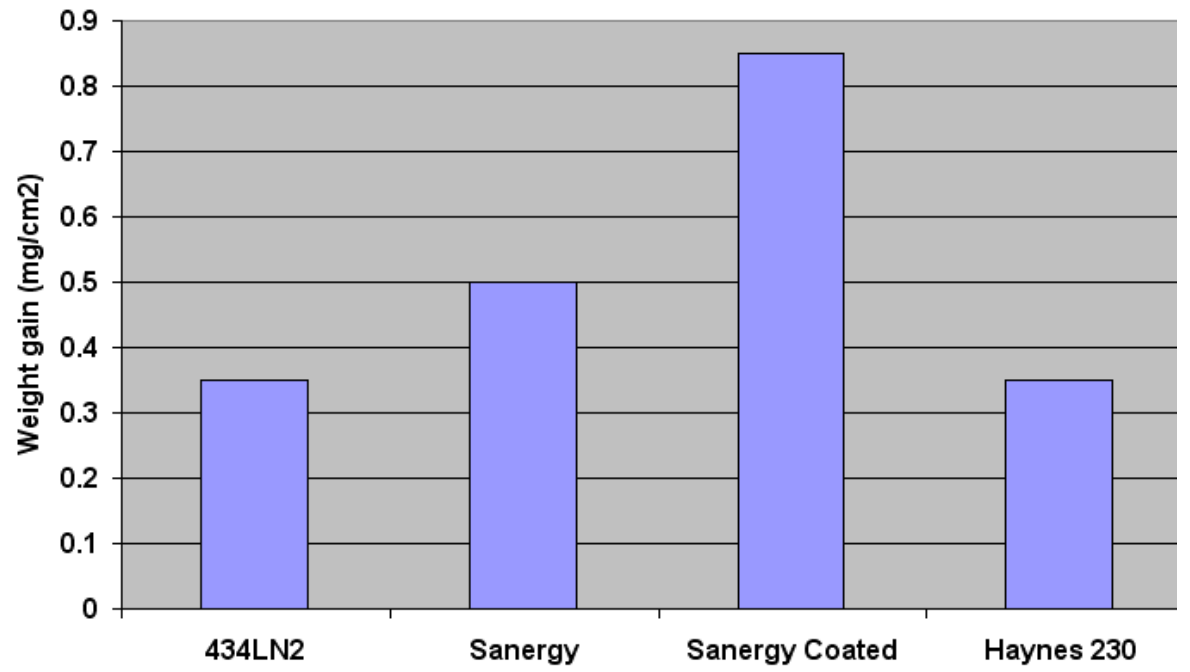

Figure 26. Weight Gain Results of 434LN2, Sanergy, Haynes 230, and Cobalt Coated Sanergy at $800^{\circ} \mathrm{C}$ in Pure $\mathrm{O}_{2}$

Oxide surface were observed and analyzed by SEM. There were some differences among the four sample surfaces. Both Sanergy and Co-coated Sanergy samples had an external surface consisting of uniform size crystals. The 434LN2 sample had similar crystals but not of uniform coverage. Haynes 230 had large crystals following a pattern surrounding smaller crystals as shown in Figure 27. 

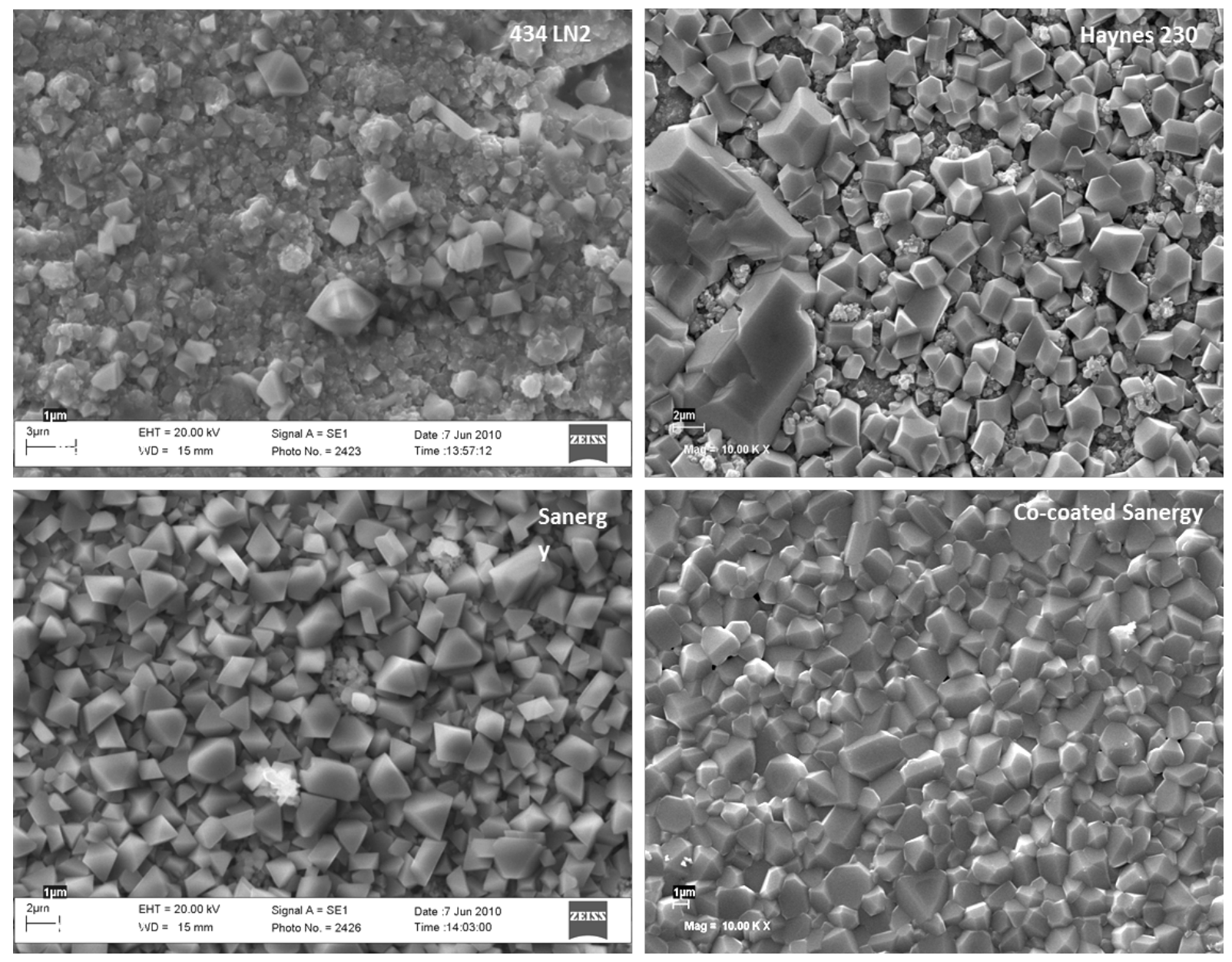

Figure 27. Surface Oxide on Haynes 230 and Sanergy Coated after the Pure Oxygen Test

Cross sections were prepared from each coupon. Oxide thickness was measured as shown in Table 7.

Table 7. Oxide Thickness on Tested Coupons in Oxygen

\begin{tabular}{|c|c|c|c|c|}
\hline \multicolumn{1}{|c}{ Alloys } & 434LN2 & Sanergy & Co-Coated Sanergy & Haynes 230 \\
\hline Oxide Thickness $(\mu \mathrm{m})$ & 1.8 & 2.0 & $1.8+2.0$ & 2.2 \\
\hline
\end{tabular}

434LN2 had a thin, one micron thick layer of chromium and a discontinuous spinel MnCr oxide layer (the crystals on the surface) one half micron thick. Sanergy had a layer of chromium one half micron thick and a thick spinel layer on top. The total oxide thickness in Sanergy was almost two microns. There was also an internal oxidation in Sanergy. Haynes 230 had a thin one micron thick layer of chromium and a discontinuous spinel $\mathrm{NiCr}$ oxide layer (the crystals on the surface) one half micron thick. Sanergy coated had a one half micron thick chromium layer and a thick spinel CrCo or CoMn layer on top. The total oxide thickness in Sanergy coated was two microns. There was also an internal oxidation in both Sanergy and Haynes 230 as shown in Figure 28. The large crystals observed on the surface correspond to CrMn spinel while the smaller crystals were $\mathrm{Ni} \mathrm{Cr}$ oxides. The oxides chemical composition was determined by EDS and X-ray diffraction. 

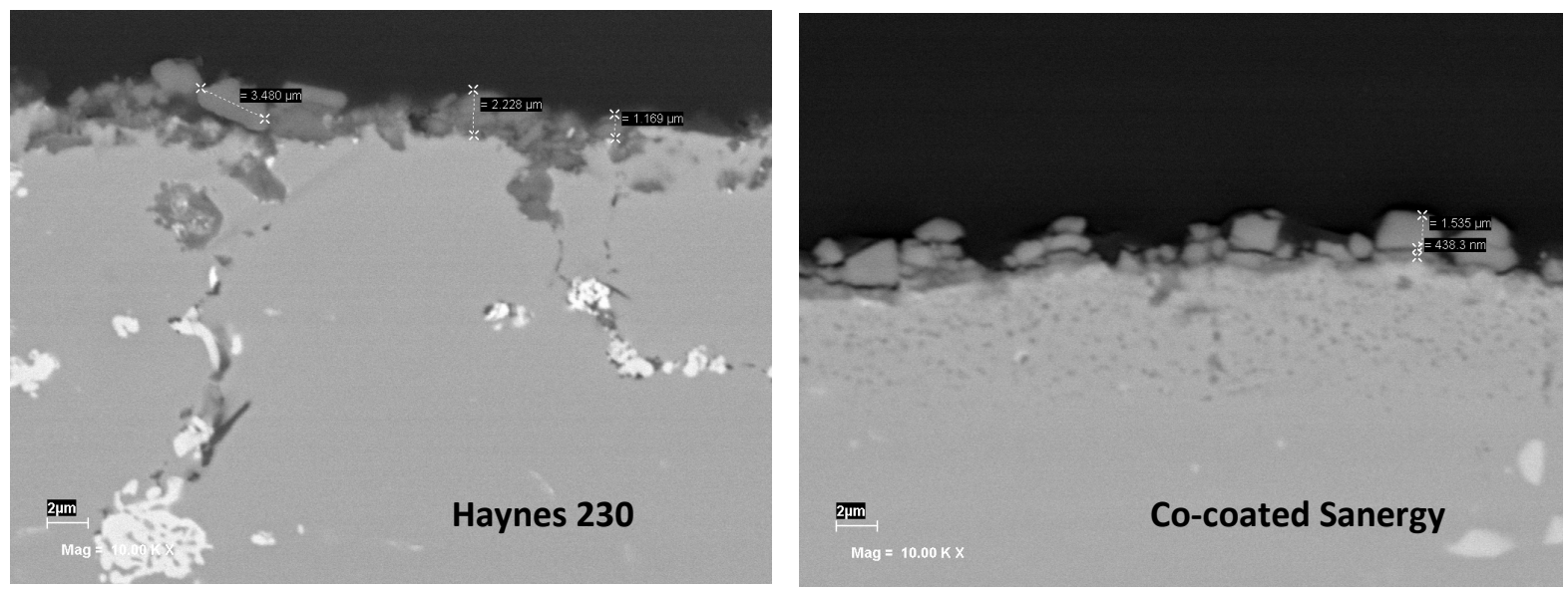

Figure 28. Surface Oxide on Haynes 230 and Sanergy Coated Stainless after the Pure Oxygen Test

In summary, Haynes 230 has a small weight gain. Co-coated Sanergy had a larger weight gain due to the oxidation of the Co coating. In addition, the Co-Mn spinel formed with Co-coated Sanergy alloy might provide better conductivity and resistance to $\mathrm{Cr}$ poisoning in the air electrode.

\section{Interconnect Validation in an RSOFC Stack}

After testing coupons in a high steam environment and pure oxygen for hundreds of hours, a 6-cell stack with selected interconnects was tested in electrolysis for 5800 hours as shown in Figure 29. Several test facility related incidents occurred during the test. Those incidents affected the cell degradation, particularly after about 4500 hours. The overall degradation before that facility incident was $3.1 \%$ per 1000 hours.

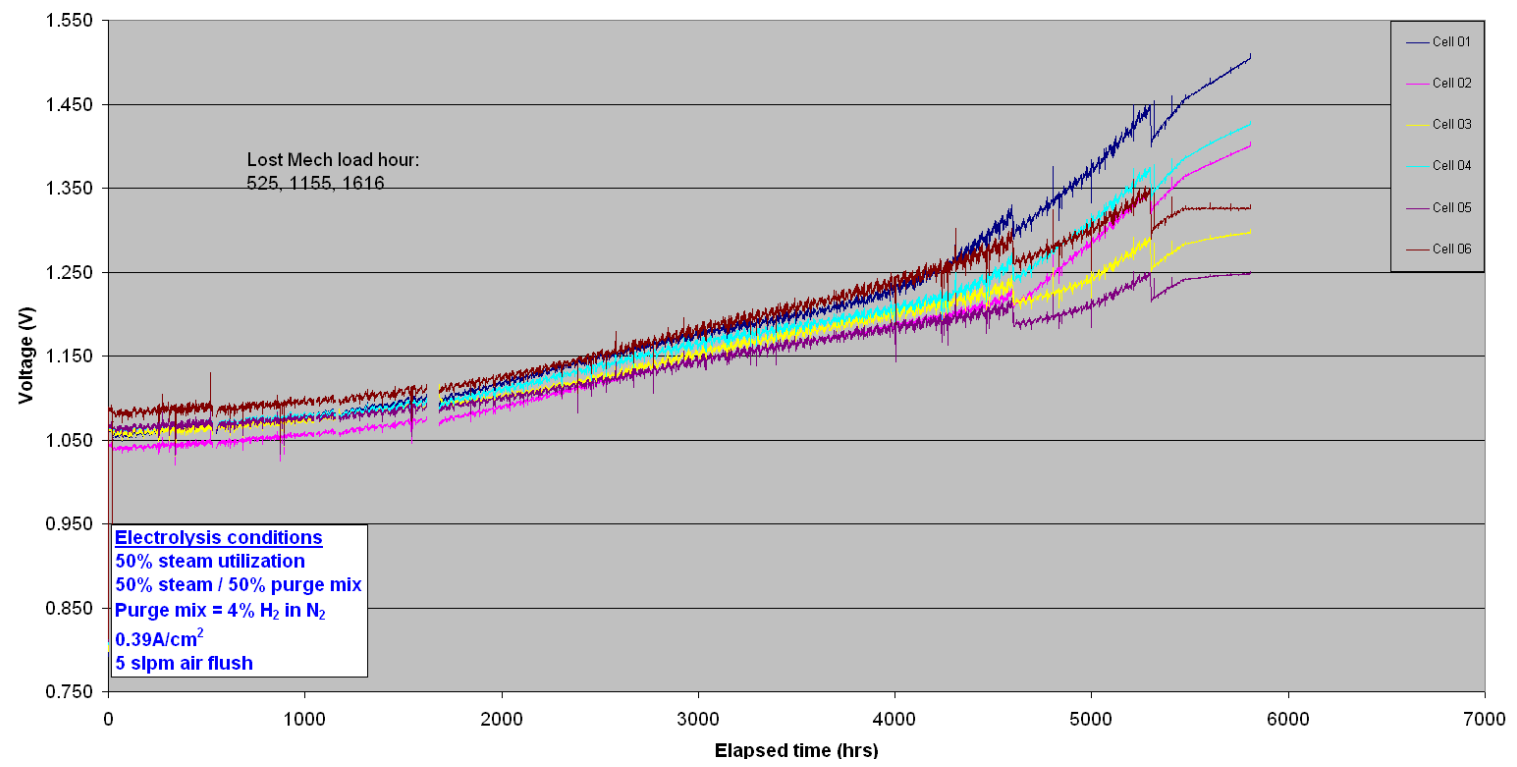

Figure 29. Steady-State Electrolysis Test (5800 Hours) of a 6-Cell Stack with Selected Interconnects

A detailed post-test analysis was performed on selected interconnects \#4 and \#5. Those interconnects were epoxied and cut. Three cut samples were taken from the steam inlet, center, and air outlet as shown in Figure 30. Those samples were polished and examined by SEM. The fuel side interconnects had 
an oxide with different thicknesses and the oxide was thicker at the steam inlet edge before the cell. The steel in that location was exposed to steam and $4 \% \mathrm{H}_{2}$. That oxide contained high amount of iron. Some iron was still present in the oxide of the center sample.

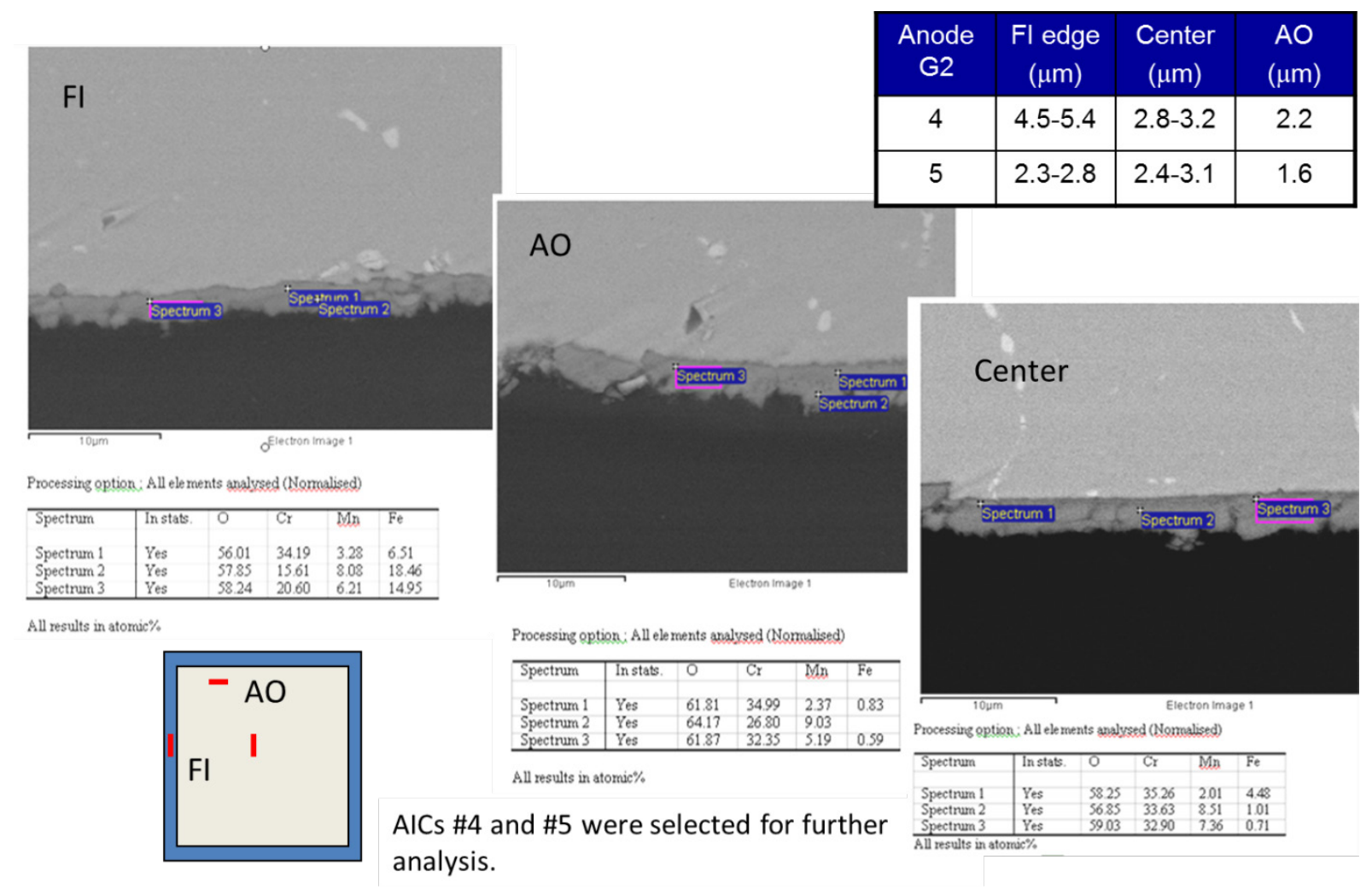

Figure 30. SEM Image of Anode Interconnect Cross Sections at (a) Steam Inlet Edge and (b) Center

In summary, post-test analysis concluded that the selected metallic components are able to meet the requirements for further stack development and demonstration in Task 4.

\section{Task 4: Stack Design and Demonstration}

Task 4 developed a high level RSOFC stack design based on modeling and test results in both SOEC and SOFC operation. Stack modeling used commercial CFD packages (FloWorks and Fluent) as well as custom developed electrochemical code integrated into Fluent to give fully coupled electrochemical modeling (flow, thermal, and electrochemistry) of operational cells and stacks. The combination of analytical test results along with previously validated modeling tools gave good guidance to the stack development.

In order to demonstrate that the technology advancements of Tasks 1 through 4 are relevant when incorporated into a fully functional stack, a stack demonstration was conducted at the end of Task 4 . The stack platform consists of VPS's baseline kW-class stack technology. The purpose of the testing was to demonstrate the integration of the various materials and operational parameters into a functional stack. The stack demonstrated the findings of Tasks 1 through 4 by incorporating the best available cell technology resulting from Tasks 1 and 2 and the best available interconnect material defined by Task 3 . 


\section{RSOFC Stack Operating Investigation}

A reversible energy storage system based on SOFC technology could conceivably operate on various fuels (ammonia, methane, carbon monoxide, hydrogen, etc.). For the purposes of discussion, a hydrogen-based system will be assumed which greatly simplifies fuel-processing requirements (although cost-effective hydrogen storage remains a challenge). With hydrogen as a basis for calculation, the stack's thermally neutral voltage can be calculated and is a function of the stack operating temperature. At $750^{\circ} \mathrm{C}$, the stack's thermally neutral voltage ${ }^{*}\left(V_{t n}\right)$ is $1.285 \mathrm{~V} /$ cell. In practical terms, this means that if the average cell voltage in an operating stack is below $1.285 \mathrm{~V}$, then there will be a net heat flux into the stack (stack absorbing heat to maintain operating temperature). Likewise, an average cell voltage above 1.285 implies a net heat flux out of the stack. This heat flux includes convective heat transfer to the streams as well as heat loss to the environment.

A second consideration is the examination of a complete system, with inlet water at a given temperature (say $25^{\circ} \mathrm{C}$ ) and product gases at a given temperature (say $25^{\circ} \mathrm{C}$ ). Choosing the same temperature for reactants and products allows a reference to the common concept of higher heating value $(\mathrm{HHV})$, corresponding to the enthalpy of formation of liquid water at $25^{\circ} \mathrm{C}$. Treating the whole system as a black box, one can calculate average cell voltage at which a stack would need to run such that no external heat would be required to support operation. This system thermally neutral voltage, or $\mathrm{HHV}$ voltage $\left(\mathrm{V}_{\mathrm{HHV}}\right)$, is $1.485 \mathrm{~V} /$ cell. This is not to imply that a system would operate a stack at this voltage given the low ASR of current cells, as this could be an unrealistically high current density. What it means is if the system uses a stack operating point with an average cell voltage $V$, current $I$, and a heat loss to the environment $Q_{\text {env }}$, then additional heat $\left(Q_{a d d}\right)$ will be needed to maintain system temperature per the following relationship:

$$
Q_{a d d}=\left(V_{H H V}-V\right) \times I+Q_{e n v}
$$

Two key conclusions from this are:

1. A system based around a stack operating at its thermally neutral voltage will always require extra heat in order to be self-sustaining.

2. Electrolysis efficiency will be determined not by stack efficiency (average cell voltage) but by the system heat loss and parasitic loads, given that the cell operating voltage will be below the system thermally neutral voltage.

a. Corollary: The system round-trip efficiency will be a function of system heat loss, parasitic loads, and fuel cell efficiency; but independent of electrolysis voltage.

An interesting design opportunity arises when designing a SOFC stack for electrolysis or reversible operation. In a pure electrolysis stack, it may not be necessary to flush the oxygen electrode with air, subject to two conditions:

1. Stability and lifetime of oxygen electrode materials, both cell and interconnect, must be stable in the resulting pure oxygen environment.

\footnotetext{
${ }^{*}$ The thermally neutral voltage at $750^{\circ} \mathrm{C}$ is calculated from the enthalpy of formation of water at $750^{\circ} \mathrm{C}$, with some variation between sources. Using FactWeb (http://www.crct.polymtl.ca/factweb.php) the thermally neutral voltage is calculated as $1.285 \mathrm{~V} /$ cell. Using Fluent's internal properties database, the thermally neutral voltage is calculated as $1.287 \mathrm{~V} /$ cell.
} 
2. Thermal management must be addressed through fuel stream convective cooling/heating and heat transfer to/from the environment, unlike solid oxide fuel cell stacks where the primary cooling method is often through high air flow.

The second condition is partially addressed by the fact that electrolysis operating points will generally be closer to the thermally neutral voltage than in fuel cell mode, leading to lower heat flux within the stack as shown in the following CFD/electrochemical modeling of a 28 cell, $1.4 \mathrm{~kW}$ stack in SOEC operation.

The stack operating conditions at SOEC mode are quite different from those for SOFC mode and require exploration and optimization. SOFC operation on hydrogen is a heavily exothermic reaction requiring active cooling of the stack in order to maintain thermal control. For this reason, along with efficiency considerations, SOFC operation generally occurs between 250 and $500 \mathrm{~mA} / \mathrm{cm}^{2}$. In contrast, the electrolysis reaction is endothermic, requiring a heat source to maintain operating temperatures. In many applications an external heat source is not available and the stack will be run near the so-called thermo-neutral potential, the point where the IR heating within the stack supplies the heat necessary for the electrolysis reaction. The thermo-neutral potential is not reached until a current density level of 500 to $1000 \mathrm{~mA} / \mathrm{cm}^{2}$ or higher is applied (depending on cell performance and operation temperature). High performance cells, with lower IR losses, require higher current in order to achieve the thermoneutral potential.

In addition to obvious differences in flow compositions, there are significant differences in current density for RSOFC dual mode stack operation, there are likely differences in the optimum operating temperature, and there will be differences in volumetric flow rates. All these factors must be characterized and optimized in any stack designed to run as an SOEC. Finally, any stack intended to run in dual mode must in addition have a process strategy to achieve the SOFC to SOEC transition without worsening stack degradation.

\section{RSOFC Modeling}

VPS has developed electrochemical modeling code that integrates with Fluent to allow fully coupled electrochemical, thermal, and flow modeling of an operating SOFC stack. This provides a tool that is used extensively in stack design and operating condition selection. For the first time this tool has been adapted and used by VPS for modeling of an operating SOEC stack. The code was adapted to represent electrochemistry and electrode performance of the new cell materials being used. Figure 31 shows the temperature distribution across the cells in a 28-cell stack with $121 \mathrm{~cm}^{2}$ active area cells $(1.4 \mathrm{~kW}$ SOEC stack). For the purpose of modeling the following conditions were used:

- $47 \mathrm{Amps}\left(0.39 \mathrm{~A} / \mathrm{cm}^{2}\right)$

- $750^{\circ} \mathrm{C}$ anode inlet gas temperature

- $750^{\circ} \mathrm{C}$ cathode inlet gas temperature

- $19.76 \mathrm{SLPM} \mathrm{H}_{2}$ and $19.76 \mathrm{SLPM} \mathrm{H}_{2} \mathrm{O}\left(50 \%\right.$ water \& 50\% $\left.\mathrm{H}_{2}\right)$

- 35 SLPM air

- Standard $\mathrm{PCl}$ stack with an instrumentation plate in the middle

- $770^{\circ} \mathrm{C}$ furnace temperature

- Thermal radiation and mixing wall conditions for stack top/bottom/surrounding walls

The total temperature range across all cells is $9^{\circ} \mathrm{C}$, representing an almost ideal thermal environment for the operating stack. In practice, the stack would be operated with a nominal temperature between 700 and $800^{\circ} \mathrm{C}$, giving a wide operating window compared to the temperature range across the stack. This 
provides advantages for system operability where, for example, the stack temperature could be varied to offer different performance characteristics in response to system requirements (e.g., minor load following, compensation for degradation, etc.).
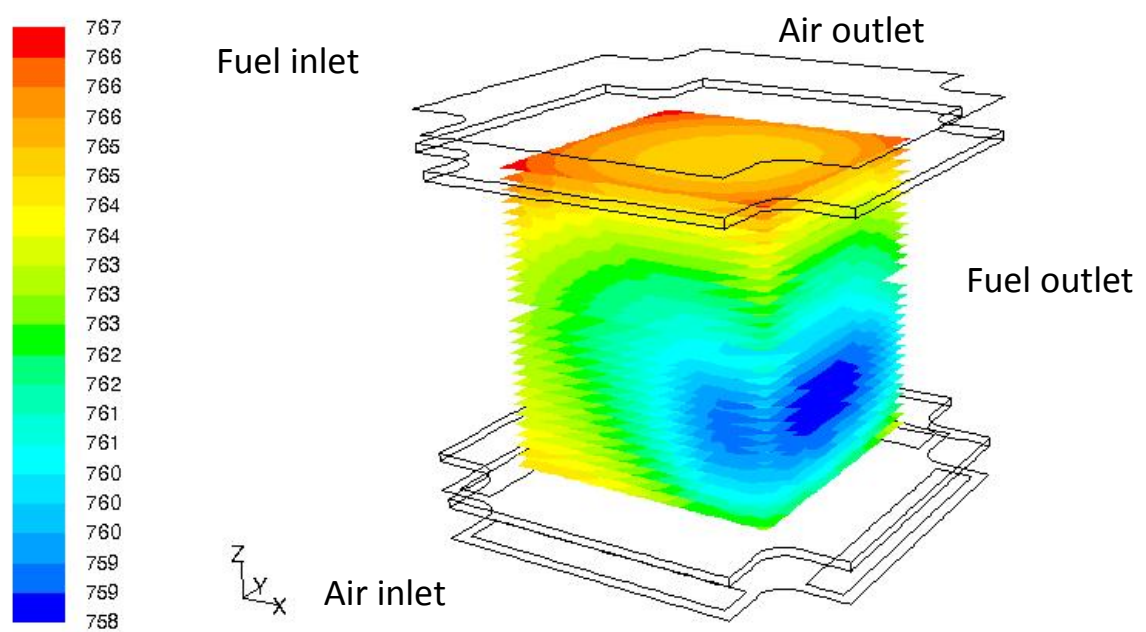

Figure 31. Temperature Distribution across Cells under Electrolysis Conditions (Modeled)

Figure 32 shows the current distribution of the stack operating at the same conditions as identified above. The electrolysis reaction is strongly favored at the fuel inlet edge of the cell, presumably due to the higher presence of reactant (steam) at this edge. It is unlikely to be a strong temperature driven phenomenon due to the low temperature delta in the stack.
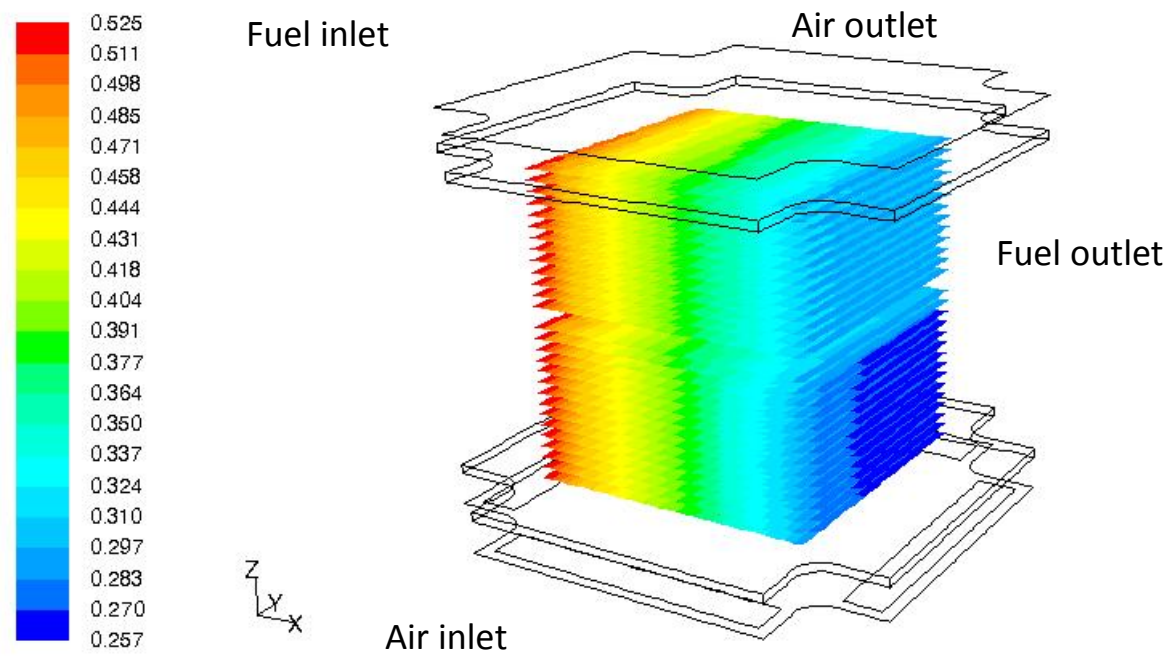

28-cell PCI SOEC, 39.5slpm fuel $(0.5 \mathrm{H} 2 / 0.5 \mathrm{H} 2 \mathrm{O})$, 35slpmair 77 A oursut: $30.5 \mathrm{~cm} 2$

Figure 32. Stack Current Density Profile (Modeled) 
The stack operating conditions at ultra-high current density in electrolysis mode were also explored. SOFC operation on hydrogen is a heavily exothermic reaction requiring active cooling of the stack in order to maintain thermal control. For this reason, along with efficiency considerations, SOFC operation generally occurs below $0.5 \mathrm{~A} / \mathrm{cm}^{2}$. The electrolysis reaction is usually endothermic if operated below the thermally neutral voltage. In this modeling exercise, VPS explored the stack operating condition above the thermally neutral voltage and exothermic. Thermal management must be considered and addressed through fuel stream convective cooling and heat transfer to the environment.

A CFD modeling case was also conducted on a 28-cell RSOFC stack with inputs from cell performance data of RSOFC-7 in Figure 19. Targeting an electrolysis current density of more than $3 \mathrm{~A} / \mathrm{cm}^{2}$ at an operating temperature window of 700 to $800^{\circ} \mathrm{C}$, the CFD model generated three-dimensional temperature, current, water, and hydrogen distributions in the stack as shown in Figure 33 . The resulting electrolysis voltage was only about $1.38 \mathrm{~V} /$ cell with an electrolysis current of $3.3 \mathrm{~A} / \mathrm{cm}^{2}$. Clearly, there was significant heat generated in the stack due to operating at high current density and above the thermally neutral voltage of $1.285 \mathrm{~V}$. The total heat load in stack was $1765 \mathrm{~W}$ or equivalent to $0.52 \mathrm{~W} / \mathrm{cm}^{2}$ active area (about double the thermal load at normal fuel cell operating current density of $0.5 \mathrm{~A} / \mathrm{cm}^{2}$ ). The on-cell temperature difference in the stack was over $70^{\circ} \mathrm{C}$ (compared to $50^{\circ} \mathrm{C}$ for the same stack operating in fuel cell mode at current density of $0.5 \mathrm{~A} / \mathrm{cm}^{2}$ ). This indicates clear thermal management challenges to the current stack design and materials systems. However, this modeling exercise shows the potential of an asymmetric RSOFC operating strategy. A similar stack operating in fuel cell mode has accumulated more than 17,000 hours (two years) with a degradation rate of less than $0.5 \%$ per 1000 hours. There are opportunities to take innovative stack and reversible RSOFC process design to address thermal management and flow management challenges. 


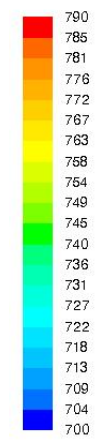

(a) Thermal Profile

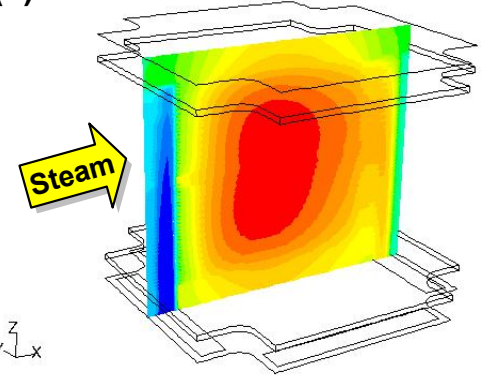

(b) Current Distribution

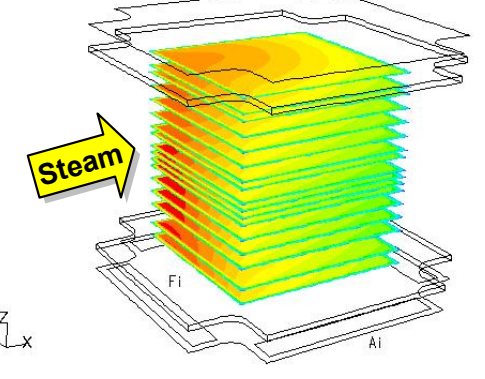
\begin{tabular}{|lr|}
\hline 28-cell PCI SOEC, $0.05 \mathrm{H} 2 / 0.95 \mathrm{H} 2 \mathrm{O}$ & $\mathrm{VPS}$ \\
Contours of Static Temperature (c) & Mar 02, 2011 \\
$397.8 \mathrm{~A}$; output: $38.73 \mathrm{v}$ & FLUENT 6.3 (3d, dp, pbns, spe, lam) \\
\hline
\end{tabular}

\subsection{0035
0.855 (c) $\mathrm{H}_{2} \mathrm{O}$ Distribution}

0.808

0.760
0.713

0.713
0.665

0.618

0.570
0.523

0.523
0.475

0.475
0.428

0.428
0.380

0.380
0.333

0.285

0.238
0.190

0.190
0.143
0.095

0.095
0.048
0.00

0.000

$397.8 \mathrm{~A}$; output: $38.73 \mathrm{v}$ of $\mathrm{h}$

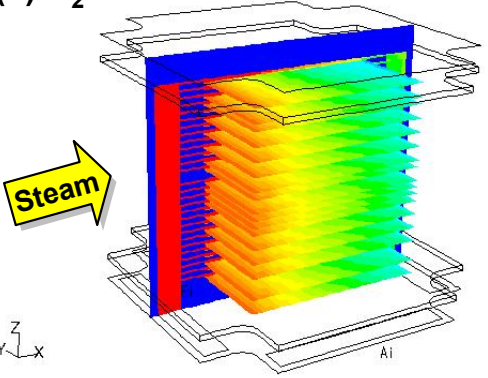

Mar 02, 201
FLUENT 6.3 (3d, dp, pbns, spe, lam

28 -cell $\mathrm{PCl}$ SOEC, $0.05 \mathrm{H} 2 / 0.95 \mathrm{H} 2 \mathrm{O}$
Conttours of Mole raction of $\mathrm{h} 2$
$397.8 \mathrm{~A}$; output: $38.73 \mathrm{v}$

(d) $\mathrm{H}_{2}$ Distribution

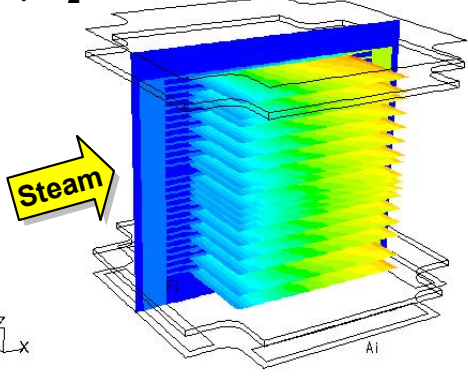

Figure 33. CFD Modeling of a 28-Cell RSOFC Stack in Electrolysis Mode at $3.3 \mathrm{~A} / \mathrm{cm}^{2}$ (Inlet Steam Temperature of $\left.700^{\circ} \mathrm{C}\right)$

In summary, an integrated electrochemical modeling code that integrates with Fluent to allow fully coupled electrochemical, thermal, and flow modeling of an operating RSOFC stack in SOEC mode has been developed. This provides a tool that is used extensively in stack design and operating condition selection. The code was adapted to represent electrochemistry and electrode performance of the new cell materials being used. The preliminary modeling results showed that the current stack design will be able to have a wide operating temperature window to facilitate various stack operating conditions. However, modeling results of the current density distribution in stack shows the electrolysis reaction is strongly favored at the fuel inlet edge of the cell, presumably due to the higher presence of reactant (steam) at this edge. Based on the single cell tests from Task 2, cell degradation is operating current density and steam utilization dependent. Further investigation of electrolysis kinetics might be required for modeling validation and RSOFC stack design improvement.

\section{Stack Validation in SOEC Operation Mode}

A kW-class stack (GT056019-0150) was built and tested for over 5000 hours in an electrolysis operation. The test also intended to compare constant current operation to constant voltage operation in electrolysis. Two interruptions occurred over the course of the test:

1. At 1540 hours, a local grid brownout resulted in an instantaneous stack unload. The stack was reloaded in constant current mode to confirm no damage had occurred then switched again to constant voltage. 
2. At 2101 hours, shortly into the second constant voltage hold, a stack furnace power solid state relay (SSR) failed, requiring a full thermal cycle to replace the SSR and re-start the test.

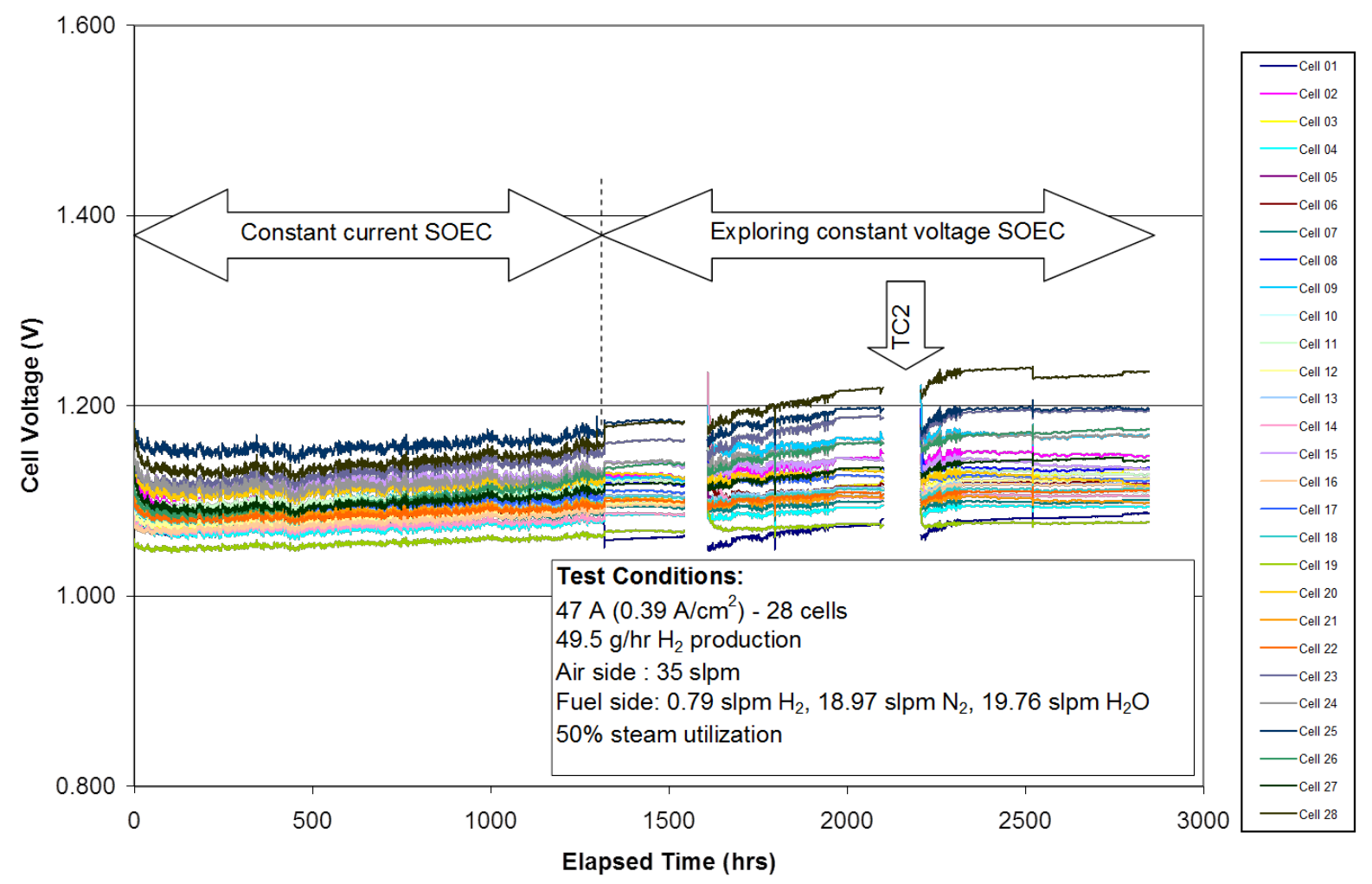

Figure 34. Long-Term Individual Cell Voltage Trends of a 28-Cell kW-Class Stack (GT056019-0150) Tested in Steady-State Electrolysis Operation

The stack demonstrated stable electrolysis operation with no individual cells moving away from the main grouping as shown in Figure 34. A comparison of degradation rates-comparing the decrease in efficiency (increase in voltage) under constant current to the decrease in hydrogen production (decrease in current) under constant voltage-demonstrated that degradation is several times higher in constant voltage operation. This is thought to be a result of the relatively low ASR of the VPS cell technology which requires a large change in current to affect a small change in voltage. As shown in Figure 35 , the ASR decay rate is constant throughout the 5000 hours of testing. 


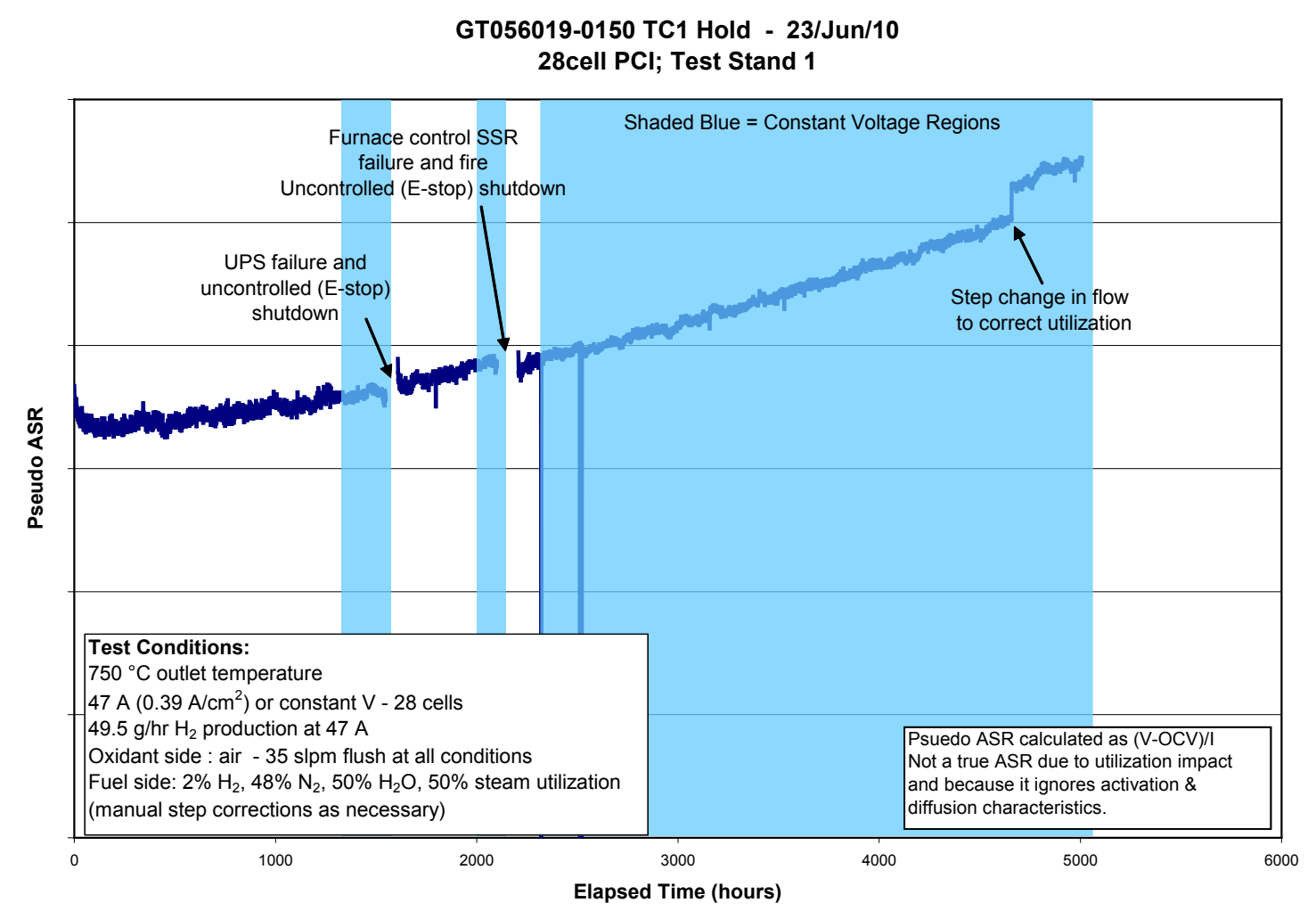

Figure 35. GT056019-0150 kW-Class Stack ASR over Both Constant Current and Constant Voltage (Shaded Blue) Electrolysis Condition

\section{RSOFC Stack Development}

In order to develop an RSOFC stack capable of dual mode operations in SOFC and SOEC with transient capability, short stacks based on VPS baseline $\mathrm{PCl}$ stack design were utilized earlier in the project. Although the stack performance in both SOFC and SOEC operations were good, those stacks had electrical contact issues during the cyclic operation between SOFC and SOEC. This problem, as shown in Figure 36, occurred consistently in all four short stacks during reversible operation with one middle cell losing electrical contact when transitioning from SOFC to SOEC operation. The problem cell (cell \#2 in this case) showed very poor performance in electrolysis mode while showing near-normal performance in fuel cell mode during cycling. The performance of the weak cell mostly recovered during the steadystate SOEC operation. 


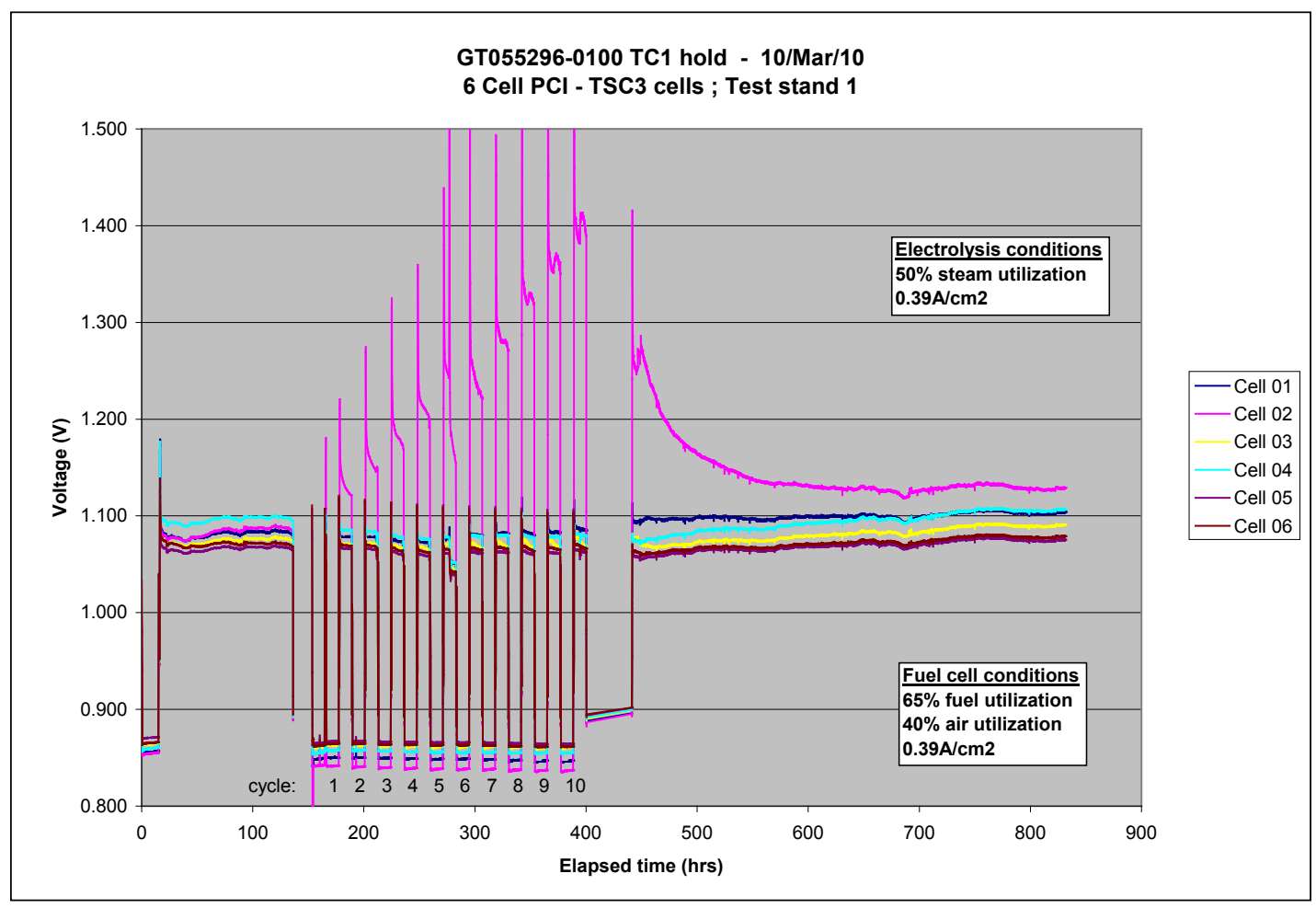

Figure 36. GT055296-0100 Fuel Cell and Electrolysis Cycles

Based on performance characterization and post-test analysis, VPS believes that the performance of cell \#2 in electrolysis mode during cyclic operation was dominated by a loss in electrical contact between the fuel electrode and the metal interconnect. It is thought to be linked to the endothermic nature of electrolysis operation, leading to contraction in the core of the stack which lessens the contact pressure between components and causes a loss in performance on an individual cell layer.

An integrated electrochemical model that integrates with Fluent to allow fully coupled electrochemical, thermal, and flow modeling of an operating RSOFC stack in SOEC mode was used to better understand the mechanisms. Figure 37 shows fully integrated electrochemical model results of a kW-class stack operating at SOFC and SOEC conditions. Assuming $750^{\circ} \mathrm{C}$ inlet temperatures and a $47 \mathrm{~A}\left(0.39 \mathrm{~A} / \mathrm{cm}^{2}\right)$ operating point, the stack generates significant heat due to exothermic SOFC reactions. The hottest spot is in the middle of the stack core where the temperature gradient exceeds $50^{\circ} \mathrm{C}$. With similar operating temperature and current density in electrolysis, the stack lost heat due to endothermic SOEC reactions. The stack core has the lowest temperature in the stack with a temperature gradient of about $10^{\circ} \mathrm{C}$. It seems that the problem is not due to overall temperature gradient in either SOFC and SOEC operation, but the transient from SOFC to SOEC cause hot spots in the SOFC operation to become cool spots in SOEC operation. 


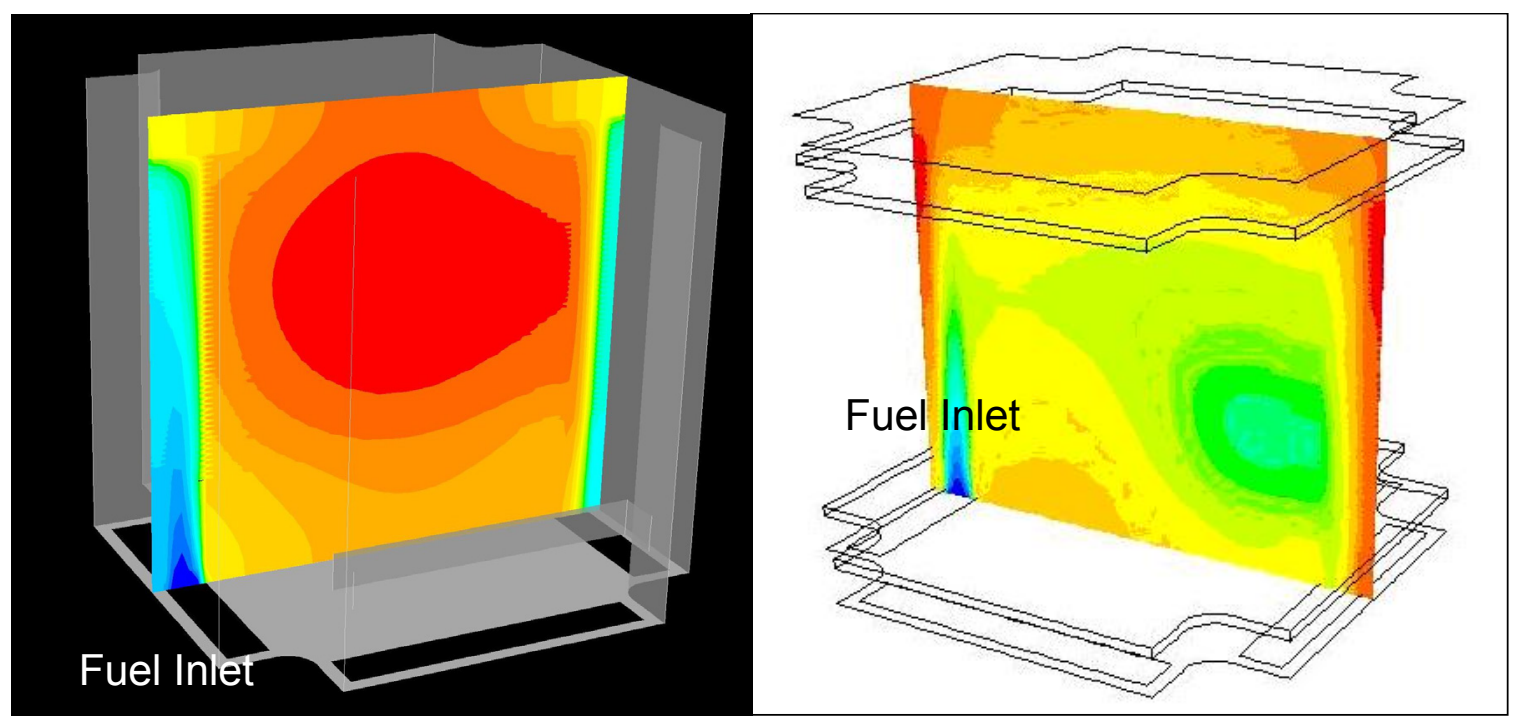

Figure 37. Fully Integrated Electrochemical Modeling of a kW-Class Stack Operating at SOFC and SOEC Conditions

In order to further explore the middle cell(s) loss-of-performance mechanisms during RSOFC cyclic operation, a reversible cyclic test of a kW-class stack was conducted. As shown in Figure 38, nine SOFC and SOEC cycles were conducted. Up to five middle cells showed various degrees of performance loss in SOEC mode. In an attempt to counter the thermal issue during the cyclic transient, the furnace temperature was adjusted from $725^{\circ} \mathrm{C}$ to $700^{\circ} \mathrm{C}$ for SOFC operation and to $760^{\circ} \mathrm{C}$ for SOEC operation after the first two cycles. This helped the weak cells significantly as predicted by stack modeling. However, most of those cells had progressively worse performance in SOEC mode, yet exhibited normal performance in SOFC mode. 


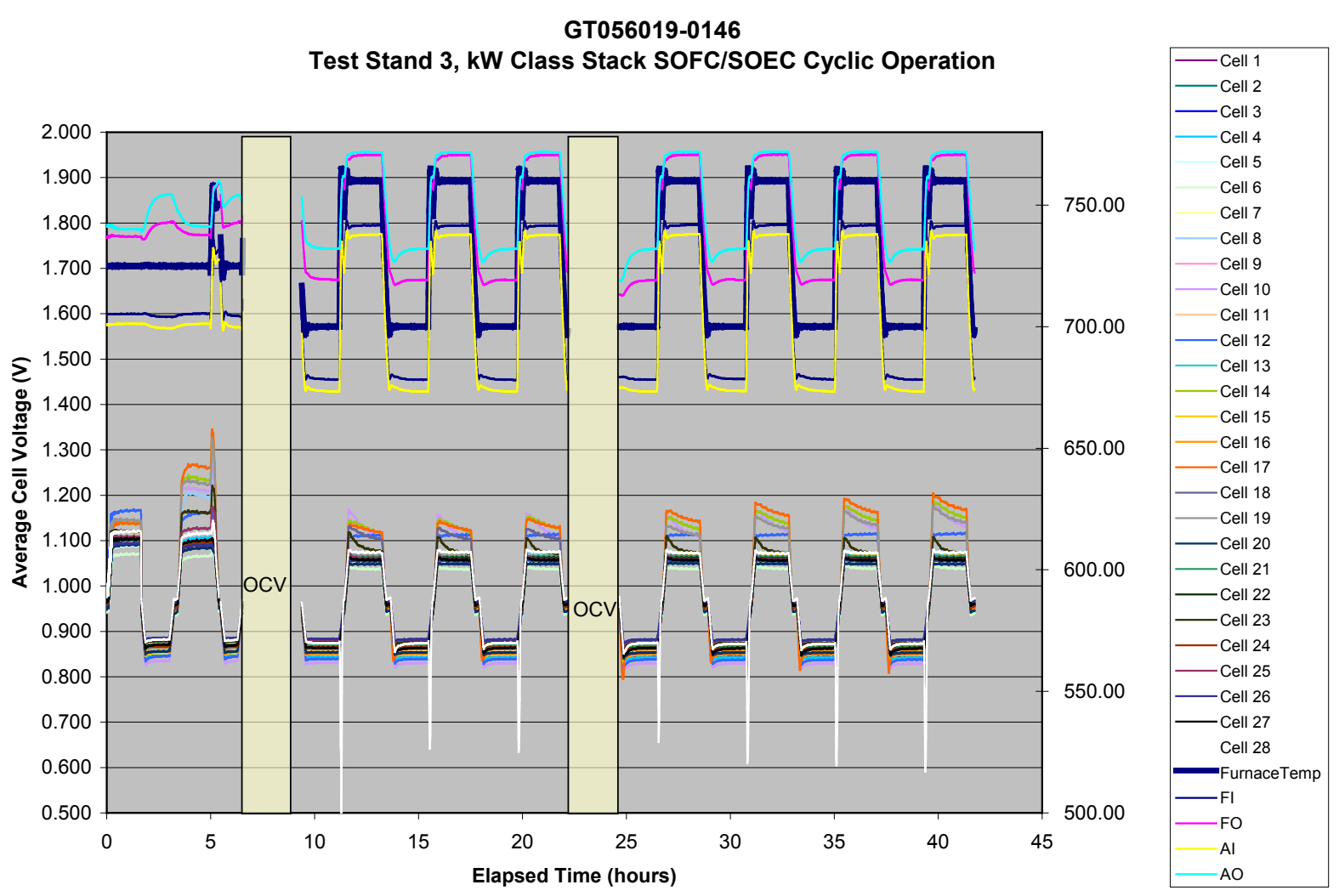

Figure 38. SOFC/SOEC Cyclic Operation of a kW-Class Stack

A similar phenomenon had been observed in the past when temperatures were decreased at the stack level. For instance, when running high levels of internal reforming or when exploring high temperature operation then transitioning to low temperature operation. In both cases, the solution was to integrate a compliant, electrically-conductive layer into the unit cell design between the fuel cell anode and the interconnect as shown in Figure 39.
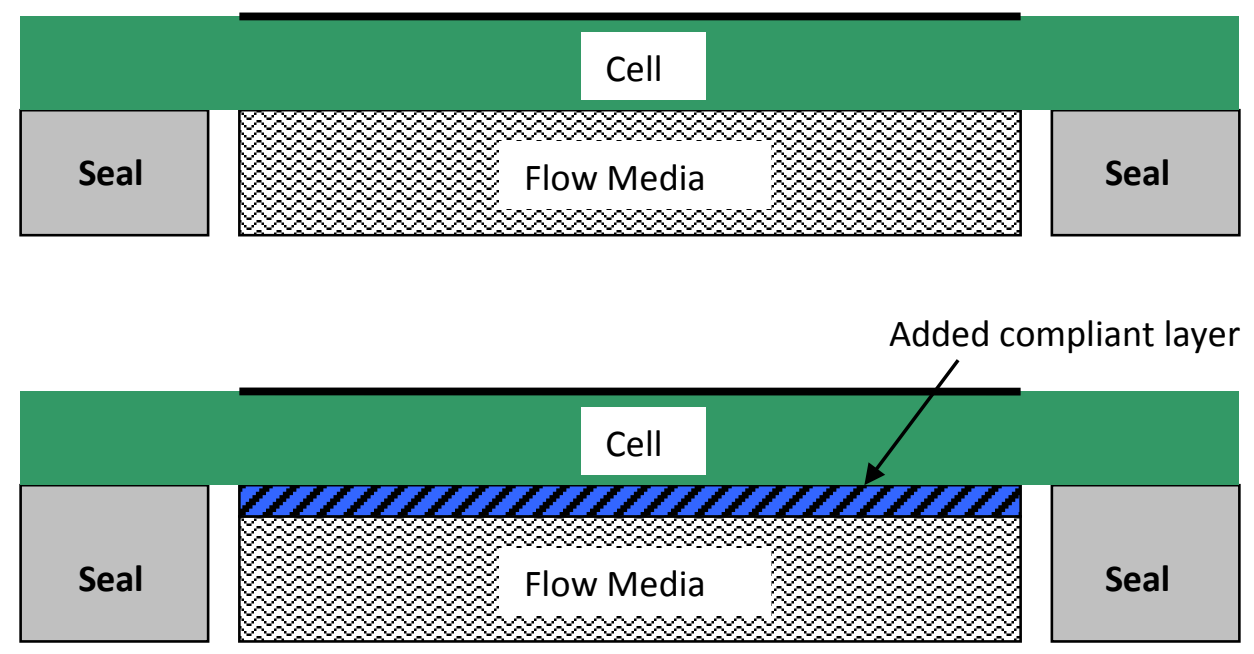

Figure 39. Original (top) and Revised (bottom) Fuel Electrode Contact 
In practice, this layer is designed to retain some compliance over its operating life. Integration of this additional layer is challenging as it required a re-balancing of the unit cell design. While conceptually simple, the task of determining both an appropriate structure for the compliant layer and an appropriate pre-load (as defined by the seal height relative to the flow media and compliant layer thickness) is non-trivial. Several iterations are usually required to generate an acceptable and repeatable solution.

After a few short stacks were built to explore this design changes, a kW-class stack was built and tested specifically for SOFC/SOEC cyclic operation. In order to understand the thermal issues due to cyclic operation, five instrumentation plates with thermal couples were placed in the stack as shown in Figure 40.

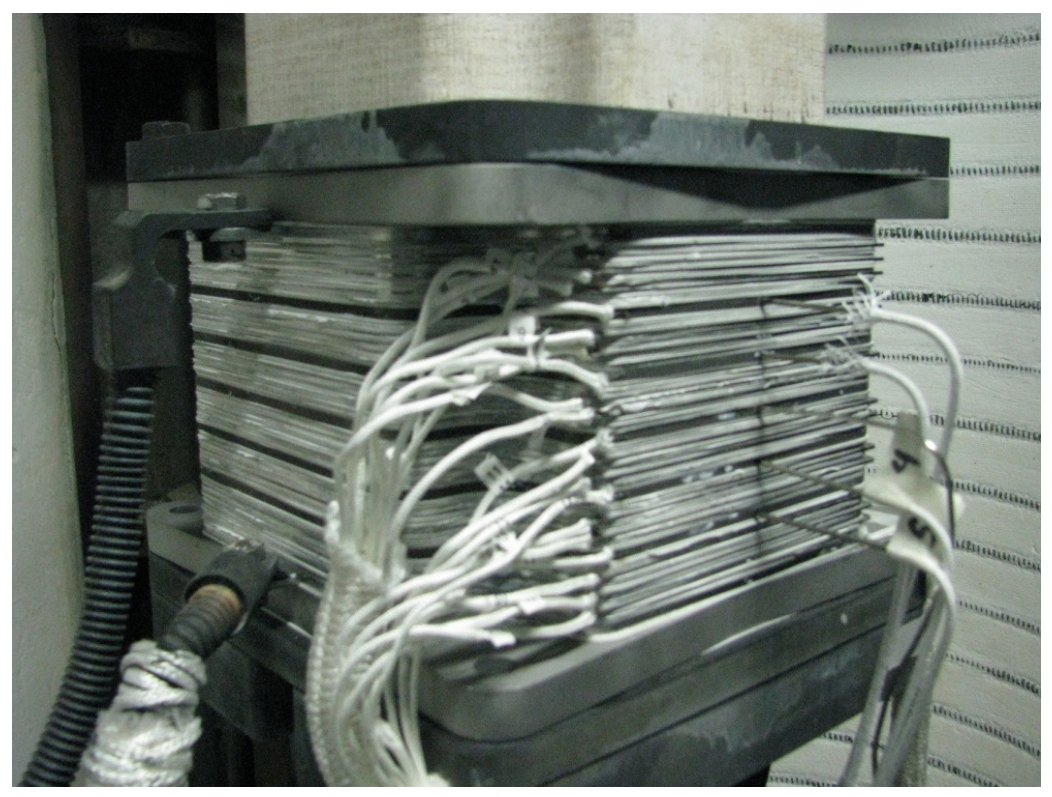

Figure 40. kW-Class Stack Built and Tested for Cyclic SOFC/SOEC Operations

The stack demonstrated better cyclic performance after the design change and completed over 100 SOFC/SOEC test cycles. Voltage responses from each cell were recorded along with stack temperatures from embedded thermocouples. Figure 41 shows the average cell voltage changes in the test. The voltage decays are $13 \mathrm{mV}$ for SOFC and $64 \mathrm{mV}$ for SOEC. Closely examining the individual voltage decays, it was clear that more than $50 \%$ of $64 \mathrm{mV}$ voltage decay in SOEC mode was attributable to cell \#12 as shown in Figure 42. 


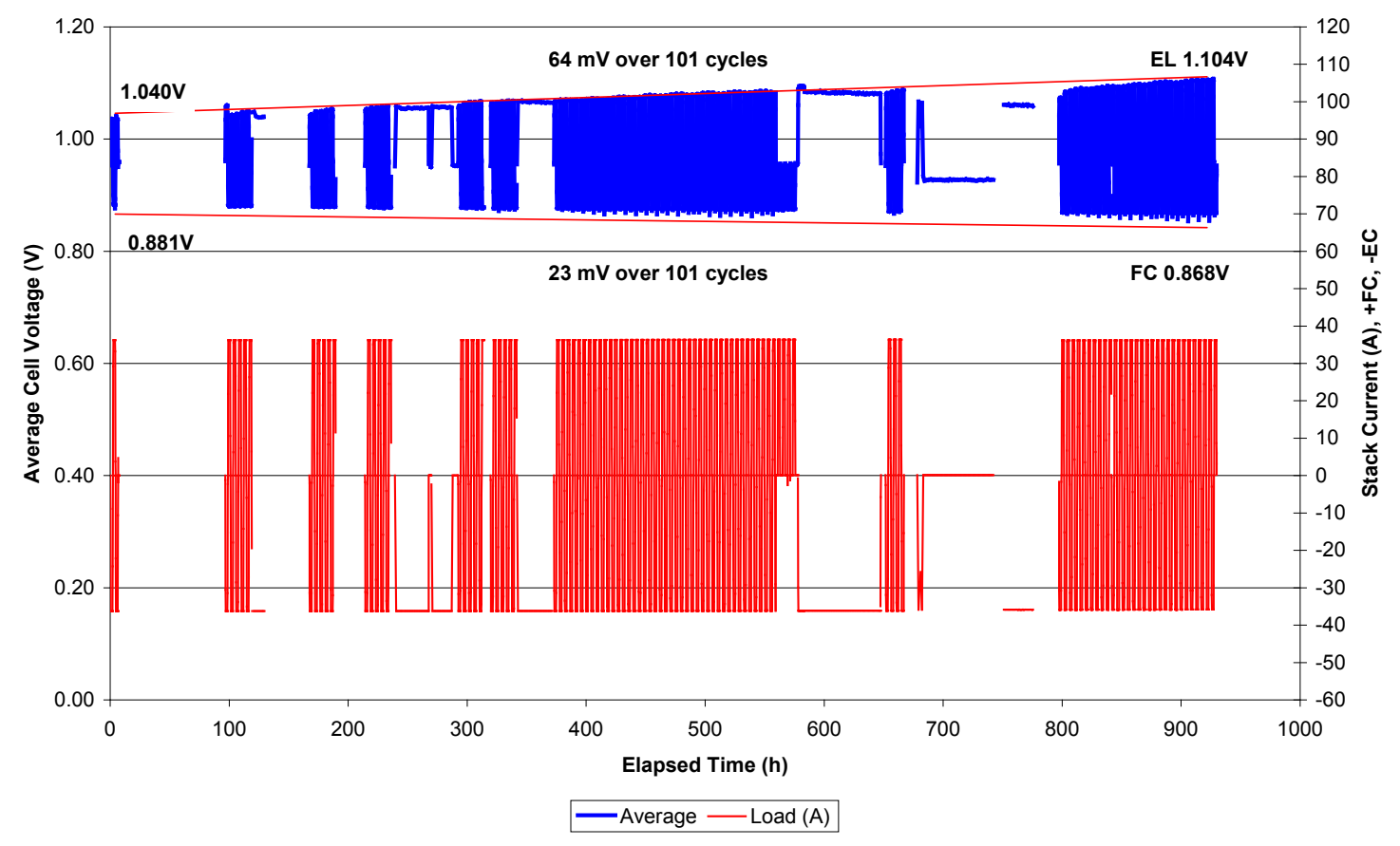

Figure 41. Cyclic Performance of a kW-Class Stack over 100 SOFC/SOEC Cycles

GT058240-0001 Cell by Cell Cyclic Degradation

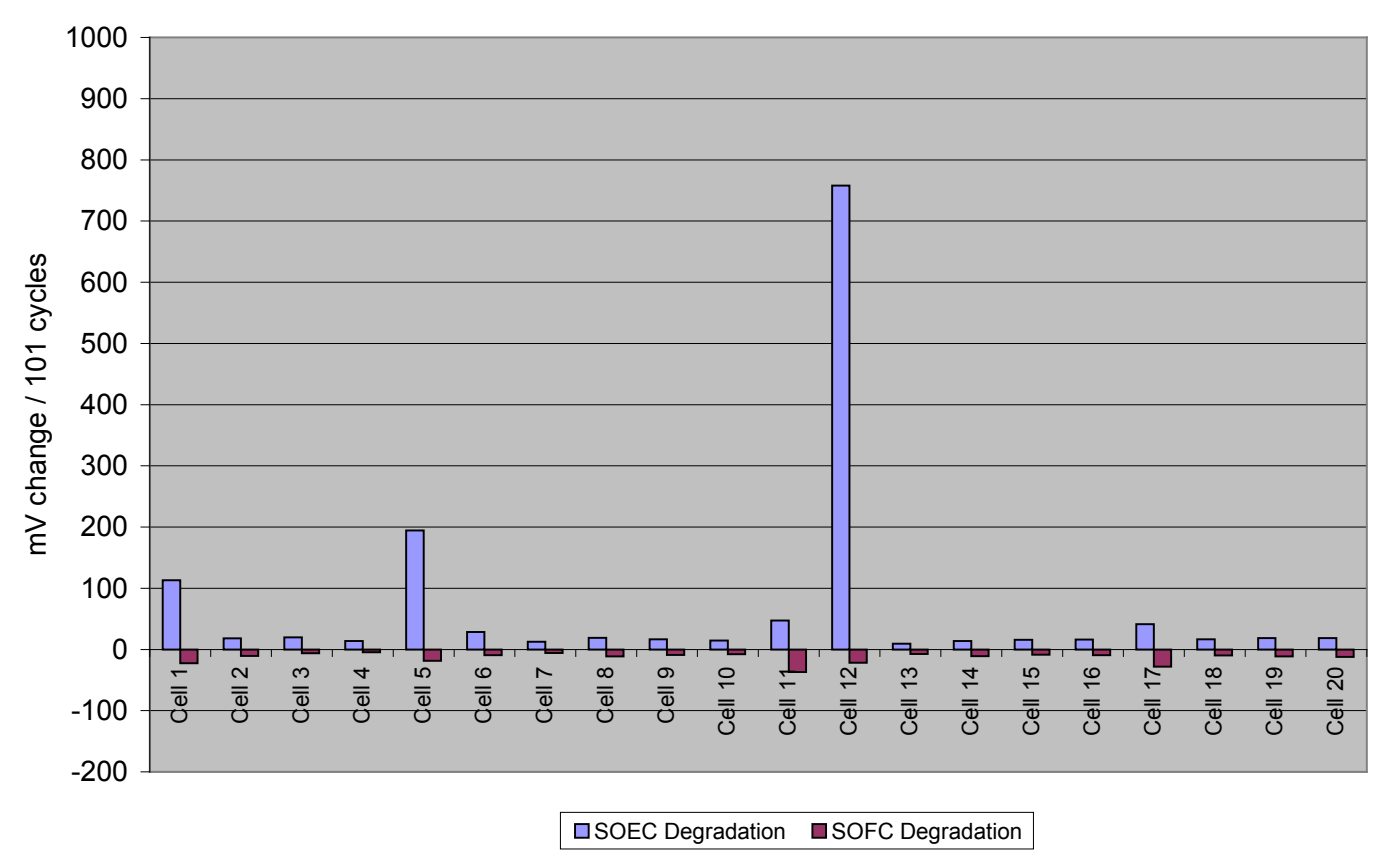

Figure 42. Individual Cell Degradation from SOFC/SOEC Cyclic Operation

The stack was further tested under steady-state SOEC operation with a current density of $388 \mathrm{~mA} / \mathrm{cm}^{2}$ and $50 \%$ steam utilization. As shown in Figure 43, the average stack decay rate is $68 \mathrm{mV}$ per 1000 hours which was significantly higher than the previous stack decay rate as shown in Figure 34 . However, most 
of the decay was from a few middle cells that developed contact issues during the cyclic test. After filtering out those cells, the average decay rate of the other cells was $25 \mathrm{mV}$ per 1000 hours. This is identical to the stack decay rate observed in previous tests.

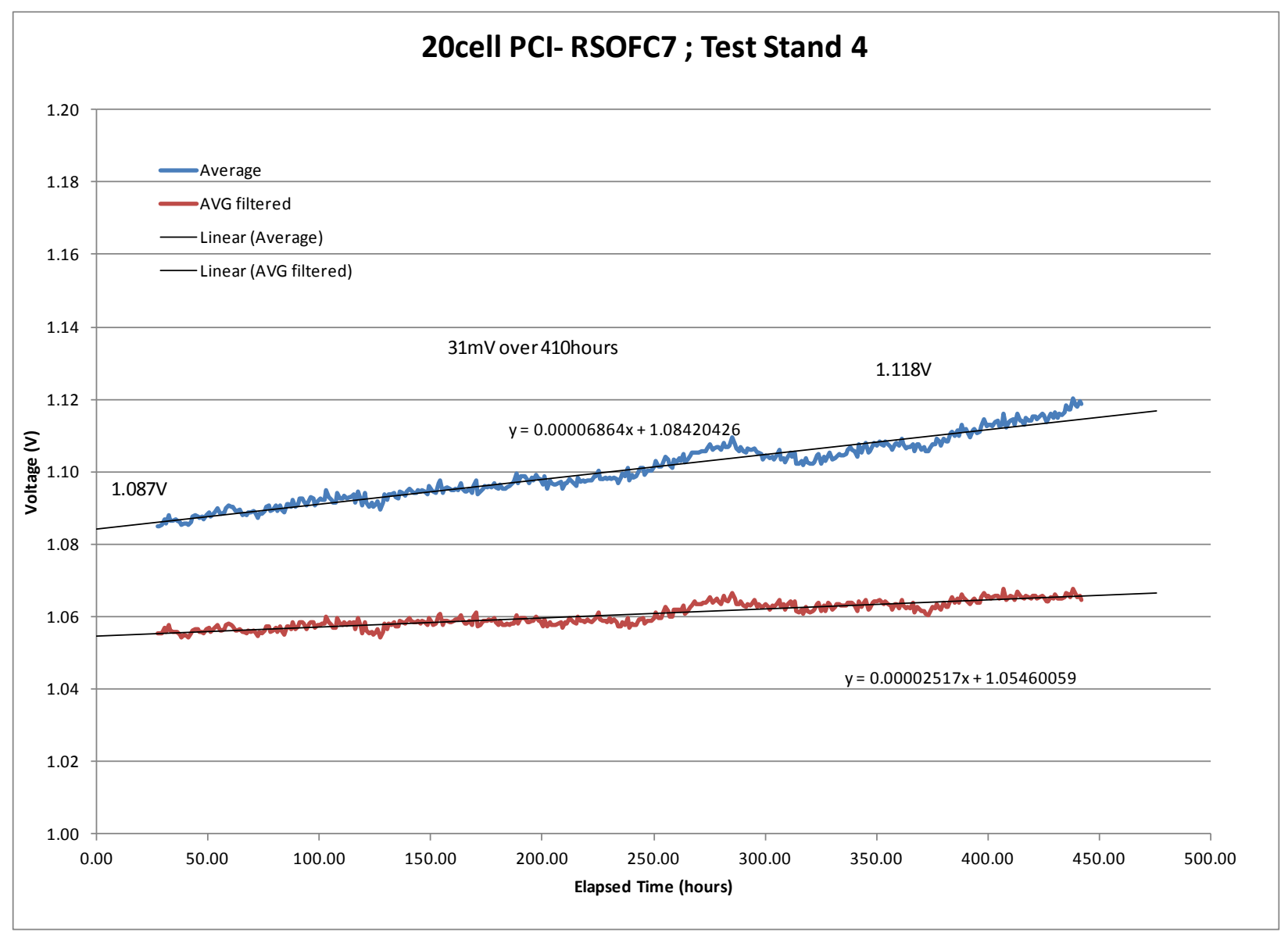

Figure 43. Stack Testing of 20-Cell kW-Class RSOFC Stack at Steady-State SOEC Conditions

In summary, the mechanism for reversible stack cyclic performance problems was identified as a thermal issue through electrochemical testing and stack modeling. Stack design changes were implemented with significant cyclic performance improvement. The stack completed over 100 cycles. However, a new RSOFC stack design is required to completely eliminate the thermomechanical stress issues in cyclic operation. The development effort and time required to complete and validate such a total new design is beyond the scope of the current project.

\section{End-of-the-Project Stack Demonstration}

To further explore reversible solid oxide cell technologies, the decision was made to conduct the end-ofthe-project kW class stack test with a large area stack using six 25 by $25 \mathrm{~cm}$ cells ( $550 \mathrm{~cm}^{2}$ active area). This arrangement was still based on VPS's existing stack design but provided a further insight to the future scalability of RSOFC materials systems.

The stack was first characterized in SOFC mode as shown in Figure 44. After initial conditioning, the stack was loaded to $500 \mathrm{~mA} / \mathrm{cm}^{2}$ with a power output of more than $1.4 \mathrm{~kW}$. As a standard stack 
characterization test, the stack was further tested to $80 \%$ fuel utilization at a current density of 364 $\mathrm{mA} / \mathrm{cm}^{2}$.

GT058711-0001 TC0

EERE - RSOFC stack $550 \mathrm{~cm} 2$ active area, TS24

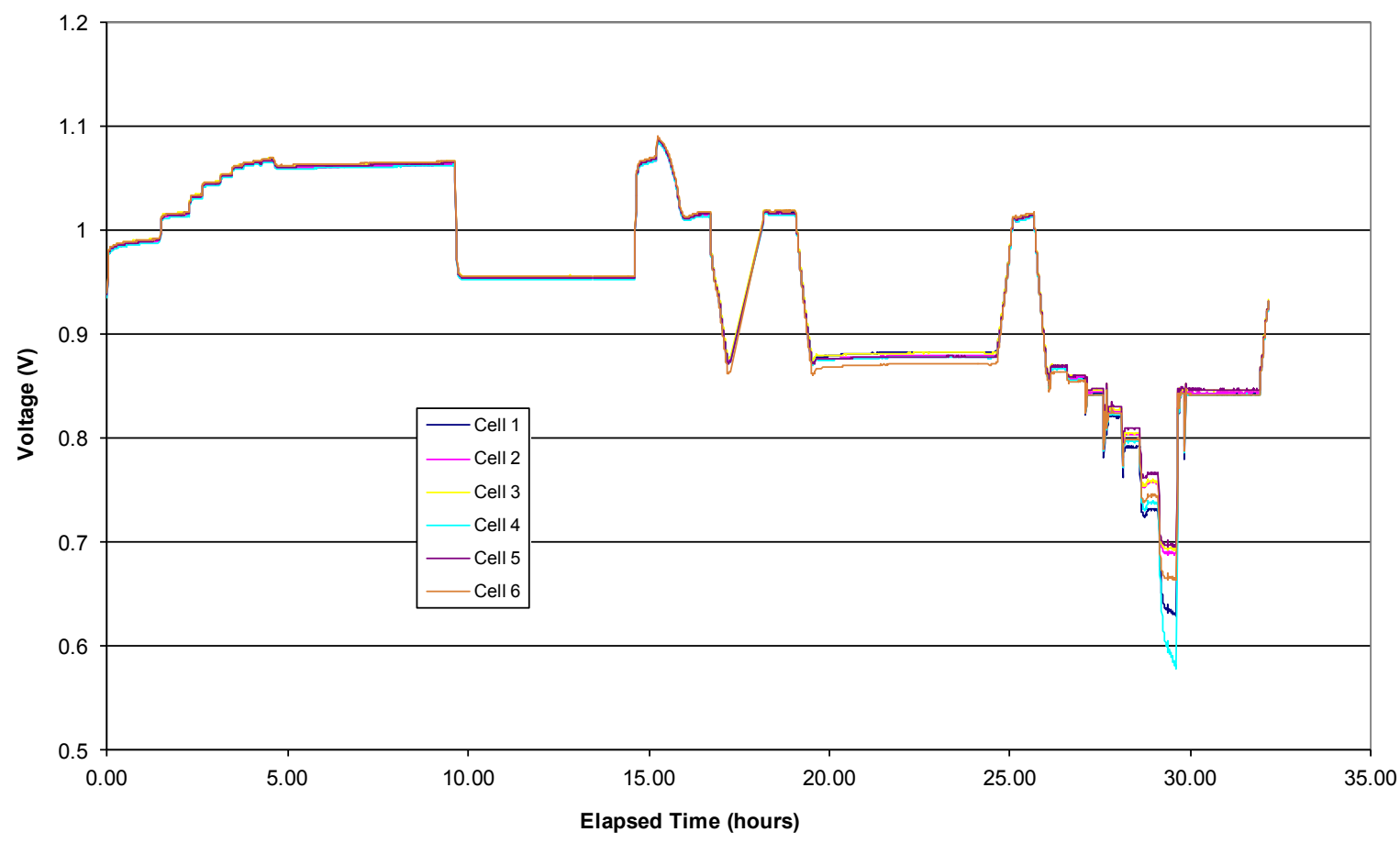

Figure 44. Stack Conditioning and Initial Characterization in Fuel Cell Mode

The thermal profile of the stack was evaluated with 13 embedded thermal couples at cell \#3. The temperature distribution of the stack was mapped out as shown in Figure 45 . The results were very close to the results from CFD modeling. The hot spot in SOFC mode was the same as the cold spot in SOEC mode. This highlights the thermal challenge in designing an RSOFC stack capable of cyclic operation. 
Fuel Cell Mode Thermal Map - GT058711-0001 61.5F13.5A 213A, 20\% H2O, 25\%DIR, $P H=710$, Furn $=690$

AO

FI

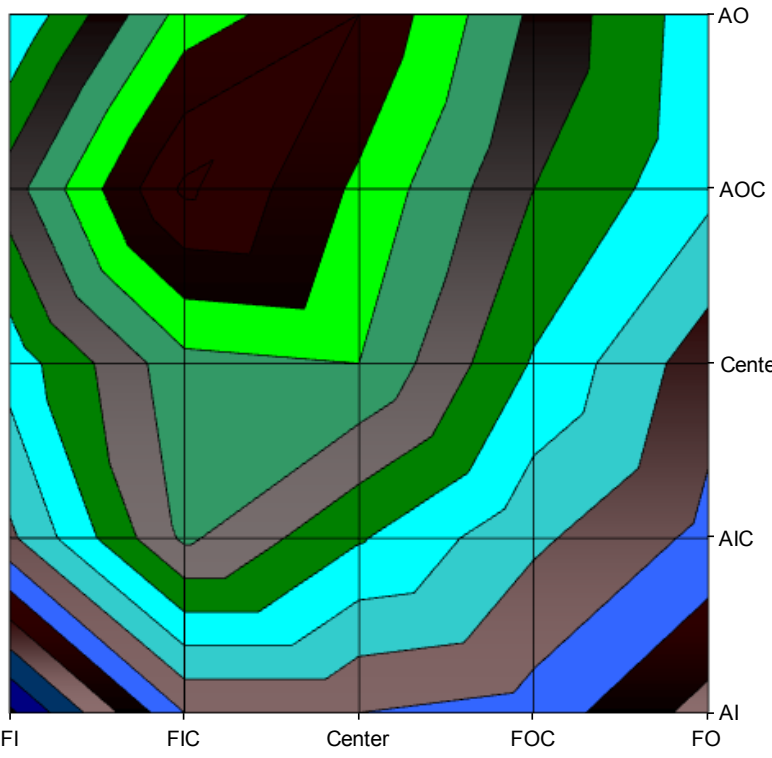

Al

Electrolysis Mode Thermal Map - GT058711-0001 30F30A 200A, 50\% H2O, $\mathrm{PH}=760$, Furn $=750$

AO

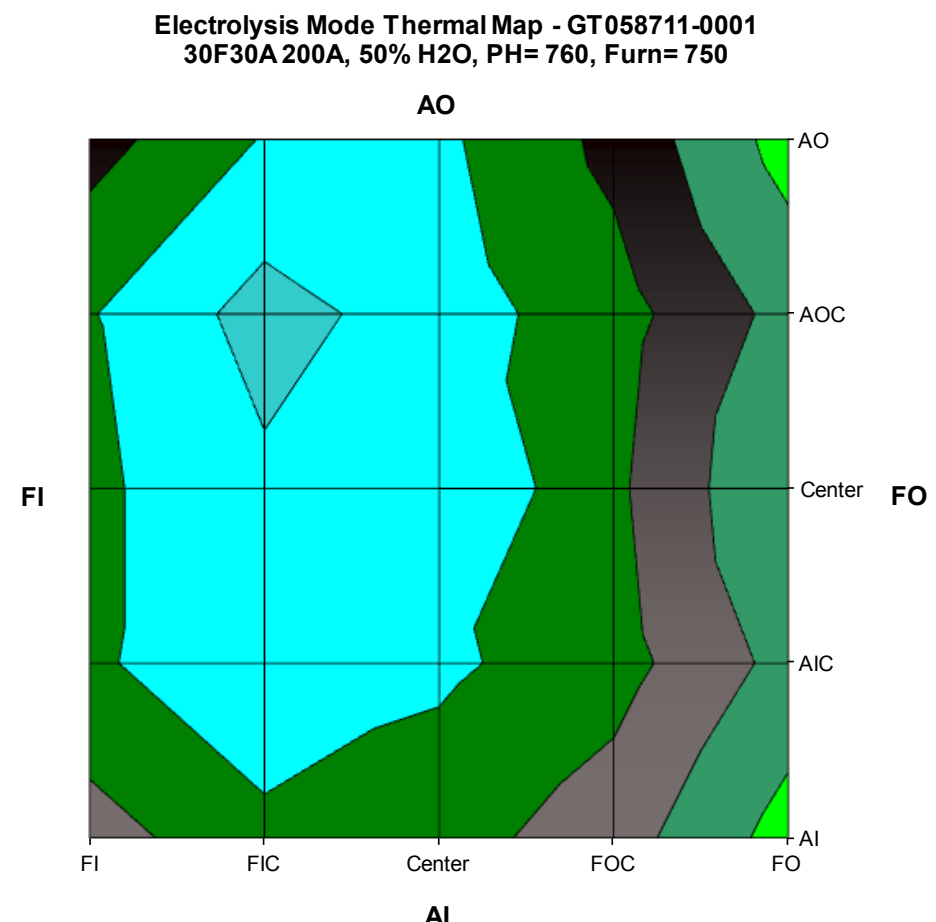

Al
776-772.5

$\square 767.5-770$

765-767.5

-760-762.5

$\square 757.5-760$

755-757.5

-752.5-755

-750-752.5

-747.5-750

$\square 745-747.5$

व742.5-745

$\square 740-742.5$

737.5-740

$0737.5-740$
$0735-737.5$

$\square 732.5-735$

$\square 730-732.5$

■727.5-730

-725-727.5

1722-5-725

-720-722.5

1720-722.5

- 717.5-720

715-717.5

- 712.5-715

7710-712.5

7707.5-710

707.5-710

प702.5-705

口700-702.5

$\square 777.5-780$

- 760-762.5

-757.5-760

-755-757.5

-752.5-755

- $750-752.5$

- 747.5-750

7445-747.5

742-747.5

740-742.5

$\square 740-742.5$
$\square 737.5-740$
$\square 735-737.5$

$\square 735-737.5$

口732.5-735

-730-7325

727.5-730

- 725-727.5

- 722.5-725

-720-722.5

-717.5-720

-715-717.5

-712.5-715

710-712.5

$\square 707.5-710$

-705-707.5

0702.5-705

ㅁ700-702.5

Figure 45. Measured Thermal Profile of the kW-Class RSOFC Stack with 6 Scale-Up Cells of $550 \mathrm{~cm}^{2}$ Active Area at Both SOFC and SOEC Operating Modes 
The stack was then tested in steady-state electrolysis mode as shown in Figure 46. During the initial steady-state test of about 1000 hours, the decay rate was about $2.6 \%$ (or $32 \mathrm{mV}$ ) per 1000 hours. Although this was a little higher than a stack using $121 \mathrm{~cm}^{2}$ cells, it was still under the project target of $4 \%$ per 1000 hours. The individual cell voltages and their decay rates were quite uniform during the steady state SOEC test of 1000 hours (Figure 47). However, the stack demonstrated large resistance increase during the $10 \mathrm{SOFC/SOEC} \mathrm{cycles.} \mathrm{Measured} \mathrm{by} \mathrm{average} \mathrm{cell} \mathrm{voltage} \mathrm{increase} \mathrm{in} \mathrm{SOEC,} \mathrm{a} \mathrm{total} \mathrm{of}$ $70 \mathrm{mV}$ voltage increase was shown for the 10 cycles as shown in Figure 46. This is more than 10 times the decay rate as compared to the previous $\mathrm{kW}$ class stack with regular cells of $121 \mathrm{~cm}^{2}$ as shown in Figure 41.

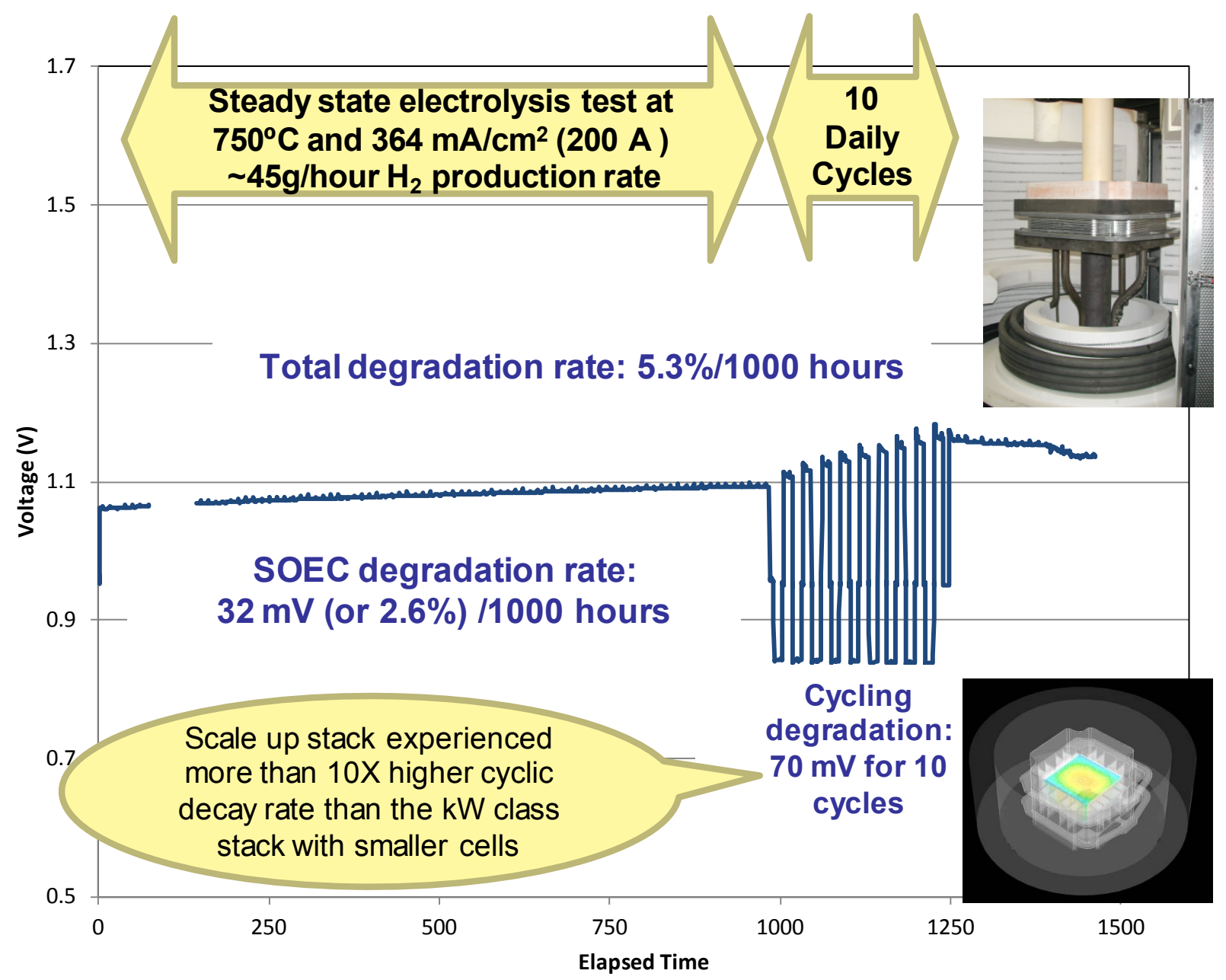

Figure 46. Project Metric Test of a kW-Class RSOFC Stack with $550 \mathrm{~cm}^{2}$ Cells: Average Cell Voltages

As shown in Figure 47, the major resistance increase was from cell \#2 during the cyclic operation. The cell \#2 voltage had a sharp jump when the stack cycled from SOFC to SOEC mode. Some recovery was shown during the steady-state SOEC operation. When the stack switched from SOEC to SOFC operation, cell \#2's performance returned to and stayed normal during SOFC operation. After cyclic operation, the stack was tested in steady-state SOEC mode for a few hundred hours. Cell \#2's performance improved continuously during that period of test. However, an unexpected test facility issue causes the current to decay downward from $200 \mathrm{~A}$ at 1381 hours. The test was terminated at 1504 hours. The total stack 
degradation including steady-state SOEC and cyclic operation was 5.3\% per 1000 hours. Excluding cell $\# 2$, the average cell voltage decay was $3.88 \%$ per 1000 hours.

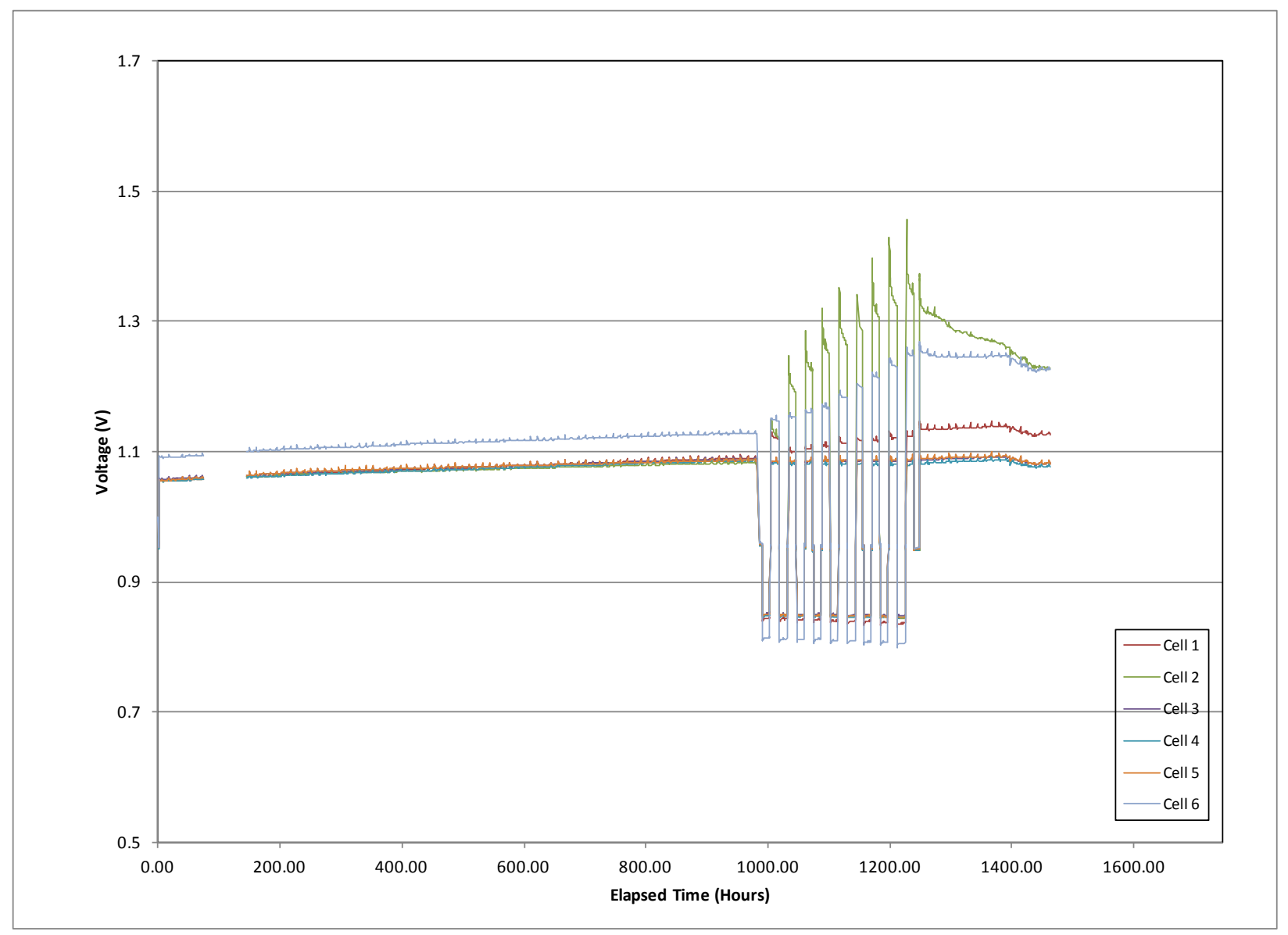

Figure 47. Project Metric Test of a kW-Class RSOFC Stack with $550 \mathrm{~cm}^{2}$ Cells: Individual Cell Voltages

Based on previous stack tests in SOFC/SOEC cyclic operation, VPS believes that the performance of cell \#2 in electrolysis mode during cyclic operation was also dominated by a loss in electrical contact between the fuel cell anode and the metal interconnect. It was linked to the endothermic nature of electrolysis operation, leading to contraction in the core of the stack which lessens the contact pressure between components and causes a loss in performance on an individual cell layer. The similar contact loss occurred in stacks with smaller cells $\left(121 \mathrm{~cm}^{2}\right)$. Stack design modification was made earlier in the project to address the issue and a kW-class stack with regular cells $\left(121 \mathrm{~cm}^{2}\right)$ was built and tested specifically for cyclic operation. Through over 100 SOFC/SOEC test cycles, the modified stack demonstrated better cyclic performance of less than $0.64 \mathrm{mV} /$ per cycle as shown in Figure $41 . \mathrm{In}$ comparison, the scale up $\mathrm{kW}$-class stack with $550 \mathrm{~cm}^{2}$ cells had more than 10 times higher cyclic decay. It seems that the thermomechanical issues associated with SOFC/SOEC cyclic operation were magnified in this scale up stack. 


\section{Conclusions}

In this DOE EERE project, VPS continuously advanced RSOFC cell stack technology in the areas of endurance and performance. Over 20 types of RSOFC cells were developed in the project. Many of those exceeded performance (ASR less than $300 \mathrm{~m} \Omega-\mathrm{cm}^{2}$ ) and endurance (degradation rate less than 4\% per 1000 hours) targets in both fuel cell and electrolysis modes at $750^{\circ} \mathrm{C}$. One of those cells, RSOFC-7, further demonstrated the following:

- Steady-state electrolysis with a degradation rate of $1.5 \%$ per 1000 hours

- Ultra high current electrolysis over $3 \mathrm{~A} / \mathrm{cm}^{2}$ at $75 \%$ water electrolysis efficiency voltage of $1.67 \mathrm{~V}$

- Daily SOFC/SOEC cyclic test of over 600 days with a degradation rate of $1.5 \%$ per 1000 hours

- Over 6000 SOFC/SOEC cycles in an accelerated 20-minute cycling with degradation less than $3 \%$ per 1000 cycles

In RSOFC stack development, a number of kW-class RSOFC stacks were developed and demonstrated the following:

- Steady-state electrolysis operation of over 5000 hours

- Daily SOFC/SOEC cyclic test of 100 cycles

- Scale up capability of using large area cells with $550 \mathrm{~cm}^{2}$ active area showing the potential for large-scale RSOFC stack development in the future

The end-of-the-project kW-class stack test met most of the technical metrics in performance and endurance. However, thermal management issues during stack SOFC/SOEC cyclic operation caused the stack test to fail to meet one of the project technical metrics of $4 \%$ degradation per 1000 hours of operation. Improving thermal management in RSOFC stacks for SOFC/SOEC transient will be the main direction for future development.

Although this project is an open-ended development project, this effort, leveraging Versa Power Systems' years of development experience, has the potential to bring renewable energy RSOFC storage systems significantly closer to commercial viability through improvements in RSOFC durability, performance, and cost. When unitized and deployed in renewable solar and wind installations, an RSOFC system can enable higher availability for intermittent renewable resources, thereby improving the commercial viability of these types of energy resources. 


\section{Appendix A - Single Cell Tests}

Cell characterization is mainly conducted by single cell tests. A single-cell test utilizing the same materials and cross-flow geometry as used in VPS SOFC stacks was setup as indicated in Figure 48. Cells of dimension 10 by $10 \mathrm{~cm}$ were used with different materials compositions to examine the effect of these materials and microstructures on performance and degradation rates.

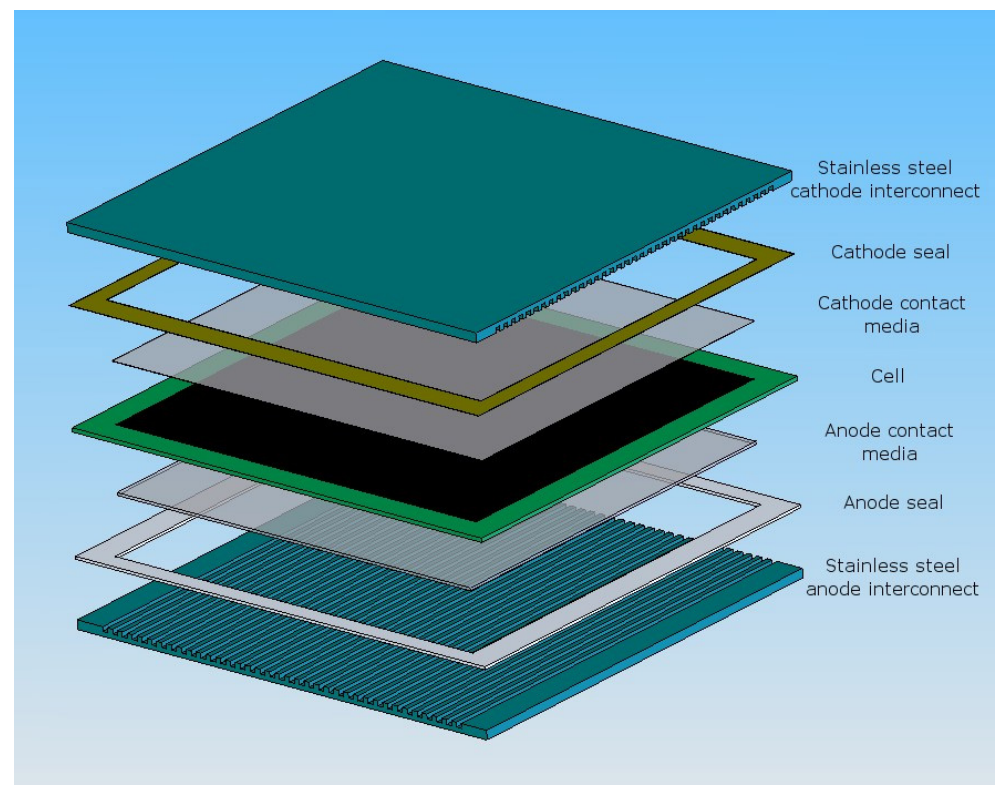

Figure 48. Schematic of Single-Cell Test Assembly

A series of characterization tests were conducted for every test, including:

1. Current-voltage tests were run from 650 to $800^{\circ} \mathrm{C}$ up to $0.74 \mathrm{~A} / \mathrm{cm}^{2}$ with $3 \%$ and $50 \%$ water in the anode fuel stream (applied by bubbling the fuel stream through a temperature controlled humidifier) with 2 SLPM hydrogen on the fuel side and 2 SLPM air on the cathode side. This represents a standard set of curves to characterize cell performance and check for setup faults.

2. The polarity of the current collection cables was then reversed and electrolysis current-voltage tests were performed at $50 \%$ water in the anode flow stream and the same temperatures and flows as above, to $0.74 \mathrm{~A} / \mathrm{cm}^{2}$. The data was used to generate a family of standard SOFC/SOEC performance curves.

3. Electrochemical impedance spectroscopy (EIS) tests were performed at 650 to $800^{\circ} \mathrm{C}$ in fuel cell and electrolysis mode up to $1 \mathrm{~A} \mathrm{DC}$ polarization with $500 \mathrm{~mA} \mathrm{AC}$ signal over the frequency range $100 \mathrm{kHz}$ to $0.1 \mathrm{~Hz}$. EIS is a method of separating out the various loss mechanisms of an operating cell and provides a direct measure of SOEC and SOFC relative performance.

4. Steady-state operation at $500 \mathrm{~mA} / \mathrm{cm}^{2}$ was run at $750^{\circ} \mathrm{C}$ for the cases of $3 \%$ and $50 \%$ water in fuel cell mode and also with $50 \%$ water in electrolysis mode for two hours in each case. In all fuel cell tests fuel utilization (hydrogen fuel) was $50 \%$ and air utilization was $25 \%$. For electrolysis testing, the water utilization was $25 \%$ and air flow on the cathode was at the same rate as for the fuel cell condition (2.898 SLPM). These tests provide an initial assessment of general operational stability of the cell and the electrolysis steady-state operation condition was maintained for varying time periods to assess degradation rate in electrolysis mode. 


\section{References}

1) W. Doenitz, et al., Hydrogen production by high temperature electrolysis of water vapour. Int J Hydrogen Energy 1980;5(1):55-63.

2) W. A. Surdoval, U.S. DOE Fossil Energy Fuel Cell Program, U.S. Department of Energy, National Energy Technology Laboratory, pp11-15, 10th International Symposium on Solid Oxide Fuel Cells (SOFC-X), June 2007

3) H. Ghezel-Ayagh, Solid Oxide Fuel Cell Program at FuelCell Energy, 9th Annual SECA Workshop, August 2008.

4) D. Norrick, Cummins Power Generation SECA Phase 1 Review, 8th Annual SECA Workshop, August 2007.

5) B. Borglum et al., Development of Solid Oxide Fuel Cells at Versa Power Systems 8th European SOFC Forum (2008), Lucerne, Switzerland

6) DOE EERE Multi-Year Research, Development and Demonstration Plan, Page 3.1-7 (2007).

7) J. Guan et al., High Performance Flexible Reversible Solid Oxide Fuel Cell, Final Technical Report, DOE DE-FC36-04G014351.

8) A Hauch, Solid Oxide Electrolysis Cells - Performance and Durability, Riso-PhD-37 (EN), Riso National Laboratory, Technical University of Denmark. (2007)

9) S.R.J. Saunders et al, Progress in Mater. Sc., 53 (2008) 775-837

10) Shen Jianian et al, Oxidation of Metals, vol48. Nos 3/4, 1997 347-356

11) Jia Gong et al, Communication, Metal and Mater. Trans. A, Sep. (2009)

12) C.T.Fuji et al, Journal of the Electrochem. Soc., Vol. 111, No 11, Nov (1964) 1215-1221

13) Jennifer R. Mawdsley et al, Int. Journal of Hydrogen Energy 34 (2009) 4198-4207

14) Zhenguo Yang et al, Solid State Ionics 176 (2005), 1495-1503

15) Zhenguo Yang et al, Int. J. of Hydrogen Energy, 32 (2007) 3770-3777

16) J. Rufner et al, Int. J. of Hydrogen Energy, 33 (2008) 1392-1398

17) J.W. Slusser and K.A, Miller, Flammability and Sensitivity of Materials in Oxygen Enriched Atmospheres, ASTM STP 812, B.L. Werley Ed. ASTM, 1983, pp. 167-191

18) R. Zawierucha et al, Flammability and Sensitivity of Materials in Oxygen Enriched Atmospheres, Ninth volume, ASTM STP 1395, T.A. Steinberg, B.E. Newton and H.D. Beeson Eds., PA, 2000, pp. 119-133

19) J.S. Zabrenski, B.L. Werley and J.W. Slusser, Flammability and Sensitivity of Materials in Oxygen Enriched Atmospheres, Fourth volume, ASTM STP 1040, J.M. Stolzfus, , F.J. Benz, and J.S. Strading Eds., ASTM, 1989, pp. 178-193 